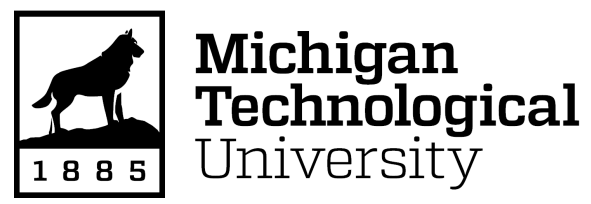

Michigan Technological University Digital Commons @ Michigan Tech

2017

\title{
CHARACTERIZATION OF ECOLOGICAL WATER STRESS IN THE U.S. GREAT LAKES REGION USING A GEOSPATIAL MODELING APPROACH
}

Sara Alian

Michigan Technological University, salian@mtu.edu

Copyright 2017 Sara Alian

Recommended Citation

Alian, Sara, "CHARACTERIZATION OF ECOLOGICAL WATER STRESS IN THE U.S. GREAT LAKES REGION USING A GEOSPATIAL MODELING APPROACH", Open Access Dissertation, Michigan Technological University, 2017.

https://doi.org/10.37099/mtu.dc.etdr/401

Follow this and additional works at: https://digitalcommons.mtu.edu/etdr

Part of the Environmental Engineering Commons, Environmental Policy Commons, Geographic Information Sciences Commons, Natural Resources and Conservation Commons, Natural Resources Management and Policy Commons, Physical and Environmental Geography Commons, Spatial Science Commons, Terrestrial and Aquatic Ecology Commons, and the Water Resource Management Commons 
CHARACTERIZATION OF ECOLOGICAL WATER STRESS IN THE U.S. GREAT LAKES REGION USING A GEOSPATIAL MODELING APPROACH

By

Sara Alian

A DISSERTATION

Submitted in partial fulfillment of the requirements for the degree of

DOCTOR OF PHILOSOPHY

In Forest Science

MICHIGAN TECHNOLOGICAL UNIVERSITY

2017

(C)2017 Sara Alian 
This dissertation has been approved in partial fulfillment of the requirements for the Degree of DOCTOR OF PHILOSOPHY in Forest Science.

School of Forest Resources and Environmental Science

Dissertation Co-advisor: Dr. Ann Maclean

Dissertation Co-advisor: Dr. Alex Mayer

Committee Member: $\quad$ Dr. David Watkins

Committee Member: Dr. Joseph Wagenbrenner

School Dean: Dr. Terry Sharik 


\section{Table of Contents}

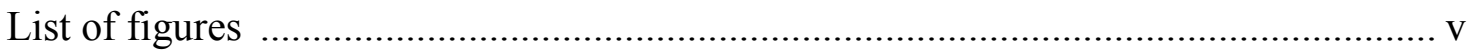

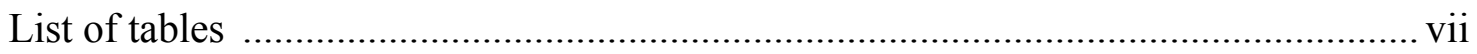

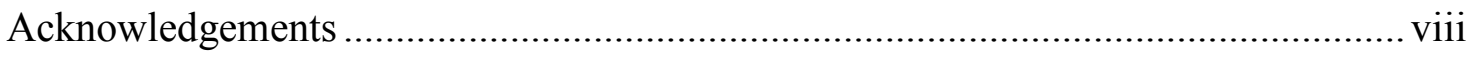

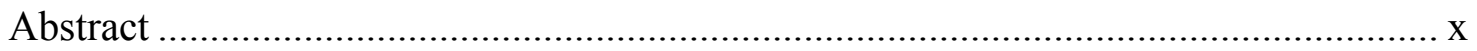

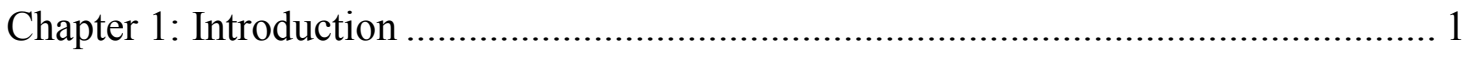

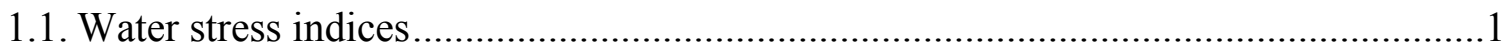

1.2. Ecological water stress in the Great Lakes region ...............................................

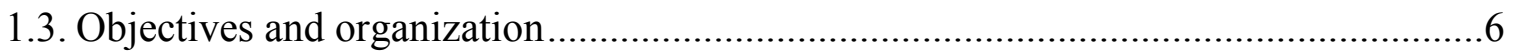

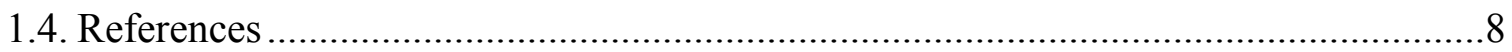

Chapter 2: Systematic use of geospatial information in water stress mapping ............. 13

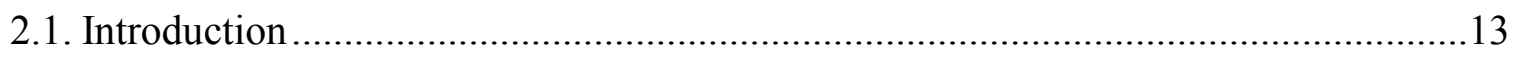

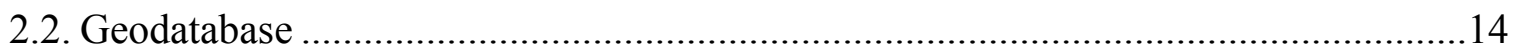

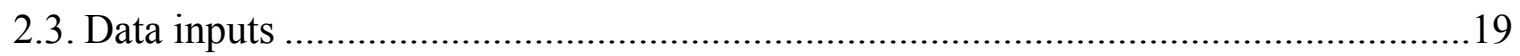

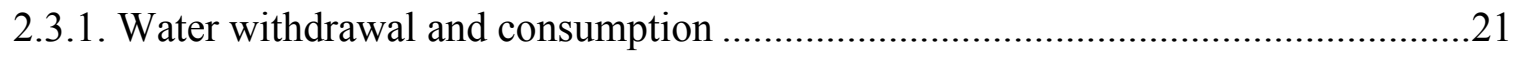

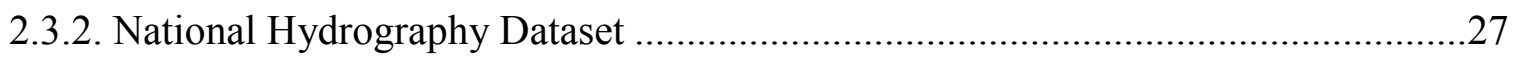

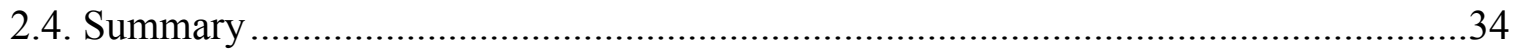

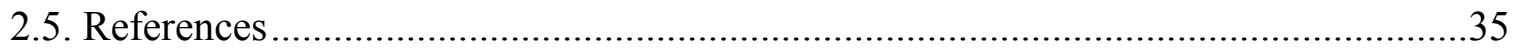

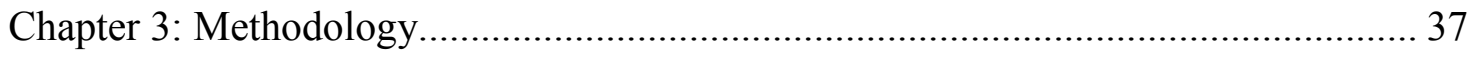

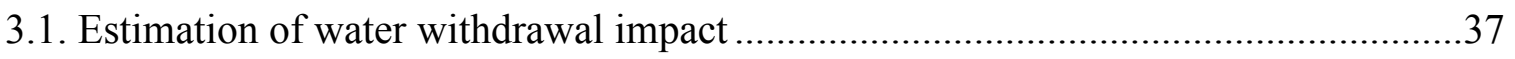

3.2. Spatial aggregation and propagation of withdrawal impacts ................................43

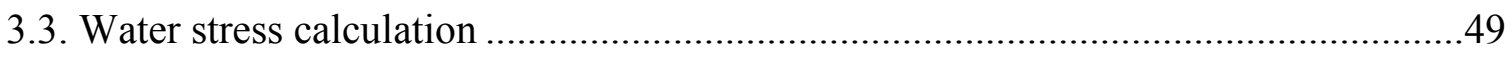

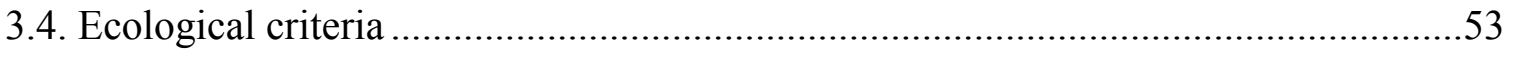

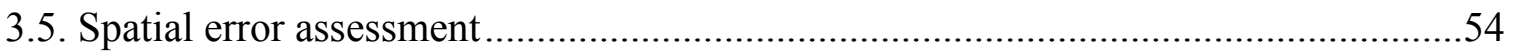

iii 
3.6. References

Chapter 4: Water stress characterization in the Great Lakes region 61

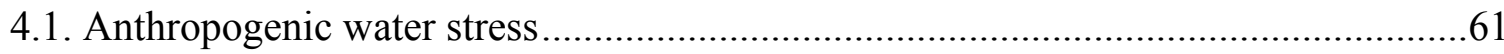

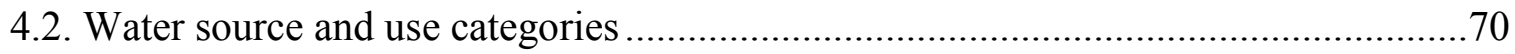

4.3. Importance of spatial and temporal scales .....................................................

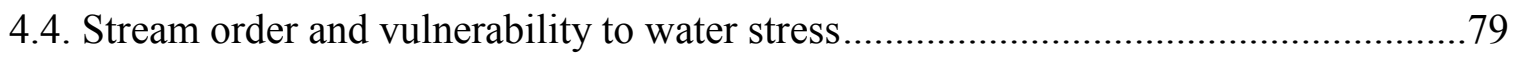

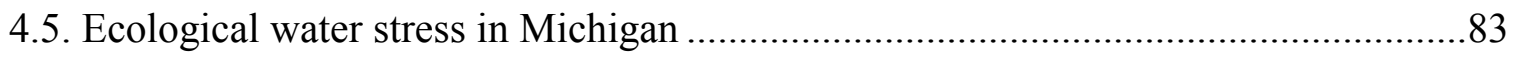

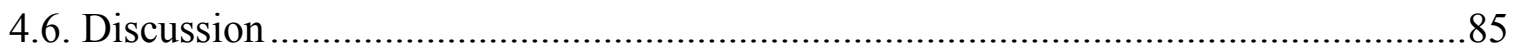

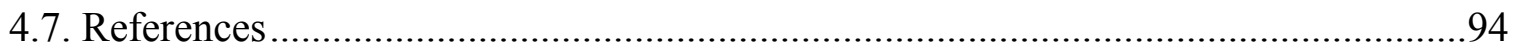

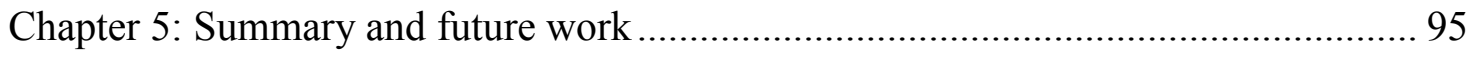

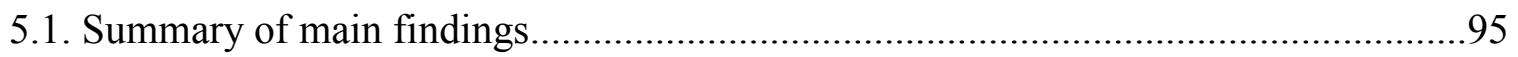

5.2. Recommendations to improve water stress characterization in the GL region ..........96

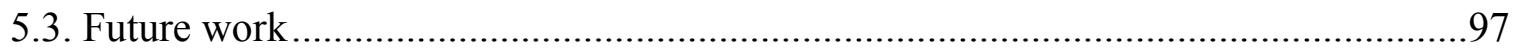

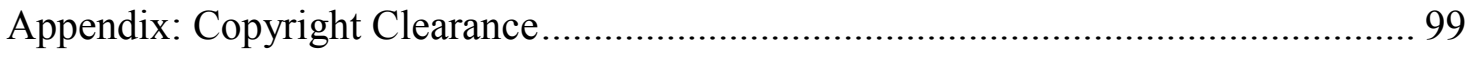




\section{List of Figures}

Figure 1.1. Map of the Great Lakes Drainage Basin ..................................................... 6

Figure 2.1. Basic feature classes in the GLB GDB.................................................... 15

Figure 2.2. Relationship class between Flowline and Catchment feature classes ............ 16

Figure 2.3. Geometric network properties in GLB GBD............................................... 17

Figure 2.4. Basic (left) and generalized (right) GDBs of the GLB................................. 18

Figure 2.5. Distribution of water withdrawal points across the GLB ............................... 22

Figure 2.6. Water withdrawal from inland sources by state ........................................... 23

Figure 2.7. Different water use categories in the GLB .................................................. 24

Figure 2.8. Example NHDPlus V2 catchments and stream network .............................. 29

Figure 2.9. Catchment size distributions in six basins constituting the U.S. GLs ............ 30

Figure 2.10. Size distribution of mean annual flows. ………………………………...... 31

Figure 2.11. Size distribution of mean August flows. ………………………………...... 32

Figure 2.12. Stream order classification in NHDPlusV2 using the Strahler Method ....... 33

Figure 3.1. Water withdrawal from different sources to meet sectoral demands ............. 37

Figure 3.2. Ecological water stress analysis framework............................................... 38

Figure 3.4. Adjoint catchments with corresponding stream network .............................. 44

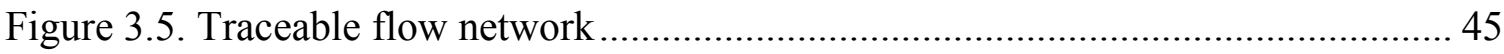

Figure 3.6. Progression of flow accumulation process ................................................... 47

Figure 3.7. Cumulative flow adjustment of the unimpaired flows ................................... 48

Figure 3.8. Water stress calculation procedure (example).............................................. 50

Figure 3.9. Water stress calculation procedure in a spatially connected network ............ 52

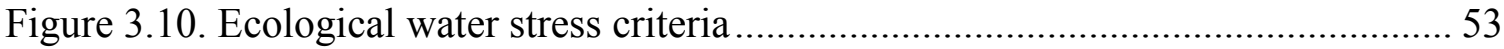

Figure 3.11. Classification of streams and rivers based on size and thermal regime ....... 54

Figure 3.12. Illustration of implicit location of the catchment boundaries....................... 55

Figure 3.13. Buffer zones around the withdrawal points within the catchments............. 57

Figure 3.14. Change in the number of withdrawal points and the water withdrawal ....... 58

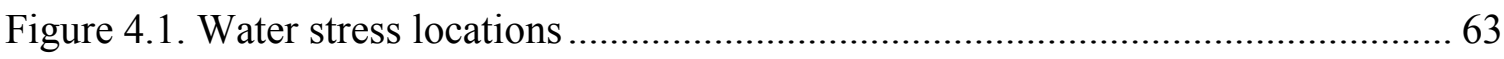

Figure 4.2. Summary of water stress index calculations using annual ............................ 64 
Figure 4.3. Adjusted annual flows versus unimpaired NHDPlus V2 flows ................... 65

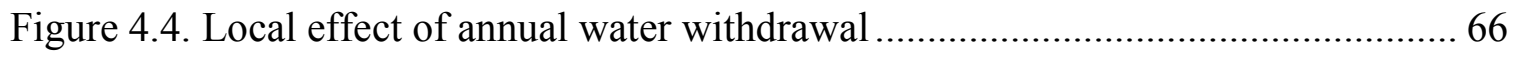

Figure 4.5. Positive water stress locations due to annual withdrawal and return flows ... 67

Figure 4.6. Negative water stress locations due to annual withdrawal and return flows.. 68

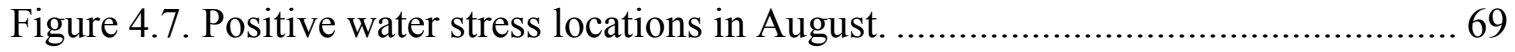

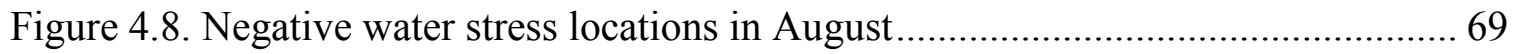

Figure 4.9. Withdrawal sources in the significantly stressed catchments...................... 71

Figure 4.10. Withdrawal sources in the significantly stressed catchments..................... 72

Figure 4.11. Effect of water use category (positive) annual water stress ....................... 73

Figure 4.12. Effect of water use category (negative) annul water stress ........................ 74

Figure 4.13. Effect of water use category (negative/positive) August water stress......... 75

Figure 4.14. Distribution of annual water stress relative to catchment size. ................... 77

Figure 4.15. Distribution of August water stress relative to catchment size. .................. 77

Figure 4.16. Annual water stress relative to catchment size (excluding groundwater) .... 78

Figure 4.17. August water stress relative to catchment size (excluding groundwater) .... 79

Figure 4.18. Stream orders in catchments with positive annual water stress. ................. 80

Figure 4.19. Stream orders in catchments with negative annual water stress.................. 80

Figure 4.20. Stream orders in catchments and August water stress.............................. 82

Figure 4.21. Length of MI streams in negative annual water stressed catchments. ......... 84

Figure 4.22. Land use/land cover types in catchments as potential ARI in August. ........ 85

Figure 4.23. Stream orders in catchments classified as potential ARI in August............. 85

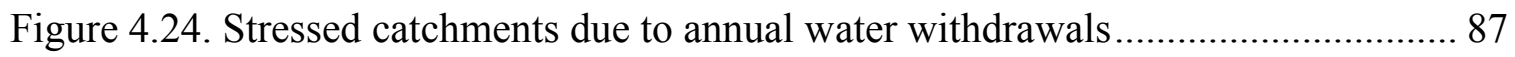

Figure 4.25. Stressed catchments due to annual water withdrawals (satellite image) ...... 88

Figure 4.26. Stressed catchments due to August water withdrawals .............................. 89

Figure 4.27. Stressed catchments in southwestern Michigan (excluding groundwater)... 90

Figure 4.28. Stressed catchments for increasing water withdrawals (annual,August) .... 91 


\section{List of Tables}

Table 1.1. Summary of example water stress indicators ............................................. 3

Table 2.1. Key attributes of withdrawal points feature class...................................... 19

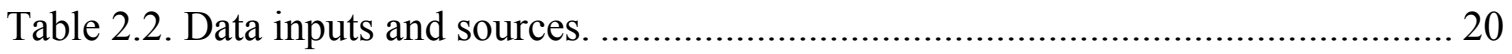

Table 2.3. Median monthly consumptive use coefficients $(\%)$................................... 25

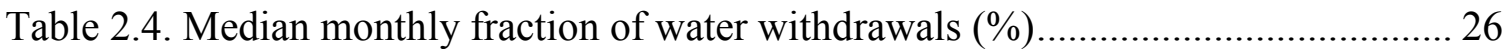

Table 2.5. August consumptive use coefficients for water use categories in Michigan... 26

Table 3.1. Source-specific impact of water withdrawal on stream flow. ........................ 39

Table 3.2. Key populated attributes of Catchment and NHDFlowline.......................... 46 


\section{Acknowledgements}

I appreciate all the direct and indirect support of Dean Terry Sharik, Dr. Andrew Storer, and the faculty and staff of the School of Forest Resources and Environmental Science. I acknowledge their help and support at different stages of my doctoral education at Michigan Technological University. Most importantly, I want to thank my co-advisors, Dr. Ann Maclean and Dr. Alex Mayer, for trusting a young architect who wanted to learn more about geospatial analysis and the use of geographic information science in the field of water resources. I thank them for being super supportive, and for helping me develop my knowledge and professional skills. I would also like to sincerely thank my Ph.D. committee members, Dr. David Watkins and Dr. Joseph Wagenbrenner. I appreciate their time and the valuable comments they provided on an earlier version of this dissertation.

Furthermore, many thanks to the former director of the International Programs and Services (IPS), Darnisha Slade and current director Cassy Tefft de Munoz and all the IPS staff who trusted me as a student worker/volunteer. They helped me develop my social and cultural skills and know myself better. Also, I wanted to thank my wonderful friends at the Canterbury House $(\mathrm{CH})$, which is a great place for international students at Michigan Tech to learn the English language, culture, and make great friends. Thank you Rick Buis, Nupur Bihari, Ameya Narkar, and many great friends and language tutors at the $\mathrm{CH}$.

I would like to say thank you to Debra and Dennis Kamrad, my amazing rowing coaches, whom I love and respect a lot because of their great, positive impact on my personal life. I want to thank Nancy and Dianne Sprague, very special and wonderful individuals, who shared all their thanksgiving dinners, New Year's Eves, and other 
important occasions with me. I want to say thank you to Rachel Hetherington, Adam Rulison, Mayra Sanchez Gonzalez, Meysam Razmara, Amir Zandnia, Ehsan Taheri, Aref Majdara, Hossein Tavakkoli and, Mehdi Malekrah, Mozhdeh Homaeerad and all the friends in the Iranian Community at Michigan Tech, and other friends from around the world who are part of my great memories in the Keweenaw.

I acknowledge the Ecosystem Science Center (ESC), Center for Water \& Society (CWS), and Graduate Student Government (GSG) for providing me with travel grants to attend conferences, workshops and other professional meetings.

I would like to thank Dean Djokic, Water Resources Practice Manager at Environmental Systems Research Institute and the Arc Hydro team for all their great support during the course of this doctoral research.

My sincere gratitude goes to my parents, Susan Zahiri and Alireza Alian for their love, support, and encouragement. Thank you for all you did during the last 2 years so I could just focus on my work. Furthermore, I would like to thank my brother, Sepehr Alian, and his wife, Atefeh Mahboob, and all my lovely friends (Leila Dorafshar, Azadeh Tabarraie, and Samereh Shafizadeh) back home whom I have missed a lot.

Finally, I want to thank my wonderful husband, Ali Mirchi, who is waiting for me in Texas, the one who has always been by my side (since 2009) anytime I needed his help and support. Thank you for your continuous, unconditional love and unlimited support. 


\section{Abstract}

Anthropocentric water resources management affects aquatic habitats by changing streamflow regime. Understanding the impacts of water withdrawal from different sources and consumption by various economic sectors at different spatial and temporal scales is key to characterizing ecologically harmful stream flow disturbances. To this end, we developed a generic, integrative framework to characterize catchment scale water stress at annual and monthly time scales. The framework accounts for spatially cumulative consumptive and non-consumptive use impacts and associated changes in flow due to depletion and return flow along the stream network. Application of the framework to the U.S. Great Lakes Region indicates that a significant number of catchments experience negative water stress due to stream flow depletion caused by surface water and shallow groundwater withdrawals. In many other catchments, however, return flow from deep groundwater withdrawals compensates for the streamflow depletion to the extent that positive water stress is likely. Results illustrate the importance of using appropriate spatial and temporal scales to evaluate water stress, demonstrating that coarse temporal (i.e., annual vs. monthly) and spatial scales reduce the ability to detect water stress due to water withdrawals in vulnerable catchments in low-flow months. 


\section{Chapter 1: Introduction}

\subsection{Water stress indices}

Water stress is a complex concept for which there is no universally accepted definition. Rijsberman (2006) maintains that a multitude of factors should be considered when defining water stress, including the portion of water that is available for use, the definition of temporal and spatial scales of water stress, and the definition of human water needs and environmental flow requirements. A water insecurity index is a measure of accessibility to clean and affordable water for food preparation, drinking, and sanitation, among others. An area may be defined as water scarce when a large group of people suffer from water insecurity over a period of time (Rijsberman, 2006). Falkenmark (1989) developed a national-scale water stress indicator based on water availability per capita per year. This method is widely used in water stress studies (e.g. (Galli et al., 2012; Green et al., 2015; Karabulut et al., 2016)) because it is straightforward and easy to apply using minimal data.

Ohlsson (2000) developed the Social Water Stress Index based on the United Nations Development Plan's Human Development Index, which includes the three dimensions of health, education, and standard of living (Anand, 1994). In more sophisticated definitions of water stress, water demand has been replaced with the term water withdrawals, and total annual withdrawal is considered as a percentage of available water resources. A country is classified as water scarce if the annual withdrawal is between $20-40 \%$ of the annual supply, and severely water scarce if it withdraws more than 40\% (Raskin et al., 1997). 
Seckler et al. (1998) considered consumptive use (evapotranspiration) and the amount of return flow on a national scale to develop Physical and Economic Scarcity Indicators. They analyzed the impact of improved water management policies on future society's adaptive capacity to cope with water stress. If countries have sufficient renewable water resources that are unavailable for use due to economic constraints, they are economically water scarce. Some countries remain physically water scarce even after increasing adaptive capacity because they cannot meet the estimated future water demand (Seckler, 1998).

Sullivan et al. (2003) defined the Water Poverty Index at community and household levels by including access to water, water quality and variability, water uses (i.e. domestic, food, and productive purpose), water quantity, capacity for water management, and environmental aspects in the water stress analysis. This indicator is comprehensive in that it includes aspects of water use and management that were ignored in other indices. However, it is relatively complicated to use and requires more data inputs when compared with the methods mentioned above.

Pedro-Monzonis et al. (2015) provide a review of drought and accounting-based water scarcity indices, including different versions of the Water Exploitation Index (WEI). Notably, the modified WEI helps quantify the pressure on water resources as the percentage of total annual freshwater demand relative to long-term mean annual freshwater availability (EEA, 2013). WEI is calculated by dividing net water consumption (water withdrawals for determined use categories minus corresponding return flows) by 
renewable water resources defined as the sum of stream flow and net water consumption.

Table 1.1 summarizes the widely applied water stress indicators.

Table 1.1. Summary of example water stress indicators

\begin{tabular}{|c|c|c|c|}
\hline $\begin{array}{l}\text { Water stress } \\
\text { indicator }\end{array}$ & Explanation & Mathematical formulation & Reference \\
\hline $\begin{array}{l}\text { Falkenmark } \\
\text { Water Scarcity } \\
\text { Indicator (WSI) }\end{array}$ & $\begin{array}{l}\text { Proportion of annual runoff } \\
\text { available for human use }\end{array}$ & $\frac{\text { water availability }}{\text { population }}$ & $\begin{array}{l}\text { Falkenmark } \\
\text { (1989) }\end{array}$ \\
\hline $\begin{array}{l}\text { Water } \\
\text { Resources } \\
\text { Vulnerability } \\
\text { Index }\end{array}$ & $\begin{array}{l}\text { Total annual withdrawals as a } \\
\text { percentage of the available } \\
\text { water resources }\end{array}$ & $\begin{array}{c}\frac{\text { total anual withdrawal }}{\text { annual water }} \\
\text { resources }\end{array}$ & $\begin{array}{l}\text { Raskin et al. } \\
\text { (1997) }\end{array}$ \\
\hline $\begin{array}{l}\text { Physical } \\
\text { Scarcity } \\
\text { Indicators }\end{array}$ & $\begin{array}{l}\text { Water scarcity due to not } \\
\text { having enough renewable } \\
\text { water resources even after } \\
\text { considering future adaptive } \\
\text { capacity }\end{array}$ & $\begin{array}{l}\text { outflow } \\
\begin{array}{c}\text { developed water } \\
\text { resources }\end{array}\end{array}$ & $\begin{array}{l}\text { Seckler et al } \\
\text { (1998) }\end{array}$ \\
\hline $\begin{array}{l}\text { Economic } \\
\text { Scarcity } \\
\text { Indicator }\end{array}$ & $\begin{array}{l}\text { Water scarcity due to poor } \\
\text { infrastructure rather than lack } \\
\text { of renewable water resources }\end{array}$ & -- & $\begin{array}{l}\text { Seckler et al. } \\
\text { (1998) }\end{array}$ \\
\hline $\begin{array}{l}\text { Water Poverty } \\
\text { Index }\end{array}$ & $\begin{array}{l}\text { Water stress assessment in } \\
\text { small communities based on } \\
\text { ratio of weighted components } \\
\text { (e.g., individuals' access to } \\
\text { water, water quality and } \\
\text { variability, water uses, water } \\
\text { quantity, capacity for water } \\
\text { management, and } \\
\text { environmental aspects) }\end{array}$ & $\begin{array}{l}\qquad \frac{\sum_{i=1}^{n} w_{i} X_{i}}{\sum_{i=1}^{n} w_{i}} \\
\mathrm{X}_{\mathrm{i}} \text { refers to component } \mathrm{i} \text { of the } \\
\text { WPI, and } \mathrm{w}_{\mathrm{i}} \text { is the applied weight } \\
\text { to the component. }\end{array}$ & $\begin{array}{l}\text { Sullivan et } \\
\text { al. (2003) }\end{array}$ \\
\hline $\begin{array}{l}\text { Social Water } \\
\text { Stress Index }\end{array}$ & $\begin{array}{l}\text { Capacity to adapt to stress } \\
\text { through UNDP's Human } \\
\text { Development Index }\end{array}$ & 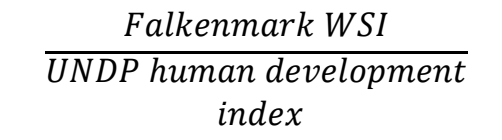 & $\begin{array}{l}\text { Ohlsson } \\
(2000)\end{array}$ \\
\hline $\begin{array}{l}\text { Modified Water } \\
\text { Exploitation } \\
\text { Index }\end{array}$ & $\begin{array}{l}\text { Percentage of total annual } \\
\text { freshwater demand relative to } \\
\text { long-term mean annual } \\
\text { freshwater availability }\end{array}$ & $\frac{(\text { abstraction }- \text { return })}{(\text { flow }+ \text { abstraction }- \text { return })}$ & EEA (2013) \\
\hline
\end{tabular}


Global assessments of annual water stress have been carried out at spatial scales ranging from country to watersheds and $1^{\circ} \times 1^{\circ}$ and $0.5^{\circ} \times 0.5^{\circ}$ grid cells (Arnell, 1999; Vörösmarty et al., 2000; Alcamo et al., 2000; Oki et al., 2001; Arnell, 2004; Islam et al., 2007; and Hanasaki et al., 2008). These water stress quantifications have provided a highlevel understanding of water scarcity, and improved strategic level insights for managing water withdrawals to safeguard sustainable water resources systems. However, annual water stress quantification at coarse spatial scales fails to provide spatiotemporal information about water stress, which is particularly important from regional and local water and environmental planning and management perspectives. A monthly water stress analysis on $0.5^{\circ} \times 0.5^{\circ}$ global grid cells (Wada et al., 2011) confirmed important temporal characteristic of water shortages, occurring only as occasional deficits at certain times of the year as was previously speculated by Meigh et al. (1999).

\subsection{Ecological water stress in the Great Lakes region}

The Great Lakes Basin (GLB) (Figure 1.1) is an example of a water-rich region where most areas generally experience little to no water stress based on the Falkenmark water scarcity indicator (Rockström et al., 2009). However, characterization of water stress in the GLB is still relevant, especially from an ecological standpoint (Barlow et al., 2010), consistent with growing awareness about the connection between water use, withdrawals, and biodiversity (Ridge et al., 2001). Tavernia et al. (2013) projected that the abundance of water resources in the U.S. Northeast and Midwest may diminish relative to human and ecological water needs under scenarios of future climate and land-use changes. The Great Lakes-St. Lawrence River Basin Water Resources Compact became state and federal law 
in 2008, providing the legal framework for the GLB states to cooperate in protecting the region's environmental resources. Flow depletion caused by different human activities (water withdrawal) will have impacts on aquatic ecosystems that are sensitive to changes in stream condition. Poff et al. (1997) discuss the importance of a natural flow regime for ecological integrity of aquatic ecosystems. Altering flow regime affects this integrity by changing the magnitude (size), duration (length of time), frequency (how often a flow of a given magnitude occurs), timing (seasonal predictability), and rate of change of flows (flashiness).

In the state of Michigan, which is located entirely in the GLB, a selection of 40 fish species have been used as indicators of stream health to develop regional ecological flow standards (Hamilton and Seelbach, 2010; Zorn et al., 2012). Using these ecological guidelines along with hydrogeological constraints, Watson et al. (2014) developed a method to estimate maximum allowable pumping rates from groundwater sources in the GLB. Mayer et al. (2012) calculated annual and monthly water stress indices using local and regionally derived withdrawals, annual and monthly consumptive use coefficients for different water use categories (Shaffer, 2009), and stream gauge data to illustrate critical stream-flow depletions in a significant number of catchments in the Kalamazoo River Watershed. Similarly, Mubako et al.(2013) demonstrated that while no significant water stress was detected at the spatial scale of the Kalamazoo River Watershed, water withdrawals for irrigation and urban sector use can cause localized water stress during the summer season, which can impact the sustainability of the freshwater ecosystem. 


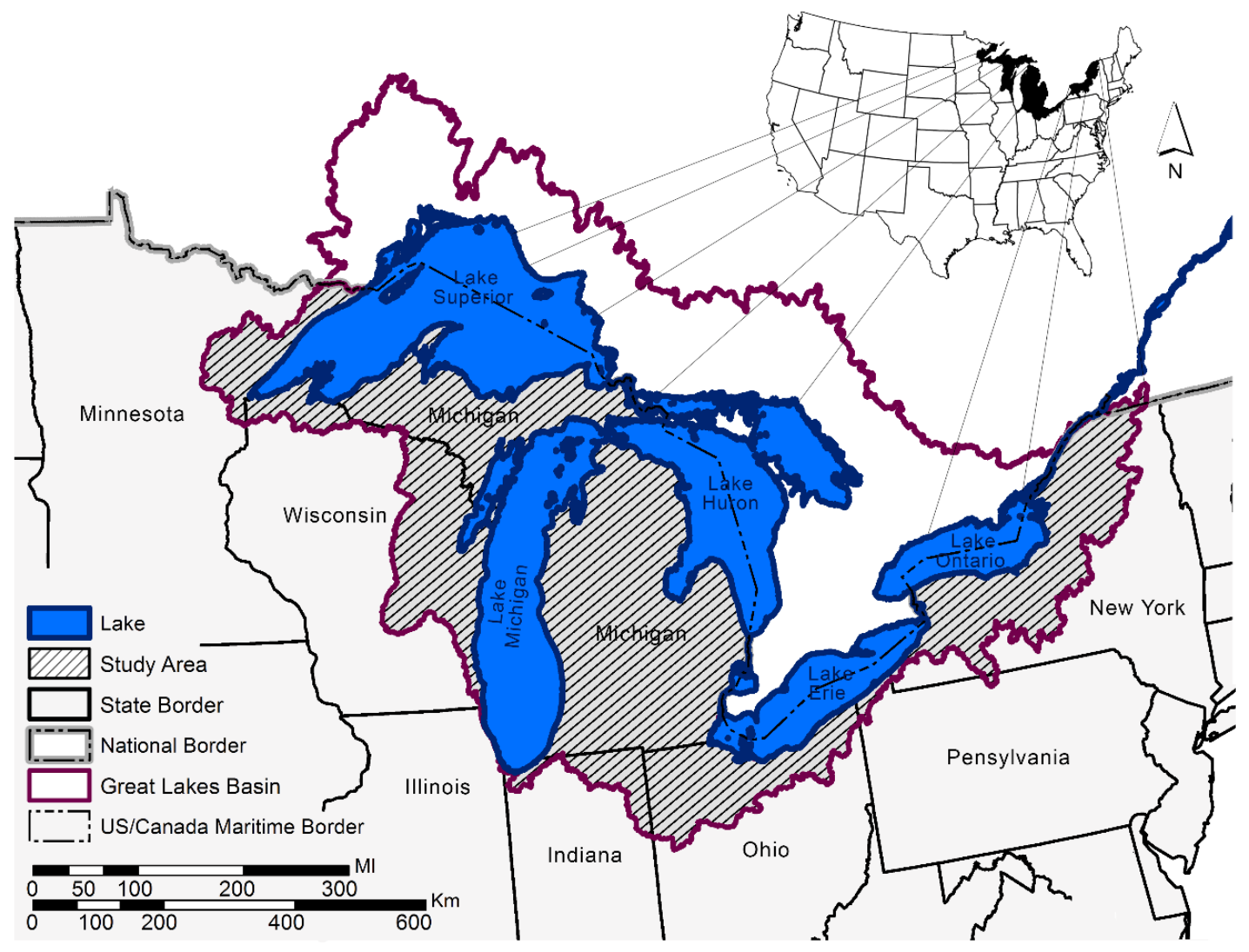

Figure 1.1. Map of the Great Lakes Drainage Basin.

\subsection{Objectives and organization}

This research will integrate and extend previous work to characterize ecological water stress in the Great Lakes region (Mayer et al., 2012; Mubako et al., 2013; Watson et al., 2014), by scaling up the analysis to the entire GLB using available ecological guidelines and water withdrawal records. The current ecological water stress framework systematically accounts for cumulative stream flow disturbance due to the collective effect of localized streamflow depletion and recharge role of return flows (i.e., non-consumptive fraction of withdrawals). The objectives of this research are: 
- Develop a comprehensive, logically structured geodatabase of major water withdrawals for different use categories in the Great Lakes states;

- Develop and apply an integrative methodology for quantifying and mapping ecological water stress along stream networks associated with the water withdrawals; and

- Investigate the impact of spatial and temporal variability on water stress in the Great Lakes region.

This dissertation is written in five chapters. Background information about water stress indices, as well as the need to characterize and map ecological water stress in the GLB was presented in the first chapter. The second chapter discusses the water withdrawal geodatabase and systematic use of geospatial information in water stress mapping. An integrative water stress analysis methodology is presented in Chapter 3 . The fourth chapter presents analysis results. Finally, the fifth chapter provides conclusions and research areas that can be investigated in greater detail in the future. 


\subsection{References}

Alcamo, J., T. Henrichs, and T. Rösch (2000), World water in 2025-Global modeling and scenario analysis for the World Commission on Water for the 21st Century, Kassel World Water Ser. Rep. 2, Cent. for Environ. Syst. Res., Univ. of Kassel, Kassel, Germany.

Anand, S. 1994. Human Development Index: methodology and measurement Human Development Report Office (HDRO), United Nations Development Programme (UNDP).

Arnell, N. W. 1999. Climate change and global water resources. Global Environmental Change, 9, S31-S49, doi:10.1016/S0959-3780(99)00017-5.

Arnell, N. W. 2004. Climate change and global water resources: SRES emissions and socio-economic scenarios. Global Environmental Change, 14, 31-52, doi:10.1016/j.gloenvcha.2003.10.006.

Barlow, P. M., Alley, W. M. \& Myers, D. N. 2010. Hydrologic aspects of water sustainability and their relation to a national assessment of water availability and use. Journal of Contemporary Water Research and Education, 127, 10.

European Environment Agency (EEA). 2013. Results and lessons from implementing the Water Assets Accounts in the EEA area. From concept to production. EEA Technical report No 7/2013, European Environment Agency.

Falkenmark, M. 1989. The massive water scarcity now threatening Africa: why isn't it being addressed? Ambio, 112-118. 
Galli, A., Wiedmann, T., Ercin, E., Knoblauch, D., Ewing, B. \& Giljum, S. 2012. Integrating ecological, carbon and water footprint into a "footprint family" of indicators: definition and role in tracking human pressure on the planet. Ecological indicators, 16, 100-112.

Green, P. A., Vörösmarty, C. J., Harrison, I., Farrell, T., Sáenz, L. \& Fekete, B. M. 2015. Freshwater ecosystem services supporting humans: Pivoting from water crisis to water solutions. Global Environmental Change, 34, 108-118.

Hamilton, D. A. \& Seelbach, P. W. 2010. Determining environmental limits to streamflow depletion across Michigan. The book of the states, 42, 534-537.

Hanasaki, N., Kanae, S., Oki, T., Masuda, K., Motoya, K., Shirakawa, N., Shen, Y. \& Tanaka, K. (2008b), An integrated model for the assessment of global water resources-Part 2: Applications and assessments. Hydrology and Earth System Sciences, 12, 1027-1037, doi:10.5194/hess-12-1027-2008.

Islam, S., Oki, T., Kanae, S., Hanasaki, N., Agata, Y., \& Yoshimura, K. 2007. A gridbased assessment of global water scarcity including virtual water trading. Water Resources Management, 21, 19-33, doi:10.1007/s11269-006-9038-y.

Karabulut, A., Egoh, B. N., Lanzanova, D., Grizzetti, B., Bidoglio, G., Pagliero, L., Bouraoui, F., Aloe, A., Reynaud, A., Maes, J., Vandecasteele, I. \& Mubareka, S. 2016. Mapping water provisioning services to support the ecosystem-water-foodenergy nexus in the Danube river basin. Ecosystem Services, 17, 278-292. 
Mayer, A., Watkins, D., Mirchi, A., Gyawali, R. \& Watson, K. Determination of Water Stress Indices As a Function of Ecological Flows. Proceedings, World Environment and Water Resources Congress, Albuquerque, NM, 2012.

Meigh, J. R., McKenzie, A. A., Sene, K. J. 1999. A grid-based approach to water scarcity estimates for eastern and southern Africa. Water Resources Management, 13, 85115, doi:10.1023/A:1008025703712.

Mubako, S. T., Ruddell, B. L. \& Mayer, A. S. 2013. Relationship between water withdrawals and freshwater ecosystem water scarcity quantified at multiple scales for a great lakes watershed. Journal of Water Resources Planning and Management, 139, 671-681.

Ohlsson, L. 2000. Water conflicts and social resource scarcity. Physics and Chemistry of the Earth, Part B: Hydrology, Oceans and Atmosphere, 25, 213-220.

Oki, T., Agata, Y., Kanae, S., Saruhashi, T., Yang, D. \& Musiake K. 2001. Global assessment of current water resources using total runoff-integrating pathways. Hydrological Sciences Journal, 46, 983-995, doi:10.1080/02626660109492890.

Pedro-Monzonís, M., Solera, A., Ferrer, J., Estrela, T., Paredes-Arquiola, J. 2015. A review of water scarcity and drought indexes in water resources planning and management. Journal of Hydrology 527, 482-493. http://dx.doi.org/10.1016/j. jhydrol.2015.05.003.

Poff, N. L., Allan, J. D., Bain, M. B., Karr, J. R., Prestegaard, K. L., Richter, B. D., Sparks, R. E. \& Stromberg, J. C. 1997. The natural flow regime. BioScience, 47, 769-784. 
Raskin, P., Gleick, P., Kirshen, P., Pontius, G. \& Strzepek, K. 1997. Water futures: Assessment of long-range patterns and problems. Comprehensive assessment of the freshwater resources of the world, SEI.

Ridge, T., Engler, J., Mccallum, S., O'bannon, F., Pataki, G. E., Ryan, G. H., Taft, B., Ventura, J., Harris, M. \& Landry, B. 2001. The Great Lakes Charter Annex: A Supplementary Agreement to The Great Lakes Charter. Documents on Water Law, 2.

Rijsberman, F. R. 2006. Water scarcity: fact or fiction? Agricultural water management, $80,5-22$.

Rockström, J., Falkenmark, M., Karlberg, L., Hoff, H., Rost, S. \& Gerten, D. 2009. Future water availability for global food production: the potential of green water for increasing resilience to global change. Water Resources Research, 45.

Seckler, D. W., Amarasinghe, U., Molden, D., de Silva, R. \& Barker, R. 1998. World water demand and supply, 1990 to 2025: Scenarios and issues, International Water Management Institute (IWMI).

Shaffer, K. 2009. Variations in Withdrawal, Return Flow, and Consumptive Use of Water in Ohio and Indiana, with Selected Data from Wisconsin, 1999-2004, US Geological Survey.

Sullivan, C. A., Meigh, J. R. \& Giacomello, A. M. 2003. The water poverty index: development and application at the community scale. Natural Resources Forum, 189-199. 
Tavernia, B. G., Nelson, M. D., Caldwell, P. V. \& Sun, G. 2013. Water stress projections for the Northeastern and Midwestern United States in 2060: anthropogenic and ecological consequences. Journal of the American Water Resources Association 49(4): 938-952. DOI:10.1111/ jawr.12075.

Vörösmarty, C. J., Green, P. , Salisbury, J. \& Lammers, R. B. 2000. Global water resources: Vulnerability from climate change and population growth. Science, 289, 284-288, doi:10.1126/science.289.5477.284.

Wada, Y., van Beek, L. P. H., Viviroli, D., Dürr, H. H., Weingartner, R. \& Bierkens, M. F. P. 2011. Global monthly water stress: 2. Water demand and severity of water stress, Water Resources Research, 47, W07518, doi:10.1029/2010WR009792.

Watson, K. A., Mayer, A. S. \& Reeves, H. W. 2014. Groundwater availability as constrained by hydrogeology and environmental flows. Groundwater, 52, 225-238.

Zorn, T. G., Seelbach, P. W. \& Rutherford, E. S. 2012. A Regional-Scale Habitat Suitability Model to Assess the Effects of Flow Reduction on Fish Assemblages in Michigan Streams1. JAWRA Journal of the American Water Resources Association, 48, 871-895. 


\section{Chapter 2: Systematic use of geospatial information in water stress mapping}

\subsection{Introduction}

The purpose of geographic information systems (GIS) is to provide a spatial framework to support intelligent decision making and to manage the natural and built environment. Methods for capturing, storing, manipulating, analyzing, and presenting all types of spatial or geographically-referenced data in GIS have changed drastically (i.e., from hand drawn maps to the computer based 3D maps) since the 1970s (Coppock and Rhind, 1991; Brovelli, 2011). GIS is widely used for different applications requiring the use of geospatial information. A wide range of spatial data are freely available to users, as more data become available to address increasingly complex resources management needs. In many cases, the data are publicly available through national and state level clearing houses such as USGS Earth Explorer (earthexplorer.usgs.gow), USGS National Map Viewer (viewer.nationalmap.gov.viewer/), National Land Cover Database (www.mrlc.gov), Michigan Geodata Library (www.mcgi.state.mi.us/), and Michigan GIS Open Data Portal (gis.michigan.opendata.arcgis.com), among others.

Designing appropriate geodatabases (GDB) is a best practices approach for managing and using spatial data consistently and systematically. Large-scale environmental research and resource management projects typically utilize multiple data sets to investigate multiple dimensions of resource management problems. Establishing data documentation and sharing protocols is of great importance because data sources (e.g., government and 
state agencies, research institutes, etc.) have different approaches to compiling and classifying data, which complicates their use. Creating a well-designed, topologically correct GDB can significantly facilitate the investigation of ecological water stress in large areas like the GLB. The purpose of Chapter 2 is to illustrate the importance of proper GDB design and documentation to facilitate large-scale resource management studies.

\subsection{Geodatabase}

A GDB is an original data structure in ArcGIS which is used for data management and editing (MacDonald, 2001; Arctur and Zeiler, 2004). It is a collection of geographic datasets which enforces data integrity and creates intelligent features. The purpose of the GDB data model is to make GIS feature datasets easier to manage, and to improve the utility of geospatial data through topological links and relationships between features. It brings a physical data model (table structures, including column name, column data type, relationships between tables, etc.) closer to its logical, object-orientated data model. Also, the GDB data model allows the analyst to implement the majority of custom behaviors such as defining default values, enabling and disabling parameters, etc. using built-in ArcGIS functions.

There are three primary data types in the GDB, including feature classes, raster datasets, and tables. Feature classes represent the spatial components of the GDB which include homogeneous collections of points, polylines, polygons, or annotations along with associated attribute tables. Figure 2.1 illustrates three datasets in the GLB study area, including withdrawal points as a point feature class, streams as polyline, and catchments as polygon feature classes. Raster datasets are gridded geographic features with specific 
data characteristics and associated attribute tables. Attribute tables are non-spatial elements of the GDB which store attribute data, addresses, and XY coordinates, among other data, in rows and columns.

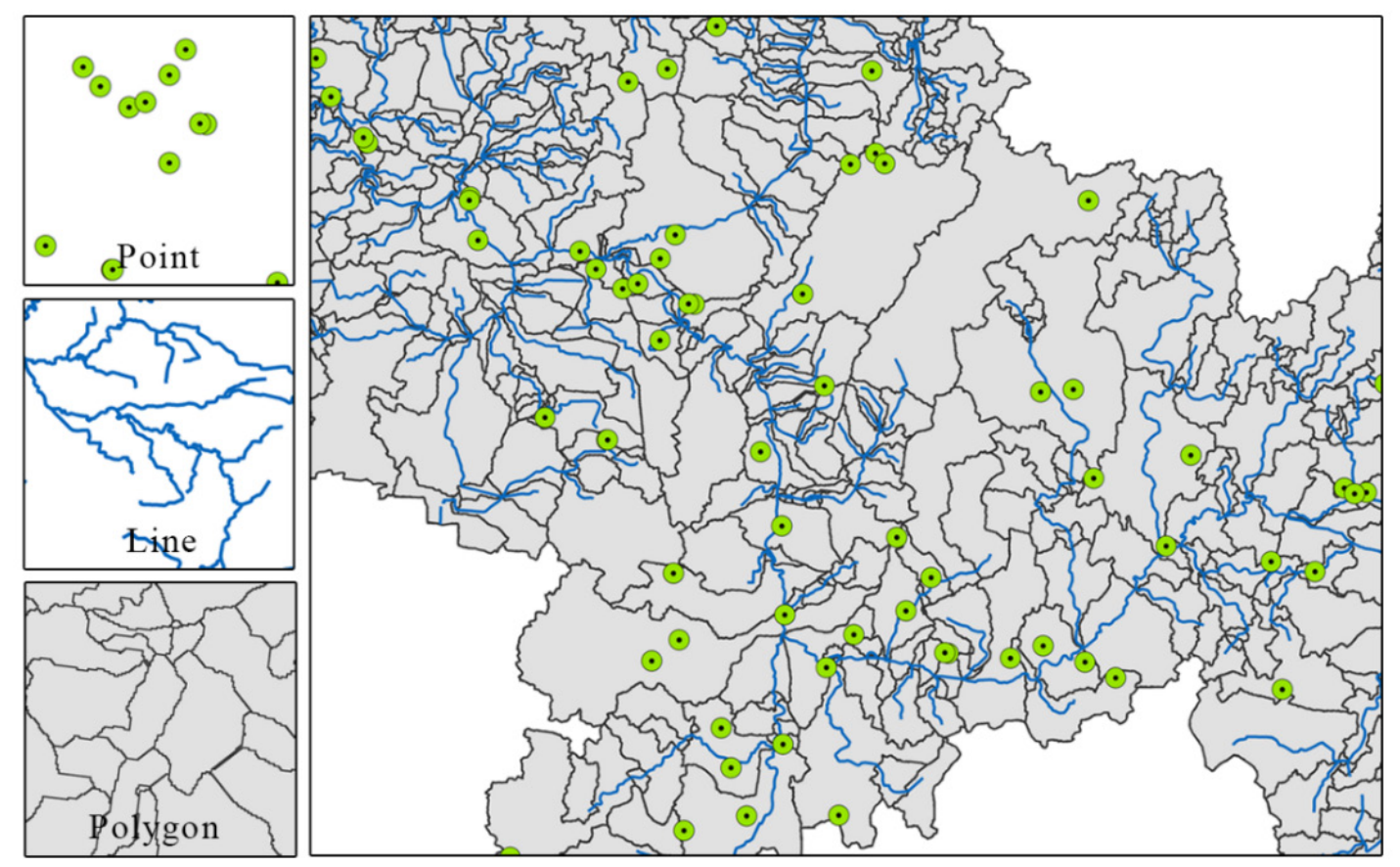

Figure 2.1. Basic feature classes in the GLB GDB, including points (withdrawal points), polylines (streams), and polygons (catchments).

The GDB data model offers additional capabilities such as relationship classes and networks (MacDonald, 2001; Arctur and Zeiler, 2004). Relationship classes function like join and relate commands in ArcMap, although they provide more advantages. The use of a GDB can reduce data maintenance costs by enforcing automatic updates to the related objects, facilitating editing, and querying related features and records. Furthermore, the GDB data model can be used to help enforce referential integrity between related objects. For example, in the GLB, the GDB relationship has been used to relate NHD catchments and streams, which are two different feature classes with a common identifier (i.e., 
COMID), which makes linking the attributes possible using a common field between tables (Figure 2.2).

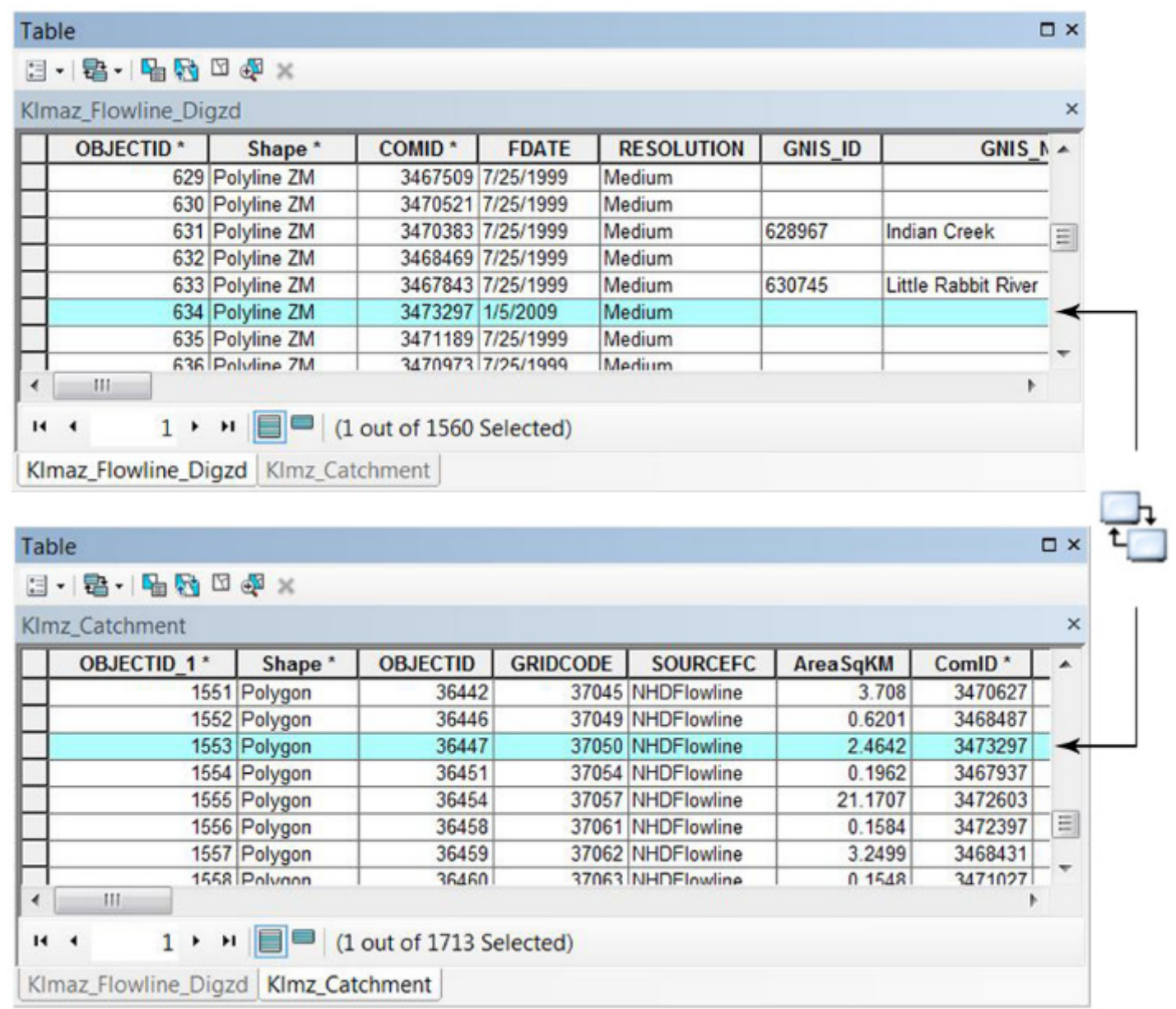

Figure 2.2. Relationship class between Flowline and Catchment feature classes.

A geometric network is another spatial element located inside the feature dataset. It includes a series of edges (lines) that are connected through junctions (points) to form a logical network that traces flow from edge to edge through junctions. Edges are flowlines that are connected through the intersection of streams and catchment boundaries (junctions). Both edges and junctions in the network are topologically connected and a 
unique ID has been assigned to them and they follow connectivity rules to form an actual, intelligent flow network. Figure 2.3 illustrates the geometric network properties in the GDB of the GLB.

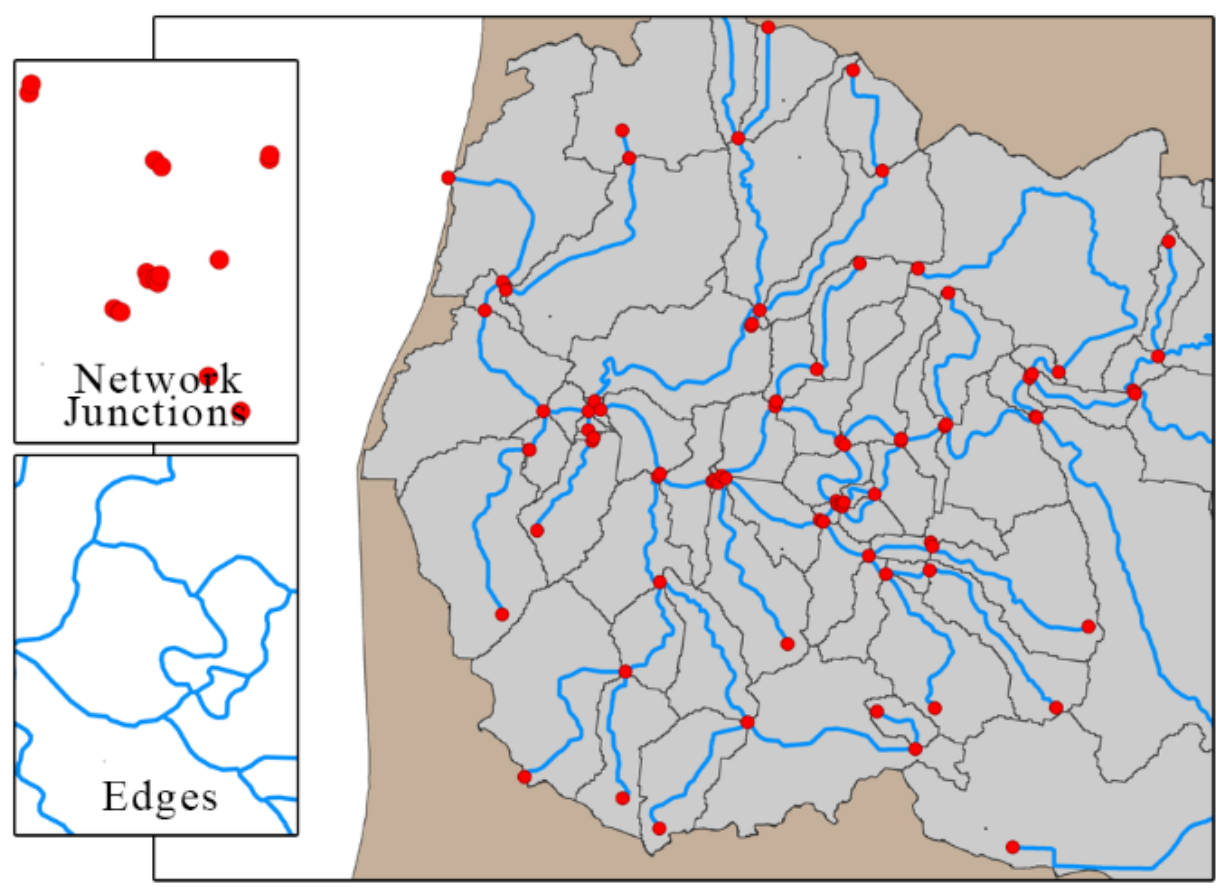

Figure 2.3. Geometric network properties in GLB GBD. Geometric network includes junctions (intersection of the streams and catchments boundaries) and edges (streams).

The GDB data model accommodates very large spatial sets of features without tiles or other spatial partitions, which can be used for making dynamic maps whereby features on a map display are dynamic (i.e., they respond to changes in neighboring features). The GDB can be used as a systematic data repository with intuitive data objects that support resource management at small spatial scales, making it a suitable data storage and data management framework for the analysis of water stress in the GL Region. The main utility of the GDB storage model is to facilitate the implementation of relational data base 
concepts, providing a common storage for all vector files, raster files, and attribute tables, which are essential for developing the geometric network and establishing relationship classes. Figure 2.4 shows a basic GDB consisting of catchment polygons, streams, state boundaries, and withdrawal points. Additional layers created at different stages of analysis are stored in a generalized GDB. Examples include the flow-catchment relationship and drainage network, which are explained in the next chapter. Using the GDB as the main workspace for data storage for current and future analysis will facilitate data access, more accurate data editing, and making data layers intelligent (i.e., updating data layers in the GDB based on changes made to a particular layer). It essentially provides a convenient geospatial data management tool, especially when conducting the analysis at monthly time scales with numerous data layers. Table 2.1 summarizes key attributes of the generalized GDB, which are used as main inputs in the calculations of water stress index.

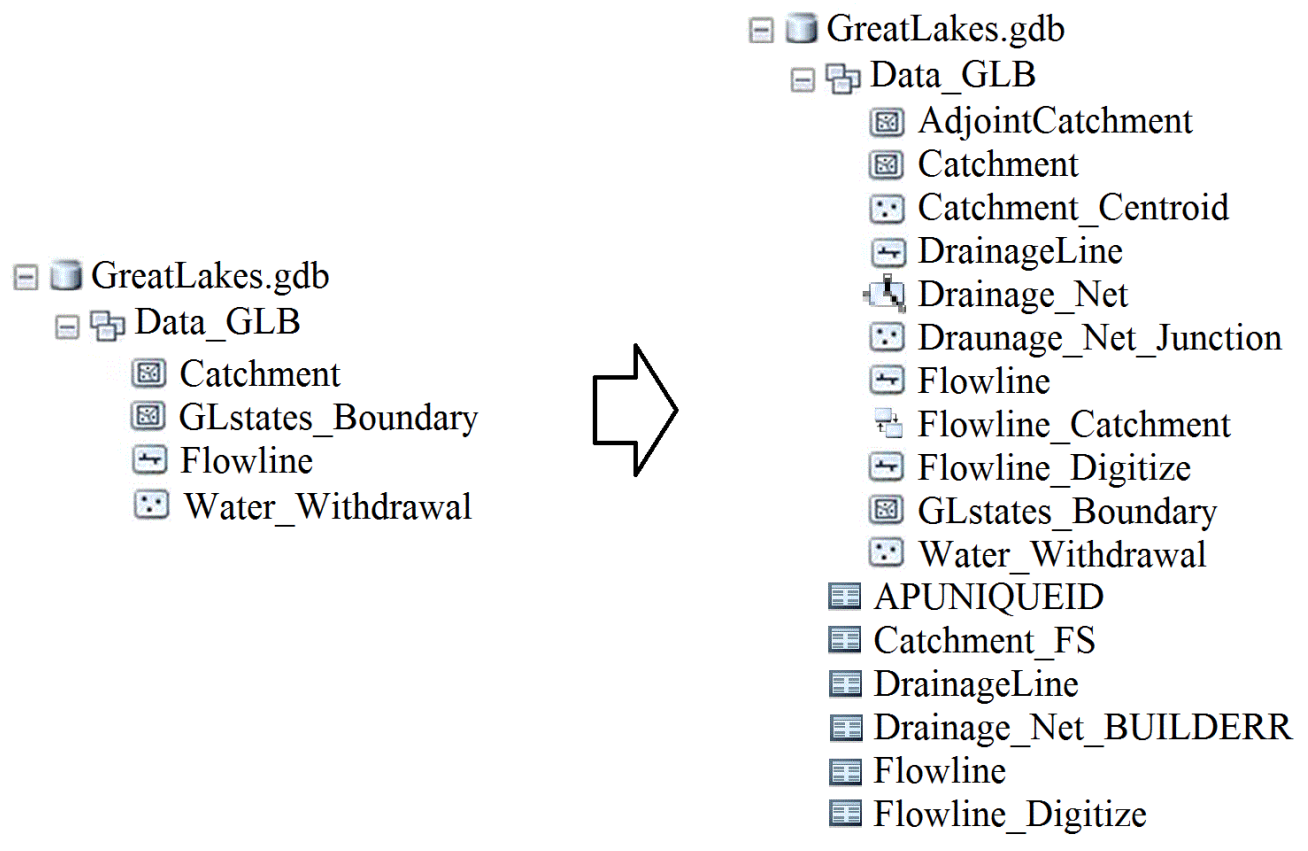

Figure 2.4. Basic (left) and generalized (right) GDBs of the GLB. 
Table 2.1. Key attributes of withdrawal points feature class.

\begin{tabular}{|c|c|}
\hline Attribute field & ition \\
\hline Code & $\begin{array}{l}\text { Includes name of the states, water withdrawal } \\
\text { source, and the identifying number }\end{array}$ \\
\hline Source & $\begin{array}{l}\text { Source of water withdrawal (inland surface } \\
\text { water (SW), deep groundwater (GWD), shallow } \\
\text { groundwater (GWSH), and Great Lakes (GLW)) }\end{array}$ \\
\hline Total withdrawal & Total withdrawal (million gallons per year) \\
\hline Water use category & $\begin{array}{l}\text { Water use category for each withdrawal as } \\
\text { reported by state }\end{array}$ \\
\hline Water use & $\begin{array}{l}\text { Water use category based on USGS } \\
\text { classification (Shaffer and Runkle, 2007) }\end{array}$ \\
\hline Area & Local catchment area from NHDPlus V2 $\left(\mathrm{Km}^{2}\right)$ \\
\hline Common ID & Common identifier of an NHD Flowline feature \\
\hline Total area & $\begin{array}{l}\text { Total upstream cumulative drainage area in } \\
\text { square kilometers at the downstream end of the } \\
\text { NHD Flowline feature }\end{array}$ \\
\hline Cumulative flow & $\begin{array}{l}\text { Annual gage-adjusted cumulative flow from } \\
\text { NHDPlus V2 in unit of cubic feet per second } \\
\text { (cfs) (McKay et al., 2012) }\end{array}$ \\
\hline Consumptive use coefficient & $\begin{array}{l}\text { Proportion of water that is consumed; it is does } \\
\text { not return to water source (from Shaffer (2009)) }\end{array}$ \\
\hline Streamflow depletion factor & $\begin{array}{l}\text { Reduction of streamflow due to withdrawal } \\
\text { (Watson et al., 2014) }\end{array}$ \\
\hline
\end{tabular}

\subsection{Data inputs}

The current framework for characterizing ecological water stress in the GLB is based on local streamflow disturbance due to water withdrawals to meet demands in different use 
categories. Private, state, and national geospatial data-including water withdrawals, the National Hydrography Dataset Plus Version 2 (NHDPlus V2, 2012), and consumptive use categories (Shaffer, 2009)-have been used to design the GDB framework. The data inputs collected from different national and local agencies and geospatial clearing houses are summarized in Table 2.2. Illinois is not included in the study as it is a negligible portion of the US GL region.

Table 2.2. Data inputs and sources.

\begin{tabular}{|c|c|}
\hline Data Type & Source \\
\hline Michigan water withdrawal points & Michigan Department of Environmental Quality \\
\hline Minnesota water withdrawal points & Minnesota Department of Natural Resources \\
\hline Wisconsin water withdrawal points & Wisconsin Department of Natural Resources \\
\hline Ohio water withdrawal points & Ohio Division of Soil and Water Resources \\
\hline New York water withdrawal points & $\begin{array}{l}\text { New York State Department of Environmental } \\
\text { Conservation }\end{array}$ \\
\hline Pennsylvania water withdrawal points & $\begin{array}{l}\text { Pennsylvania Department of Environmental } \\
\text { Protection }\end{array}$ \\
\hline Indiana water withdrawal points & $\begin{array}{l}\text { Indiana Department of Environmental } \\
\text { Protection }\end{array}$ \\
\hline National Hydrography Dataset (NHDPlusV2) & $\begin{array}{l}\text { http://www.horizon- } \\
\text { systems.com/nhdplus/NHDplusV2_home.php }\end{array}$ \\
\hline $\begin{array}{l}\text { Annual/Monthly Consumptive Use } \\
\text { Coefficient }\end{array}$ & Shaffer and Runkle (2007) and Shaffer (2009) \\
\hline Annual/Monthly Water withdrawal & Shaffer and Runkle (2007) and Shaffer (2009) \\
\hline Water Use Categories & Shaffer (2009) \\
\hline
\end{tabular}




\subsubsection{Water withdrawal and consumption}

A total of 6,805 points in seven Great Lakes states with water withdrawal capacity of at least 100,000 gallons per day for each withdrawal point constitute the water withdrawal data for the water stress analysis. These withdrawal points are scattered over about 106,000 catchments, each containing stream flowlines (Figure 2.5). Figure 2.6a shows the percentage of water withdrawal points by source of water in different states and in the GLB. The majority of water in the Great Lakes states is withdrawn from surface waters (Figure 2.6b), with the exception of Pennsylvania, which relies predominantly on shallow groundwater. A mix of shallow and deep groundwater withdrawals is used as the secondary inland source of water in Wisconsin, Michigan, Indiana, and Ohio, whereas shallow groundwater is the second major inland water source in Minnesota. The state of New York predominantly withdraws from inland surface water. Illinois is not included in the study, as it is a negligible portion of the US GL region. 


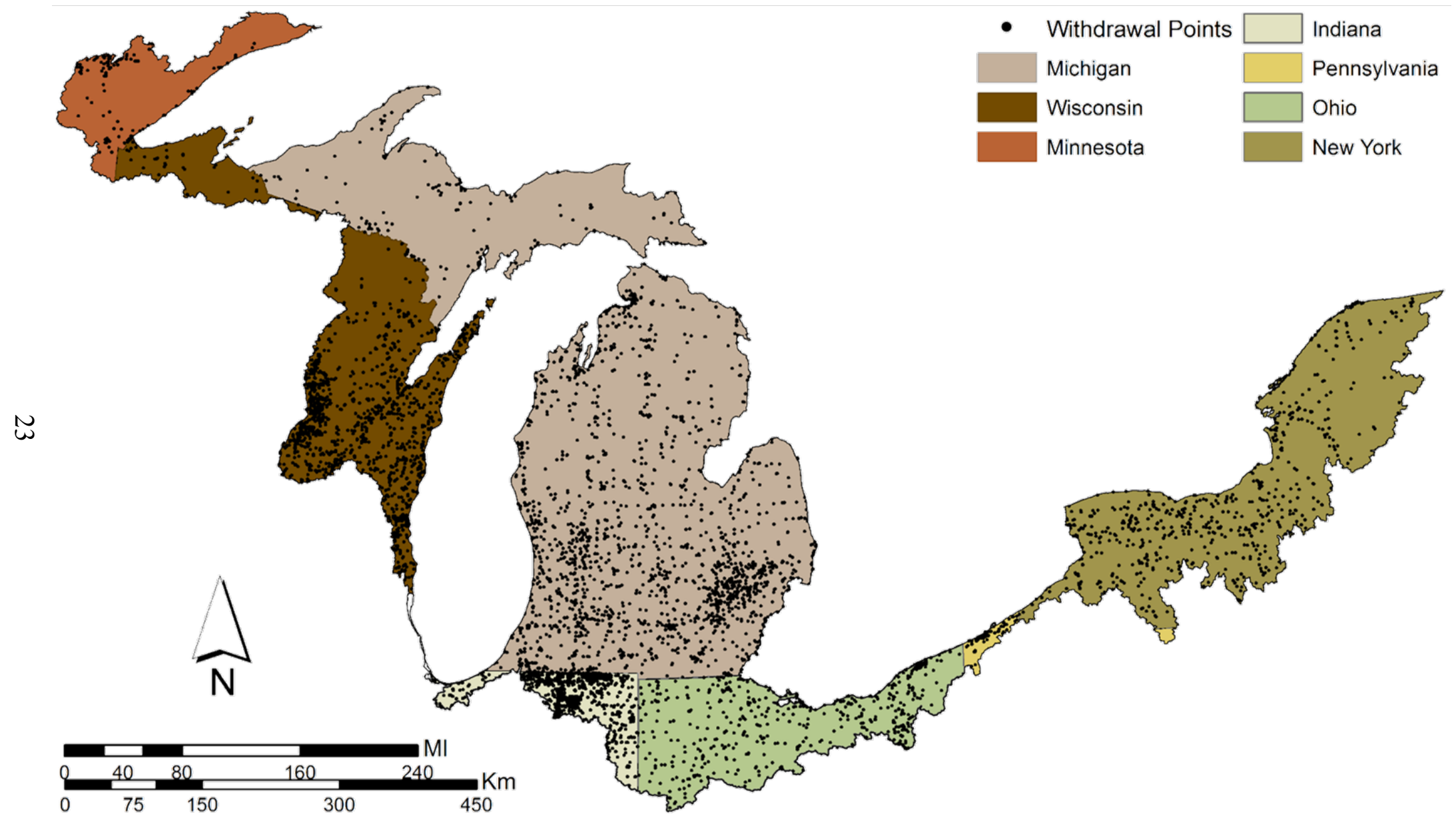

Figure 2.5. Distribution of water withdrawal points across the GLB. 


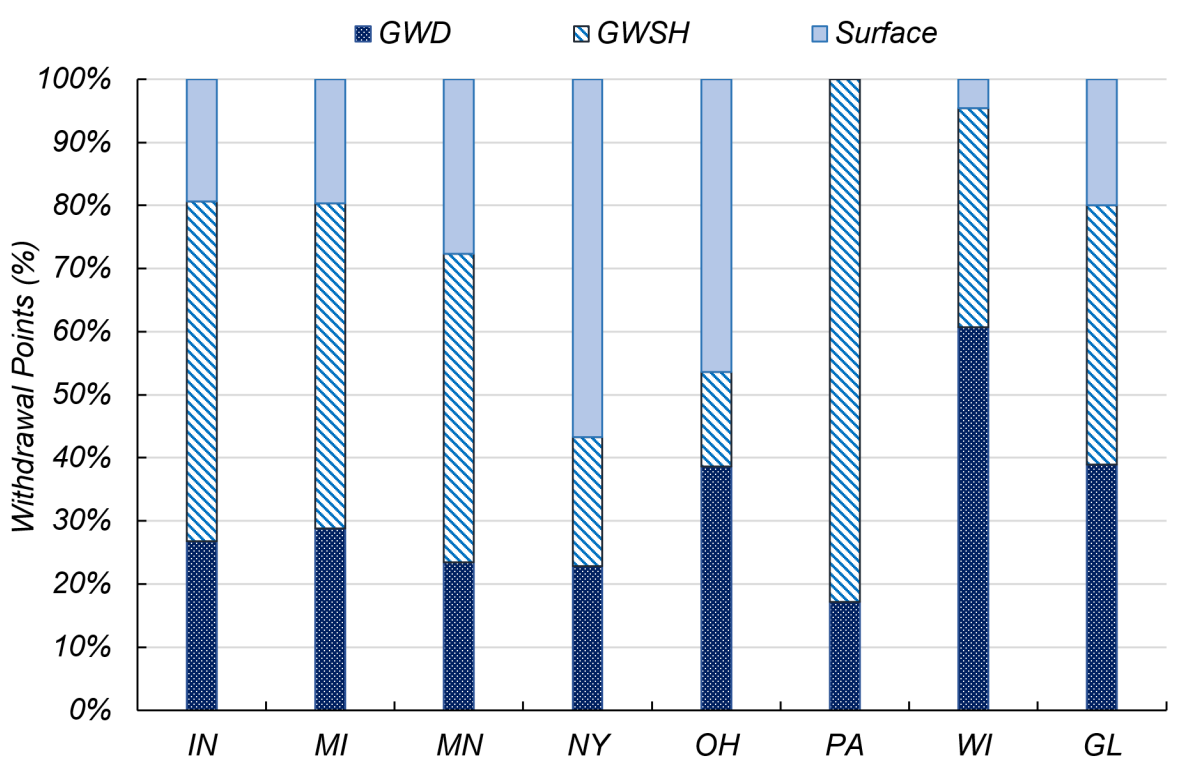

(a)

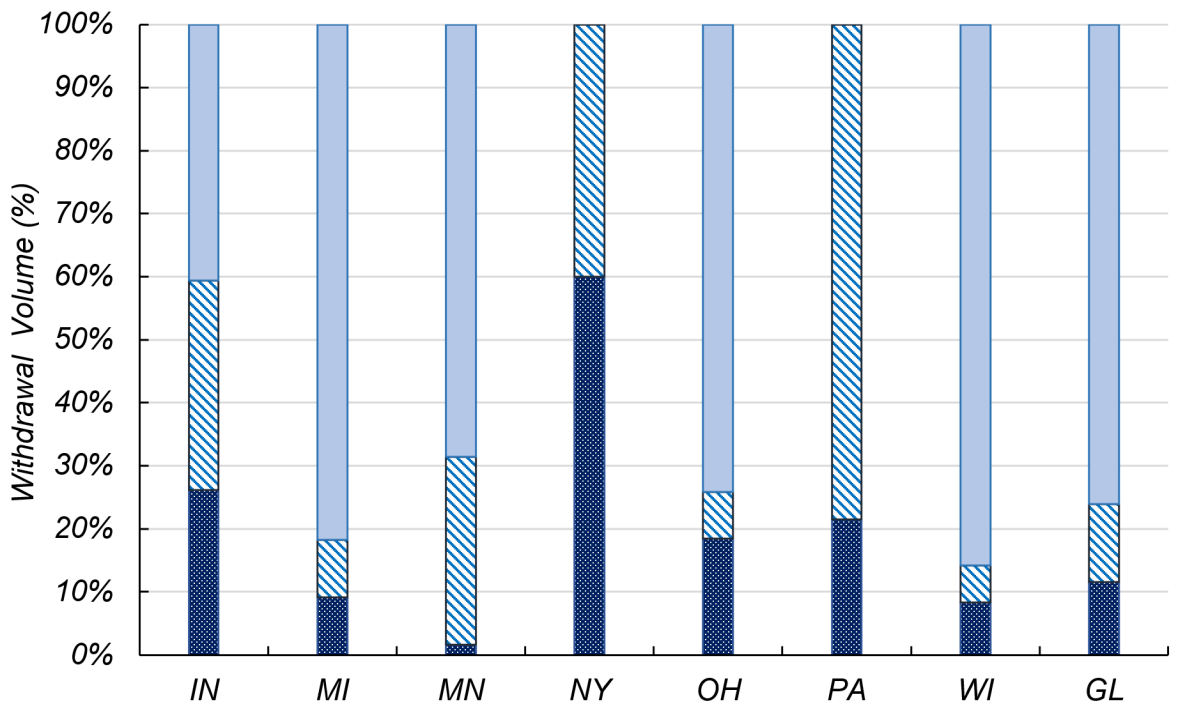

(b)

Figure 2.6. Water withdrawal from inland sources by state (inland surface water (Surface); shallow groundwater (GWSH); and deep groundwater (GWD)); (a) percentage of locations withdrawing water from different sources, and (b) percentage of total volume of withdrawals. Surface water withdrawal for power production in New York $(99 \%$ of total withdraws in the state) which was about 46,500,000 MGY was excluded to better illustrate the percentage of volumetric withdrawals from different sources. 
Water use categories reported by different states were reclassified based on Shaffer and Runkle (2007) and Shaffer (2009), for consistency. This is necessary for using the annual and monthly consumptive use coefficients for the major use categories across the Great Lakes region (Shaffer and Runkle, 2007; Shaffer, 2009). For example, community water supply in the state of Michigan; apartments, municipal, mobile home park, and association co-ops in Pennsylvania; public water supply in New York; and public use in Ohio were all classified as domestic and public supply water use. Figure 2.7 shows different water use categories in the Great Lakes states and the percentage of water use classes.
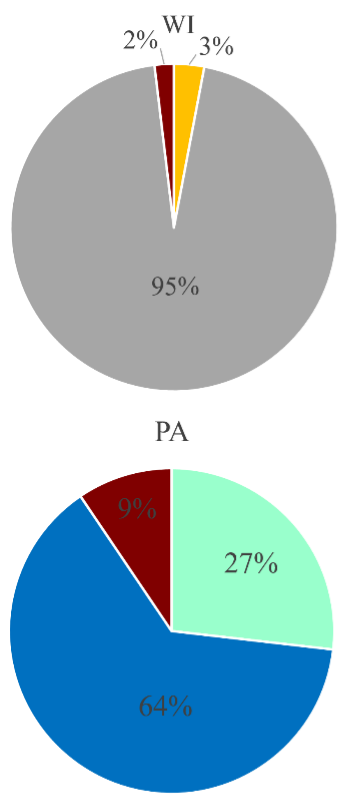

- Domestic \& Public Supply

- Power - Other
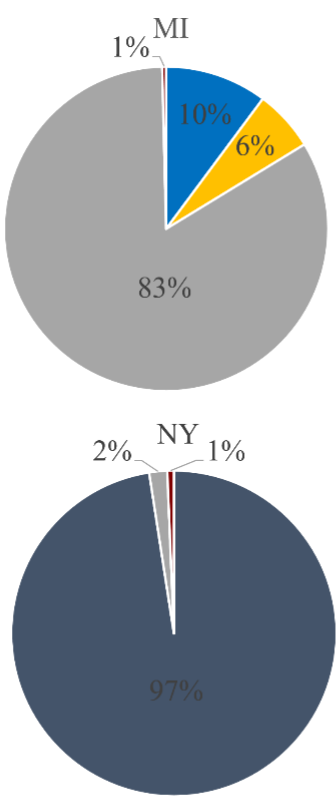

- Industrial

n Thermoelectric Power
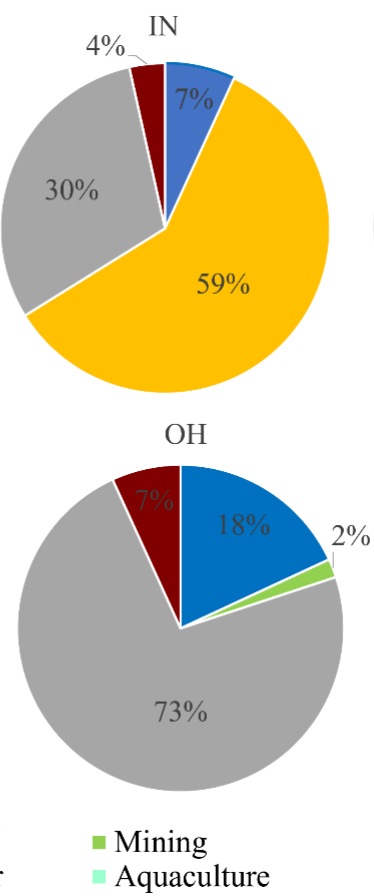

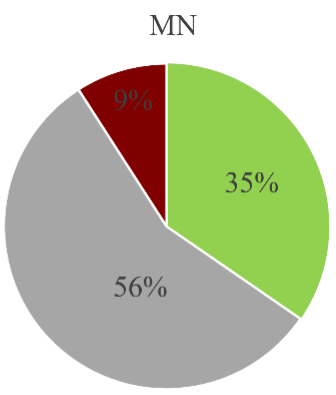

All Uses in GLB

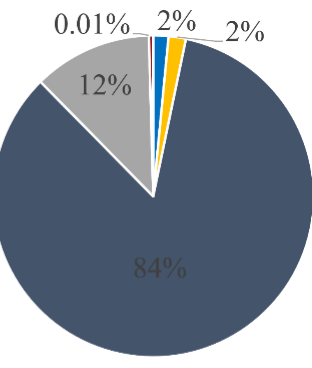

- Other

Figure 2.7. Different water use categories in the GLB based on Shaffer and Runkle (2007) and Shaffer (2009) classifications.

Shaffer and Runkle (2007) and Shaffer (2009) provides consumptive use coefficient statistics for the GL region based on the range of reported values for different use categories 
such as agricultural, industrial, public, etc. She also offers information about monthly fractions of water withdrawal, which help scale down annual water withdrawal to monthly consumption levels. Tables 2.3 and 2.4 summarize median monthly consumptive use coefficients and monthly fraction of annual water withdrawals calculated based on available data from Ohio and Indiana. Table 2.5 summarizes the consumptive use coefficients for the month of August for Michigan, where consumptive use is highest (i.e., up to $100 \%$ ) for crop irrigation and livestock water use categories. When category-specific consumptive use coefficient statistics are unavailable for a state, the corresponding values for Ohio and Indiana were used.

Table 2.3. Median monthly consumptive use coefficients (\%) calculated based on the arithmetic average of median monthly consumptive use values of Indiana and Ohio (Shaffer, 2009).

\begin{tabular}{lcccccccccccc}
\hline $\begin{array}{l}\text { Water use } \\
\text { category }\end{array}$ & Jan & Feb & Mar & Apr & May & Jun & Jul & Aug & Sept & Oct & Nov & Dec \\
\hline Commercial & 4 & 4 & 5 & 7 & 7 & 7 & 8 & 19 & 17 & 16 & 3 & 4 \\
Industrial & 8 & 9 & 9 & 9 & 8 & 8 & 9 & 9 & 9 & 8 & 9 & 9 \\
Thermoelectric & 1 & 2 & 1 & 3 & 2 & 5 & 3 & 3 & 2 & 2 & 2 & 2 \\
Crop irrigation & -- & -- & -- & 79 & 78 & 82 & 80 & 80 & 81 & 81 & 70 & -- \\
Nursery irrigation & -- & -- & -- & 79 & 78 & 82 & 80 & 80 & 81 & 81 & 70 & -- \\
Golf course & -- & -- & -- & 71 & 75 & 82 & 80 & 84 & 82 & 75 & 3 & -- \\
Mining & 3 & 5 & 10 & 10 & 10 & 10 & 10 & 10 & 10 & 10 & 10 & 10 \\
Domestic \& public & -- & -- & -- & -- & 5 & 13 & 19 & 16 & 11 & 3 & -- & -- \\
Livestock & -- & -- & -- & -- & -- & -- & 83 & 83 & 83 & -- & -- & -- \\
Aquaculture & 0 & 0 & 0 & 0 & 0 & 0 & 0 & 0 & 0 & 0 & 0 & 0 \\
\hline
\end{tabular}


Table 2.4. Median monthly fraction of water withdrawals (\%) calculated based on the arithmetic average of median monthly fraction of water withdrawals for different use categories in Indiana and Ohio (Shaffer, 2009).

\begin{tabular}{|c|c|c|c|c|c|c|c|c|c|c|c|c|}
\hline $\begin{array}{l}\text { Water use } \\
\text { category }\end{array}$ & $\mathbf{J}$ & $\mathbf{F}$ & $\mathbf{M}$ & $\mathbf{A}$ & $\mathbf{M}$ & $\mathbf{J}$ & $\mathbf{J}$ & $\mathbf{A}$ & $\mathbf{S}$ & $\mathbf{O}$ & $\mathbf{N}$ & $\mathbf{D}$ \\
\hline Commercial & 6.65 & 6.55 & 7.05 & 7.75 & 8.60 & 8.55 & 9.20 & 9.60 & 9.10 & 8.30 & 6.65 & 6.35 \\
\hline Industrial & 7.65 & 7.30 & 8.05 & 8.15 & 8.50 & 8.65 & 8.70 & 9.00 & 8.40 & 8.45 & 7.90 & 7.35 \\
\hline Thermoelectric & 7.85 & 7.15 & 7.70 & 7.45 & 8.40 & 9.05 & 10.05 & 9.90 & 8.60 & 8.25 & 7.65 & 7.80 \\
\hline Crop irrigation & 0.00 & 0.00 & 0.00 & 0.00 & 1.15 & 11.85 & 31.00 & 27.75 & 4.15 & 0.00 & 0.00 & 0.00 \\
\hline $\begin{array}{l}\text { Nursery } \\
\text { irrigation }\end{array}$ & 0.00 & 0.00 & 0.00 & 4.75 & 9.65 & 14.10 & 16.40 & 16.90 & 12.85 & 7.80 & 1.55 & 0.00 \\
\hline Golf course & 0.00 & 0.00 & 0.00 & 0.10 & 6.75 & 15.95 & 23.15 & 23.40 & 15.85 & 5.00 & 0.00 & 0.00 \\
\hline Mining & 4.35 & 5.15 & 8.15 & 9.10 & 9.75 & 9.60 & 9.40 & 9.50 & 9.15 & 9.25 & 8.25 & 6.45 \\
\hline $\begin{array}{l}\text { Domestic \& } \\
\text { public }\end{array}$ & 7.90 & 7.20 & 7.90 & 7.80 & 8.40 & 8.60 & 9.60 & 9.30 & 8.50 & 8.20 & 7.50 & 7.70 \\
\hline Livestock & 7.85 & 7.75 & 8.10 & 8.00 & 8.35 & 8.40 & 8.70 & 8.70 & 8.35 & 8.30 & 8.15 & 8.15 \\
\hline Aquaculture & 7.60 & 7.10 & 8.45 & 9.35 & 8.60 & 8.90 & 7.50 & 7.80 & 8.15 & 8.15 & 7.55 & 7.75 \\
\hline
\end{tabular}

Table 2.5. August consumptive use coefficients for water use categories in Michigan.

\begin{tabular}{lcccc}
\hline \multirow{2}{*}{ Water use category } & \multicolumn{4}{c}{ Consumptive use coefficient statistic } \\
\cline { 2 - 5 } Domestic \& Public Supply & $\mathbf{2 5 t h}$ & $\mathbf{5 0 t h}$ & $\mathbf{7 5 t h}$ & Max \\
\hline Industrial & 10 & 12 & 15 & 74 \\
\hline Thermoelectric Power & 7 & 10 & 14 & 35 \\
\hline Irrigation & 1 & 2 & 2 & 21 \\
\hline Livestock & 90 & 90 & 96 & 100 \\
\hline Commercial & 80 & 83 & 90 & 100 \\
\hline Mining & 8 & 10 & 15 & 26 \\
\hline
\end{tabular}




\subsubsection{National Hydrography Dataset}

The United States Environmental Protection Agency Office of Water and the United States Geological Survey developed the NHDPlus V2 for the conterminous U.S (Moore and Dewald, 2016), providing hydrographic, hydrologic, and spatial attributes at fine spatial scale (i.e., catchment) and at different temporal scales (e.g., annual and monthly). The NHD Flowline and NHD Catchment vector layers, plus the elevation, flow accumulation, and flow direction raster data sets available from the NHDPlus V2 data base, were used in the water stress characterization framework. Furthermore, different corresponding attribute tables from the NHDPlus V2 data base were compiled, as they contain important information related to the chosen NHDPlus V2 data layers. Other information such as stream order and topological attributes required to build a continuous network were also used to implement the water stress characterization framework. The hydrologic data (e.g., catchment scale mean annual (MA) and mean monthly (MM01-12) gage adjusted cumulative flow and gage adjusted incremental flow) derived from the Enhanced Runoff Method (EROM; NHDPlus V2, 2012) were used in the analysis. EROM uses runoff, temperature, precipitation, and gage flow within a water balance framework to estimate the hydrologic information at ungagged sites for the 1971 to 2000 timeframe. Figure 2.8 shows an example of NHDPlus catchments and stream network. Catchment level analysis provides an opportunity to investigate water stress at finer spatial scales than previous watershed scale analyses (e.g., Hydrologic Unit Code (HUC) 12 (Eldardiry et al., 2016)). 


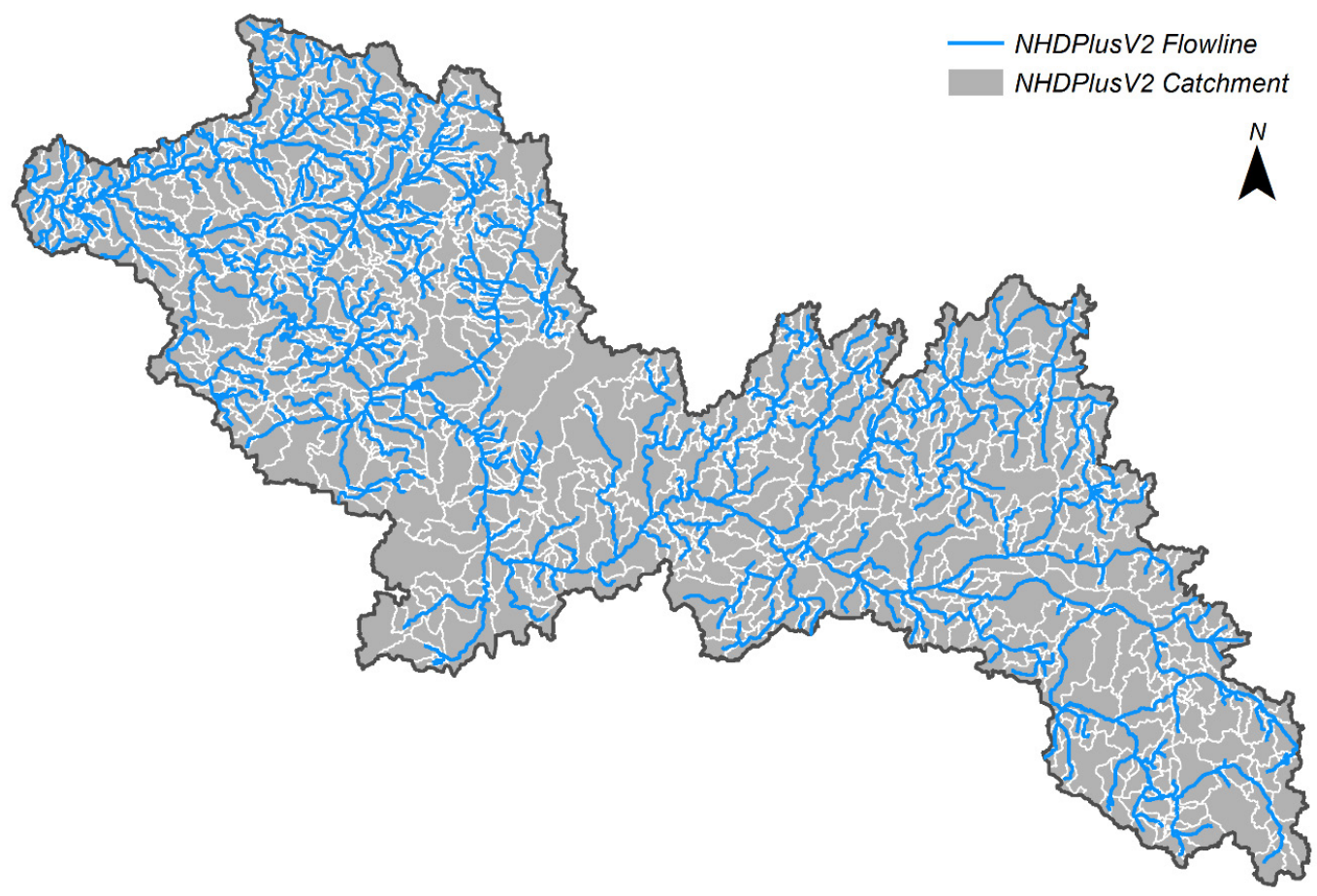

Figure 2.8. Example NHDPlus V2 catchments and stream network in the Kalamazoo River Watershed in Michigan.

Figure 2.9 provides catchment size distributions for six basins (Lake Michigan, St. Lawrence River, Lake Superior, Lake Ontario, Lake Erie, and Lake Huron) that constitute the GL Region in the NHDPlus V2 data base. The majority of catchments in all the basins are very small (i.e., up to $2 \mathrm{~km}^{2}$ ). While there is a range of larger catchments within the major basins, their frequency drastically decreases with increasing catchment size, i.e., from tens of thousands to a few hundred as catchment size increases from $2 \mathrm{Km}^{2}$ to $20 \mathrm{Km}^{2}$ or more. 

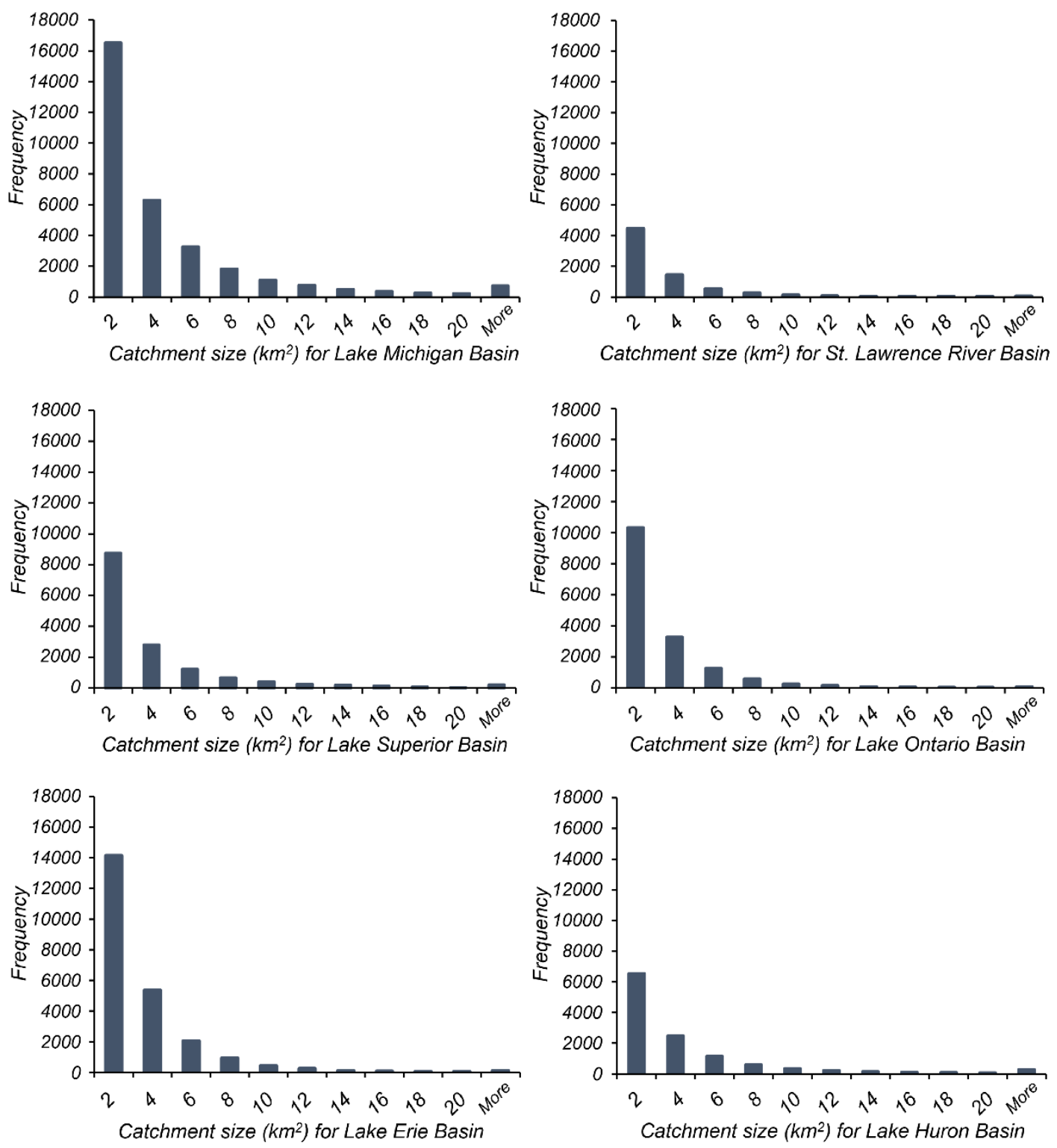

Figure 2.9. Catchment size distributions in six basins constituting the U.S. GL Region.

The flow data available from NHDPlus V2 represent unimpaired flow conditions, meaning the flows do not account for human impacts. Consistent with the small spatial scale of catchments, the majority of average annual flows in the six basins in the GL Region are very small (i.e., up to $0.1 \mathrm{cms}$ ). In the month of August, which was selected for monthly 
water stress analysis, the frequency of major flows decreases, while small flows of up to 1 cms become more frequent, denoting smaller flows as compared with average annual conditions. Figures 2.10 and 2.11 provide size distributions of mean annual and mean August flows at the catchment scale.
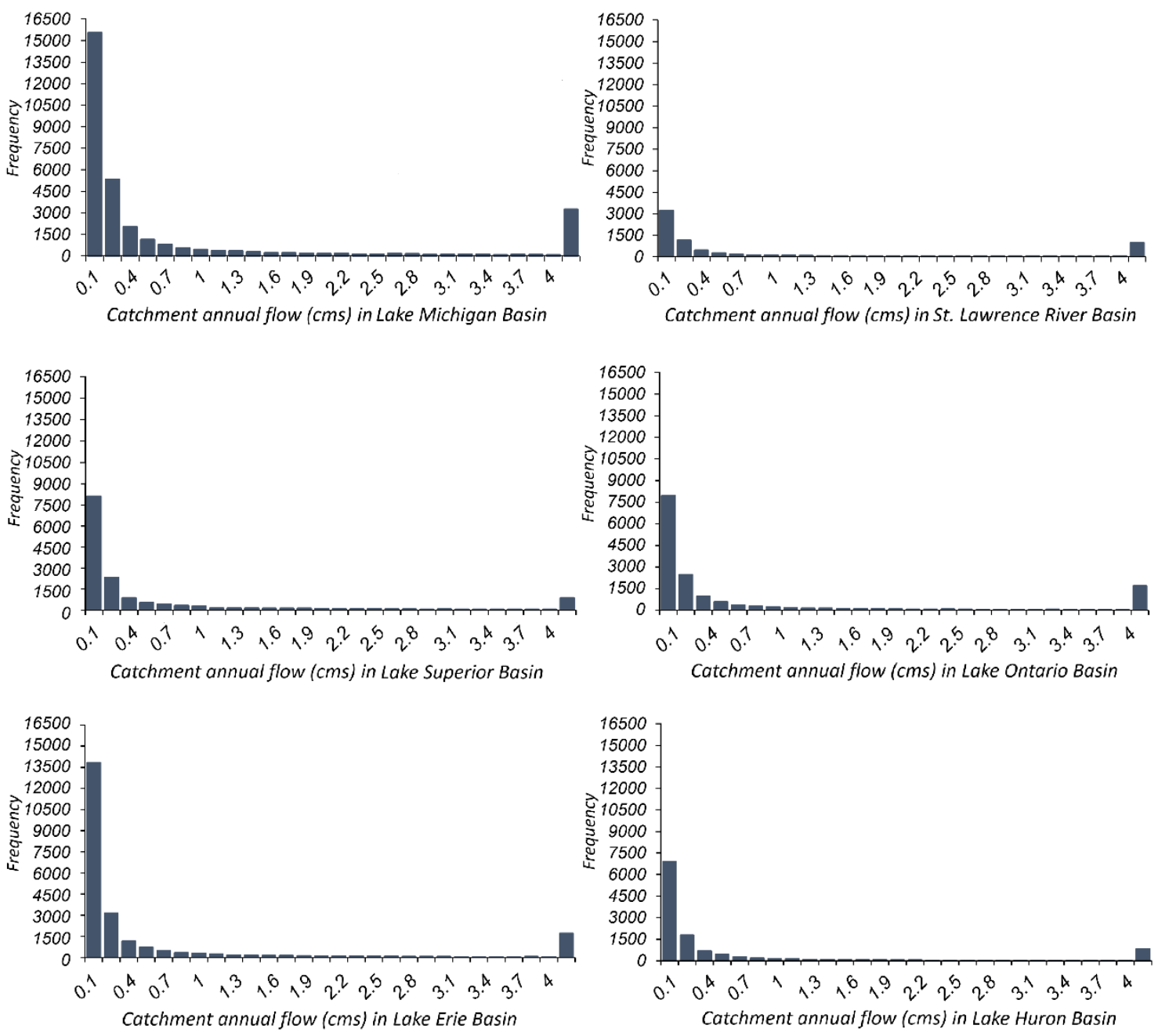

Figures 2.10. Size distribution of mean annual flows. 

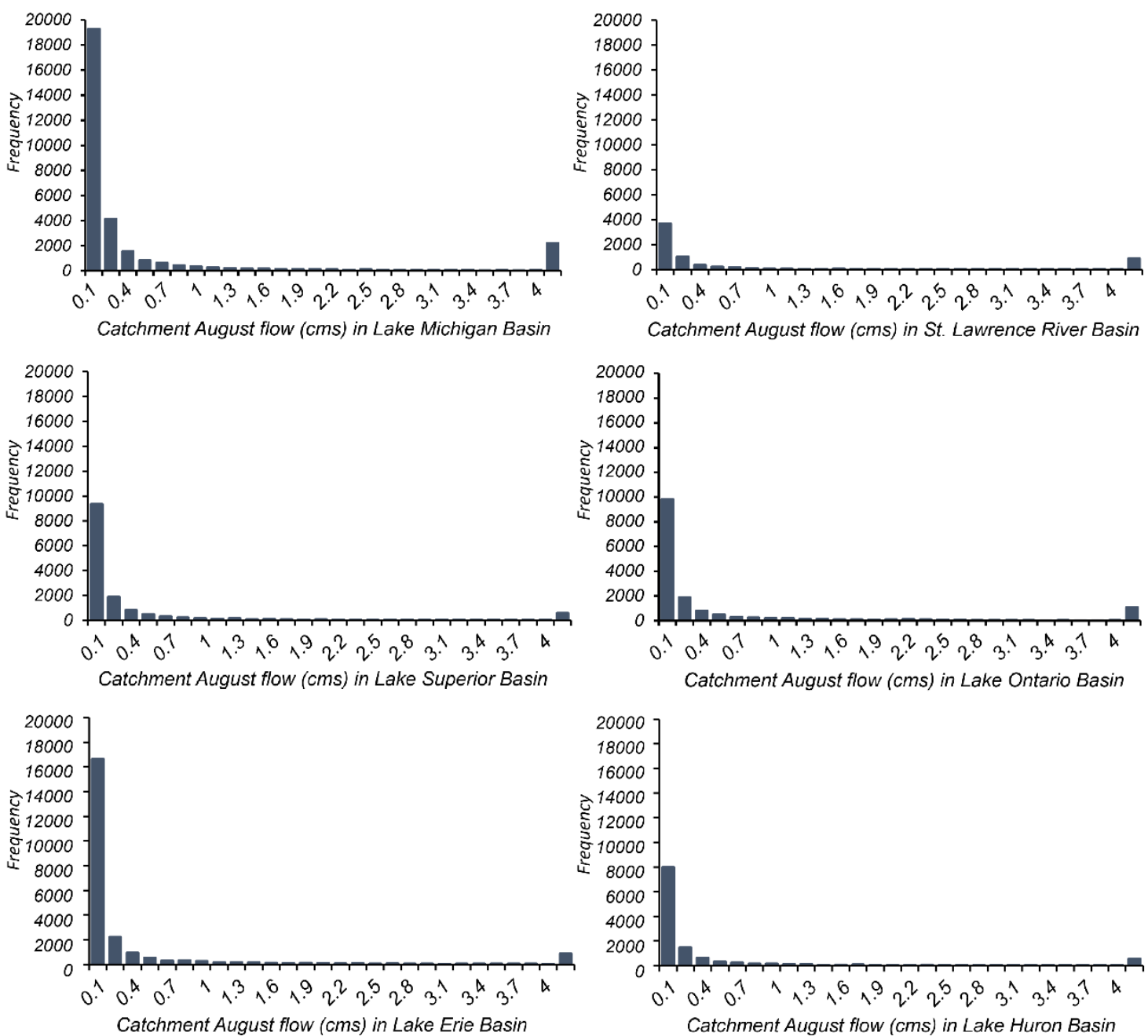

Figures 2.11. Size distribution of mean August flows. 
A modified Strahler Stream Order method is used in the NHDPlusV2 to determine the stream order. This method ranks streams based on their relative sizes within the network. The headwaters are the first order streams. When two first order streams join at a junction, they form a second order stream. Likewise, higher order streams are formed at the confluence of two streams with the same stream order. When two streams with different stream orders come together, the higher stream order is assigned to the next stream segment after the junction (Figure 2.12). The use of stream order information helps investigate the effect of spatial scale on water stress by contrasting the vulnerability of headwater catchments compared with catchments with larger streams as indicated by stream order.

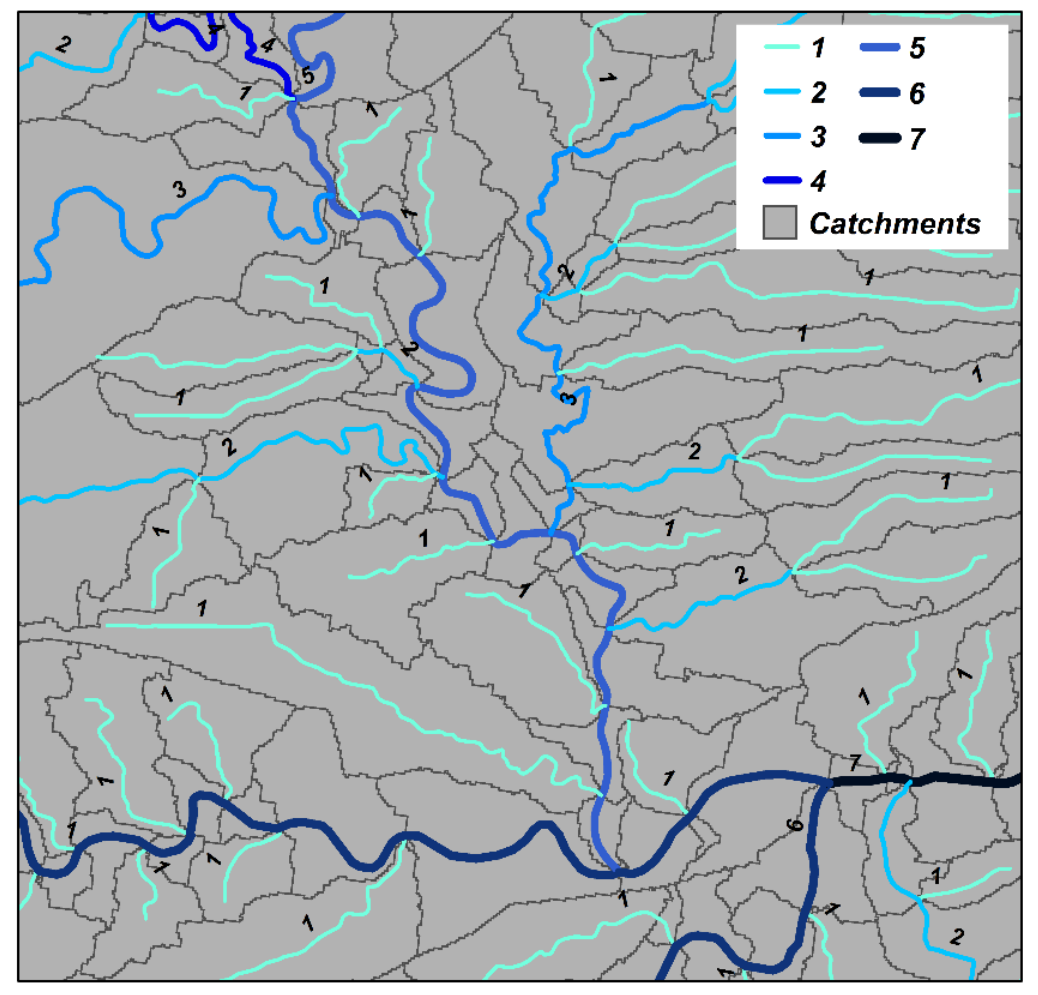

Figure 2.12. Stream order classification in NHDPlusV2 using the Strahler Method. 


\subsection{Summary}

This chapter provided an overview of the GDB data model as a systematic repository of spatial and non-spatial data inputs. Various data inputs were used to develop a comprehensive, logically structured geodatabase to facilitate water stress characterization and mapping in the Great Lakes states. These data include water withdrawals from different sources, different water use categories and water consumption information, and spatial and hydrologic data inputs (e.g., catchments and flows). 


\subsection{References}

Arctur, D. \& Zeiler, M. 2004. Designing geodatabases: case studies in GIS data modeling, ESRI, Inc.

Brovelli, M. A. 2011. History of GIS. Laboratorio di Geomatica Politecnico di Milano.

Coppock, J. T. \& Rhind, D. W. 1991. The history of GIS. Geographical information systems: Principles and applications, 1, 21-43.

Eldardiry, H., Habib, E., \& Borrok, D. M. 2016. Small-scale catchment analysis of water stress in wet regions of the US: an example from Louisiana. Environmental Research Letters 11.12: 124031.

Macdonald, A. 2001. Building a geodatabase, ESRI Redlands.

Mckay, L., Bondelid, T., Dewald, T., Johnston, J., Moore, R. \& Rea, A. 2012. NHDPlus Version 2: user guide. Unites States Environmental Protection Agency. Available: www. horizon-systems. com/NHDPlus/index. php.(October 2014).

Moore, R. B. \& Dewald, T. G. 2016. The Road to NHDPlus-Advancements in Digital Stream Networks and Associated Catchments. JAWRA Journal of the American Water Resources Association.

Shaffer, K. 2009. Variations in Withdrawal, Return Flow, and Consumptive Use of Water in Ohio and Indiana, with Selected Data from Wisconsin, 1999-2004, US Geological Survey.

Shaffer, K. \& Runkle, D. 2007. Consumptive Water, Use Coefficients for the Great Lakes Basin and Climatically Similar Areas. 
Watson, K. A., Mayer, A. S. \& Reeves, H. W. 2014. Groundwater availability as constrained by hydrogeology and environmental flows. Groundwater, 52, 225-238. 


\section{Chapter 3: Methodology}

\subsection{Estimation of water withdrawal impact}

Understanding the impacts of water withdrawal from different sources and consumption by various economic sectors at different spatial and temporal scales is key for characterizing ecologically harmful streamflow disturbances in terms of depletion and return flow along the stream networks. Figure 3.1 illustrates the conceptual model of water withdrawal from surface water, shallow groundwater, and deep groundwater to meet sectoral demands, and the return flows to the nearby streams. Various shades of green represent a network of catchments.

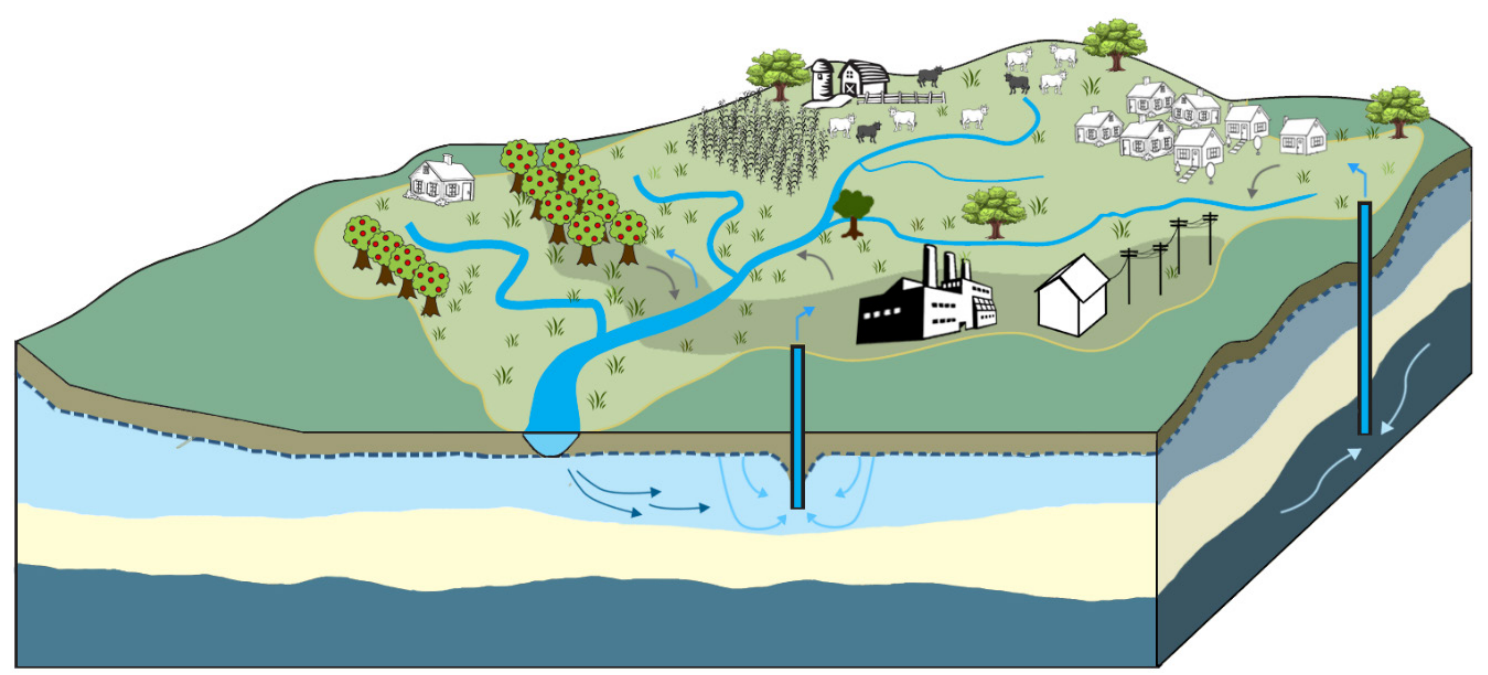

Figure 3.1. Water withdrawal from different sources to meet sectoral demands.

The general framework for characterizing ecological water stress in the GLB is illustrated in Figure 3.2. Direct surface water withdrawals or groundwater extractions from shallow aquifers that are hydraulically connected to the streams decrease stream flow, also known as stream flow depletion. The magnitude of streamflow depletion depends on the 
net water loss or the consumptive proportion of water withdrawal, defined as the amount of water that is removed from an immediate water environment, for example, due to evapotranspiration, incorporation in products, and consumption by humans and livestock. On the other hand, the non-consumptive proportion of water withdrawal returns to the system (i.e., return flow) and is available for downstream use.

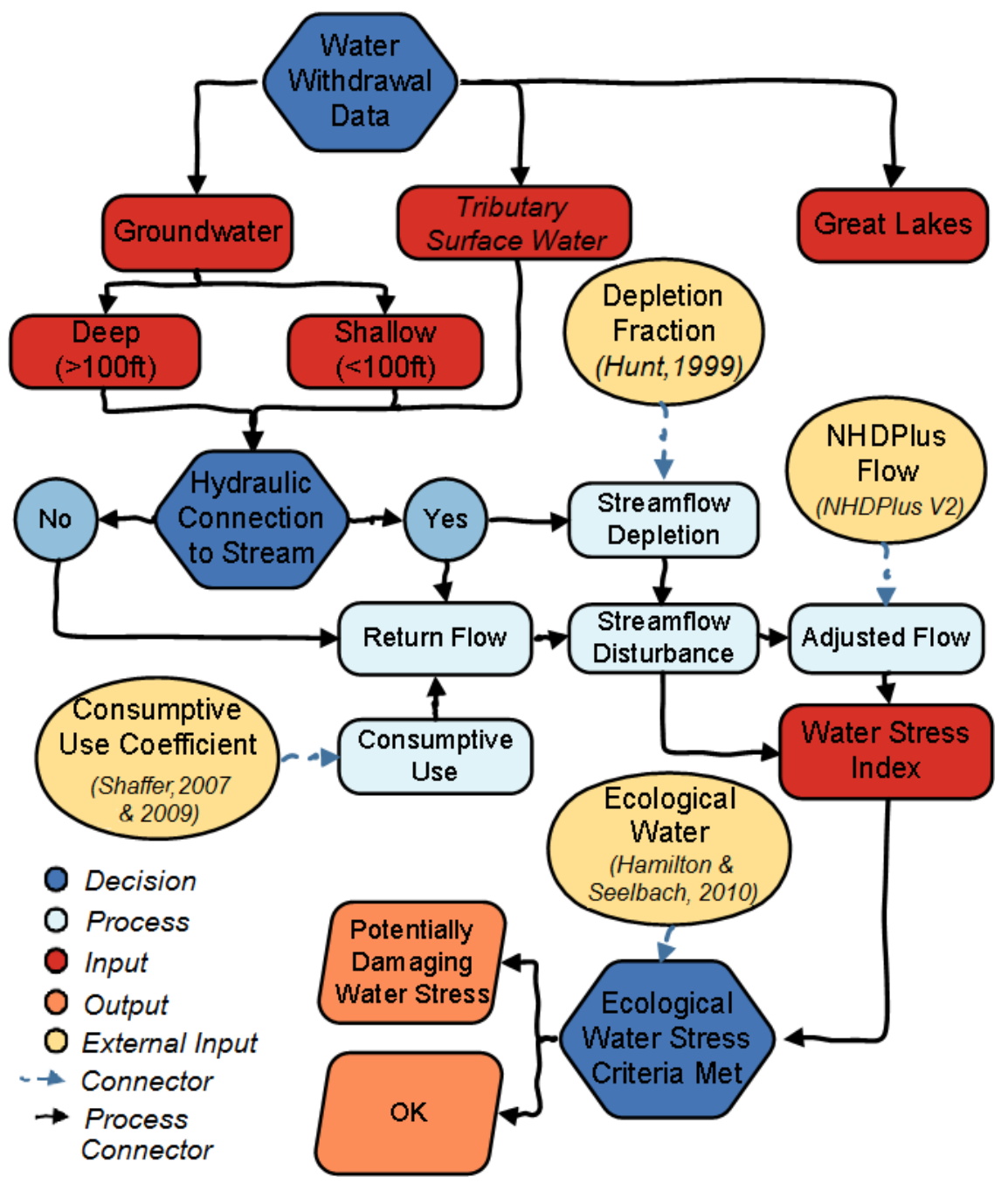

Figure 3.2. Ecological water stress analysis framework. 
Hydraulic connections between withdrawal locations and the stream network depend on the withdrawal source. Since surface water is directly withdrawn from the streams, a stream flow depletion factor of 1 is considered for this withdrawal type. Determining the hydraulic connection is particularly important for quantifying streamflow depletion or recharge due to return flow from groundwater withdrawal. The surface water depletion fraction due to shallow groundwater withdrawal can range from 0 to 1 , while deep groundwater wells that are not in hydraulic connection with streams are assigned a stream flow depletion coefficient of 0 (Watson et al., 2014), Table 3.1. In other words, in the case of water withdrawal from deep aquifers that are not hydraulically connected to the nearby streams, the non-consumptive portion of withdrawals contributes a net recharge to the streams because the return flow from these sources can increase the streamflow.

Table 3.1. Source-specific impact of water withdrawal on stream flow.

\begin{tabular}{lllll}
\hline Source & $\begin{array}{l}\text { Hydraulic } \\
\text { connection } \\
\text { to stream }\end{array}$ & $\begin{array}{l}\text { Surface water } \\
\text { depletion } \\
\text { fraction }\end{array}$ & $\begin{array}{l}\text { Net flow } \\
\text { adjustment } \\
\text { impact }\end{array}$ & Explanation \\
\hline $\begin{array}{l}\text { Surface water } \\
\text { Yes }\end{array}$ & 1 & Decrease & - \\
$\begin{array}{l}\text { Shallow } \\
\text { groundwater }\end{array}$ & Yes & $0-1$ & Decrease & $\begin{array}{l}\text { Wells less than 100ft deep unless in } \\
\text { rock stratum } \\
\text { Wells more than 100ft deep unless } \\
\text { located in drift aquifer material (e.g., } \\
\text { sand and gravel) }\end{array}$ \\
$\begin{array}{l}\text { Deep } \\
\text { groundwater }\end{array}$ & No & 0 & Increase & \\
\hline
\end{tabular}

Groundwater withdrawals were classified as shallow or deep by linking the water withdrawal datasets to the Wellogic GIS layers (MDEQ, 2011) to obtain quantitative and qualitative information about such parameters as depth and aquifer material. In cases of coordinate mismatch between the available water withdrawal data and the Wellogic system, the properties of each withdrawal point were assumed to be similar to that of the 
nearest well in the Wellogic system. Shallow aquifers in the GLB are typically less than 100ft deep (Neff et al., 2006). All shallow wells ( $\leq 100 \mathrm{ft})$ in coarse-grained drift material (e.g., sand and gravel) were considered hydraulically connected to the nearby stream. In contrast, it was assumed that there is no hydraulic connection between a deep $(\geq 100 \mathrm{ft})$ rock well and the streams.

In the GLB, groundwater is an important component of streamflow during dry seasons, playing a significant role in maintaining sensitive habitats (Neff et al., 2006; Reeves, 2010; Kraft et al., 2012). Surface water depletion (SWD) fractions (i.e., \% reduction in stream flow) associated with shallow groundwater withdrawals were estimated using the methodology described in Watson et al. (2014) in order to identify potentially adverse impacts on ecological functions. The approach is based on transient streamflow depletion (Hunt, 1999), which is calculated as a function of withdrawal and hydrogeological properties of the aquifer.

$$
c=\frac{\Delta \mathrm{Q}}{\mathrm{Qw}}=\operatorname{erfc}\left(\sqrt{\frac{\mathrm{Sd}^{2}}{4 \mathrm{Tt}}}\right)-\exp \left(\frac{\lambda^{2} \mathrm{t}}{4 \mathrm{ST}}+\frac{\lambda \mathrm{d}}{2 \mathrm{~T}}\right) \operatorname{erfc}\left(\sqrt{\frac{\lambda^{2} \mathrm{t}}{4 S \mathrm{~T}}}+\sqrt{\frac{\mathrm{Sd}^{2}}{4 \mathrm{Tt}}}\right)
$$

Here $\mathrm{c}$ is the capture fraction; $\Delta \mathrm{Q}$ is the stream flow depletion rate; $\mathrm{Qw}$ is the pumping rate; $\mathrm{S}$ is the storage coefficient; $\mathrm{d}$ is the shortest distance from the well to the stream; $\mathrm{T}$ is the transmissivity of the aquifer (defined as the horizontal hydraulic conductivity multiplied by the saturated thickness of the surface aquifer $\left.\left(\mathrm{T}=\mathrm{K}_{\mathrm{h}} . \mathrm{B}\right)\right)$; $\mathrm{t}$ is the pumping time; and $\lambda$ is the streambed conductance.

Surface water depletion fraction (SWD) is applied to total withdrawal at each location to calculate the amount of stream flow depletion in response to total withdrawal in 
individual catchments. Surface water depletion fraction due to shallow groundwater withdrawal varies between 0 and 1 , meaning that the withdrawal can have no effect on the stream flow or it directly depletes it. Surface water depletion fraction was set to 0 and 1 for water withdrawal from deep groundwater and surface water, respectively. Stream flow depletion is calculated as:

$\mathrm{Qd}_{\mathrm{i}, \mathrm{t}}=\mathrm{SWD}_{\mathrm{i}, \mathrm{t}} \mathrm{Wt}_{\mathrm{i}, \mathrm{t}}$

Here SWD is surface water depletion fraction (\%); and Wt is the total deep groundwater, surface water, or shallow groundwater withdrawal (volume/time); i denotes location (catchment); and $t$ denotes time (year or month).

The consumptive use coefficients are used to calculate the consumptive proportion of withdrawal, as well as return flow in order to avoid over-estimation of water stress. Return flow volume represents total return flow back to the surface water. This will include all returns from surface water, shallow groundwater, and deep groundwater. It is assumed that the non-consumptive portion of withdrawals returns to the outlet of the catchment where the withdrawal occurred. The consumptive withdrawal and return flow are calculated as follows:

$\mathrm{Wc}_{\mathrm{i}, \mathrm{t}}=\mathrm{CUc}_{\mathrm{i}, \mathrm{t}} \cdot \mathrm{Wt}_{\mathrm{i}, \mathrm{t}}$

$\operatorname{Qr}_{i, t}=\left(1-\mathrm{CUc}_{\mathrm{i}, \mathrm{t}}\right) \cdot \mathrm{Wt}_{\mathrm{i}, \mathrm{t}}$

Here $\mathrm{Wc}$ is the consumptive portion of withdrawal (volume/time); CUc is the consumptive use coefficient (\%); $\mathrm{Wt}$ is the total surface water or shallow groundwater withdrawal (volume/time); and Qr is the return flow (volume/time). 
The sum of return flow (i.e., gain) and flow depletion (i.e., loss) will determine aggregated stream flow disturbance (ASFD) at the catchment scale, which can be positive (gain) or negative (depletion) depending on the magnitude of the gains and losses.

$\operatorname{ASFD}_{i, t}=\operatorname{Qr}_{i, t}-\operatorname{Qd}_{i, t}$

Here ASFD is the aggregated stream flow disturbance (volume/time) at the catchment scale; Qr is the return flow (volume/time); Qd is stream flow depletion (volume/time); i is the location (catchment), and $t$ is time (year or month).

The catchment scale aggregated stream flow disturbance (ASFD) was accumulated in Arc Hydro (Maidment, 2002) using stream network and NHD catchments to calculate the cumulative disturbance from upstream to downstream, i.e., from one catchment to the next along the network.

$\operatorname{CASFD~}_{i, t}=\sum \operatorname{ASFD}_{i, t}$

Here CASFD is the cumulative aggregated stream flow disturbance (volume/time); ASFD is the aggregated stream flow disturbance (volume/time).

Adjusted stream flow calculates the total stream flow in each catchment by applying human-caused cumulative aggregated stream flow disturbance (CASFD) on the NHD unimpaired stream flow, i.e. flow that would occur if unaffected by human activities (NHD, 2016).

$\mathrm{Qa}_{\mathrm{i}, \mathrm{t}}=\mathrm{CASFD}_{\mathrm{i}, \mathrm{t}}+\mathrm{Q}_{\mathrm{i}, \mathrm{t}}$

Here Qa is the adjusted stream flow (volume/time); CASFD is the cumulative aggregated stream flow disturbance (volume/time); and Q is the unimpaired streamflow available from NHDPlus V2 (volume/time). 


\subsection{Spatial aggregation and propagation of withdrawal impacts}

Determining the water withdrawal impacts at the catchment scale and propagating the resulting streamflow disturbance downstream are two major key data processing tasks that are completed using Arc Hydro (Maidment, 2002). Arc Hydro is a set of data models and tools for water resources applications within ArcGIS, facilitating geospatial and temporal data analyses (Maidment, 2002). An important procedural step is to prepare stream network data from NHDPlus V2 for establishing a traceable network in Arc Hydro. The NHDPlus V2 flow data were "refined" by maintaining continuously digitized streams with "Known Flow" while removing spatially disconnected or uninitialized streams with "Unknown Flow" (Figure 3.3).

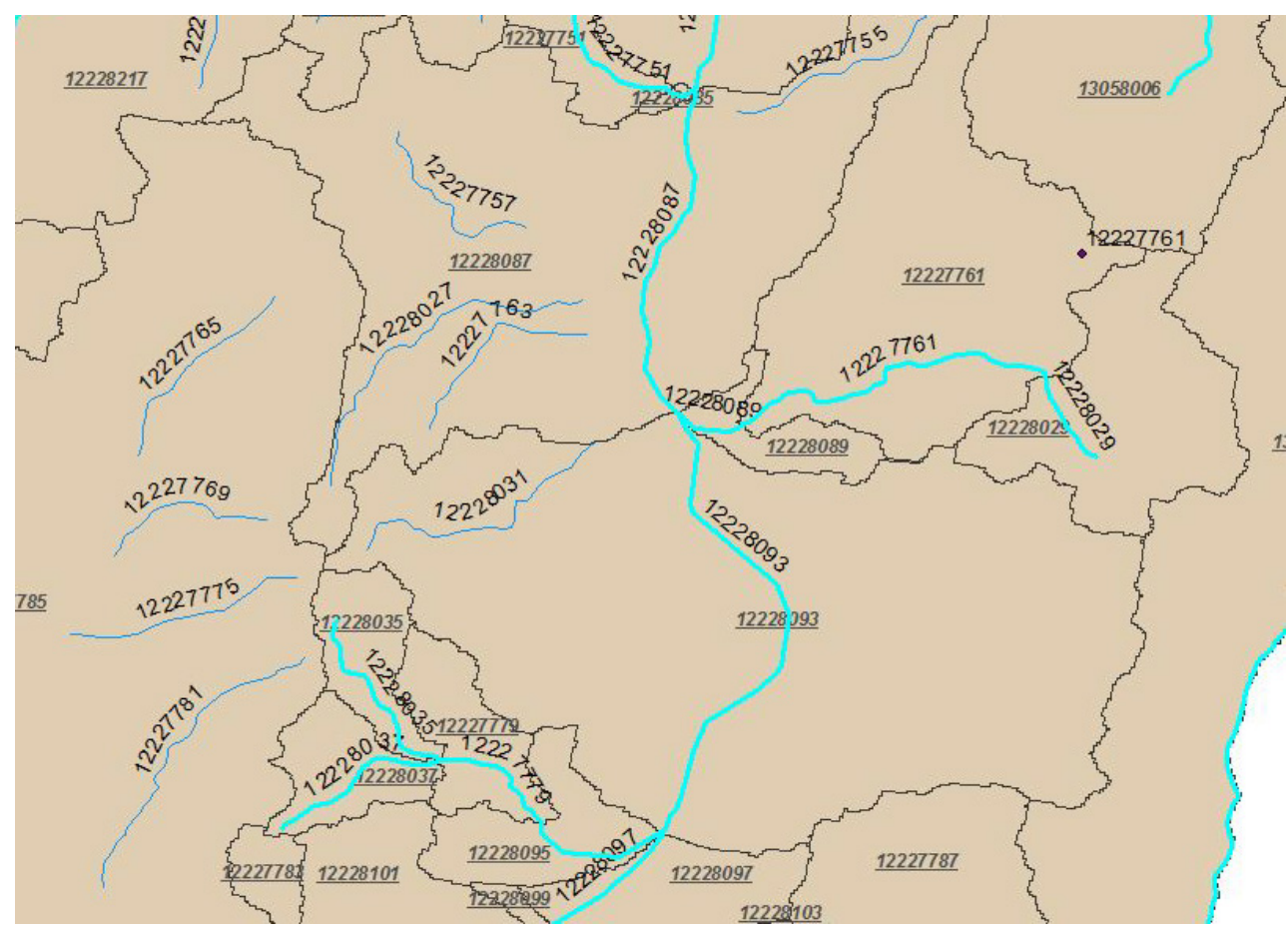

Figure 3.3. NHDFlowline including continuous streams with "Known Flow" (digitized, thick blue lines) and uninitialized streams with "Unknown Flow" (thin blue lines). 
In the next step, NHDPlus V2 layers were imported (e.g., catchment and flowline features) to the Arc Hydro environment in order to use Arc Hydro's spatial processing tools. Appropriate identifiers were defined, including HydroID, a unique internal identifier (integer) for feature class in the Arc Hydro database. HydroID is assigned to both NHDFlowline and catchment feature classes, and establishes relationships with other feature class identifiers (e.g., JunctionID, NextDownID, etc) inside the GDB, before populating all the necessary attributes and layers for running Arc Hydro (e.g., flow data). Adjoint catchments (i.e., total upstream area that drains into a single catchment) are identified as inputs to Terrain Preprocessing tool in order to identify sinks, fill sinks, and create sets of interconnected raster data (e.g., flow direction which defines DEM-based stream network) or vector data (e.g. catchments and flowlines). Figure 3.4 illustrates adjoint catchments and streams.

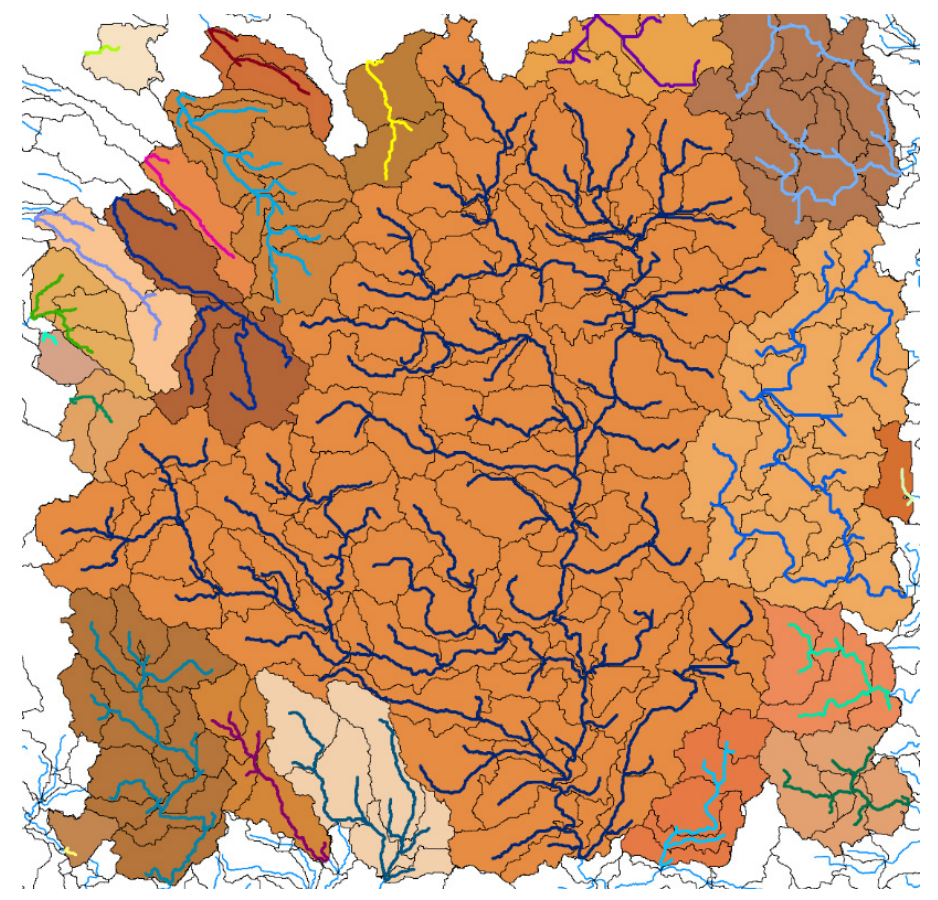

Figure 3.4. Adjoint catchments with corresponding stream network. 
The backbone of the analysis was creating a spatially connected geometric network. This was done by using the drainage system connectivity information from the NHDPlus V2 data to identity the main network paths (Figure 3.5). Table 3.2 shows the key attributes of catchment and NHDFlowline after developing the geometric network. A simple one-toone relationship was established between the catchment (i.e., origin object) and NHDflowline feature classes (i.e., destination object class).

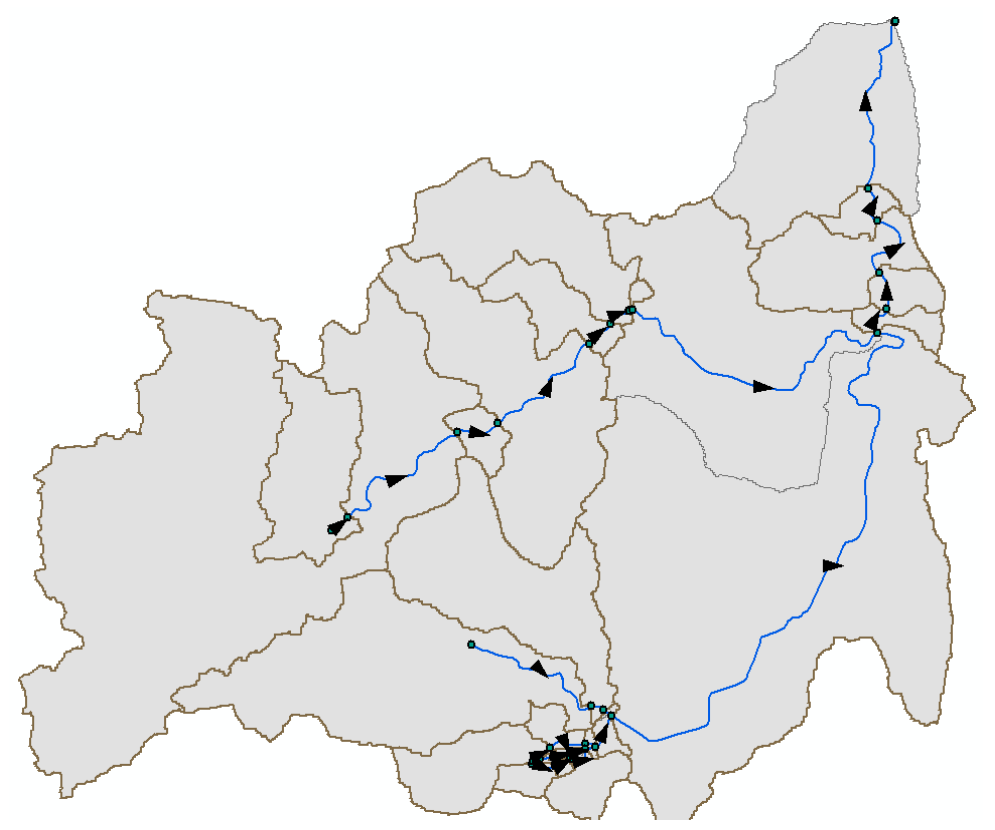

Figure 3.5. Traceable flow network. 
Table 3.2. Key populated attributes of Catchment and NHDFlowline (with flow direction) feature classes.

\begin{tabular}{|c|c|c|}
\hline Attribute field & Format & Definition \\
\hline \multicolumn{3}{|c|}{ Common attributes for both Catchment and NHDFlowline } \\
\hline GridID & Long Integer & $\begin{array}{l}\text { Unique identifier for gridded features (rasters) in } \\
\text { the GDB }\end{array}$ \\
\hline HydroID & Long Integer & Unique feature identifier in the GDB \\
\hline NextDownID & Long Integer & $\begin{array}{l}\text { Unique feature identifier for the next downstream } \\
\text { feature in a class. }\end{array}$ \\
\hline \multicolumn{3}{|c|}{ Specific attributes for NHDFlowline } \\
\hline DrainID & Long Integer & $\begin{array}{l}\text { An identifier for features within a particular } \\
\text { drainage area }\end{array}$ \\
\hline FROM_NODE & Double & $\begin{array}{l}\text { Unique feature identifier of a simplified node at } \\
\text { the "form end" point of a simplified link. }\end{array}$ \\
\hline TO_NODE & Double & $\begin{array}{l}\text { Unique feature identifier of a simplified node at } \\
\text { the "to end" point of a simplified link. }\end{array}$ \\
\hline \multicolumn{3}{|c|}{ Specific attributes for Catchment } \\
\hline JunctionID & Long Integer & $\begin{array}{l}\text { Unique feature identifier for hydro network } \\
\text { junction in the GDB (associated ID for a } \\
\text { junction). }\end{array}$ \\
\hline
\end{tabular}

In some catchments, there were more than one withdrawal point while others had no withdrawal location. Because catchments without a withdrawal point had no water consumption, they did not cause localized water stress, although they were included in the calculations to maintain network connectivity that was essential for downstream propagation of stream disturbance. The centroids of catchments within the GLB were calculated to aggregate the withdrawal impacts at catchment scale. Important attributes that were aggregated at catchment scale included total withdrawal, consumptive use volume, depletion volume, return flow volume (i.e., surface water recharge), and flow disturbance. 
Finally, aggregated streamflow disturbances were accumulated from upstream catchments to downstream along the traceable network using the established relationship between feature classes (Figure 3.6).

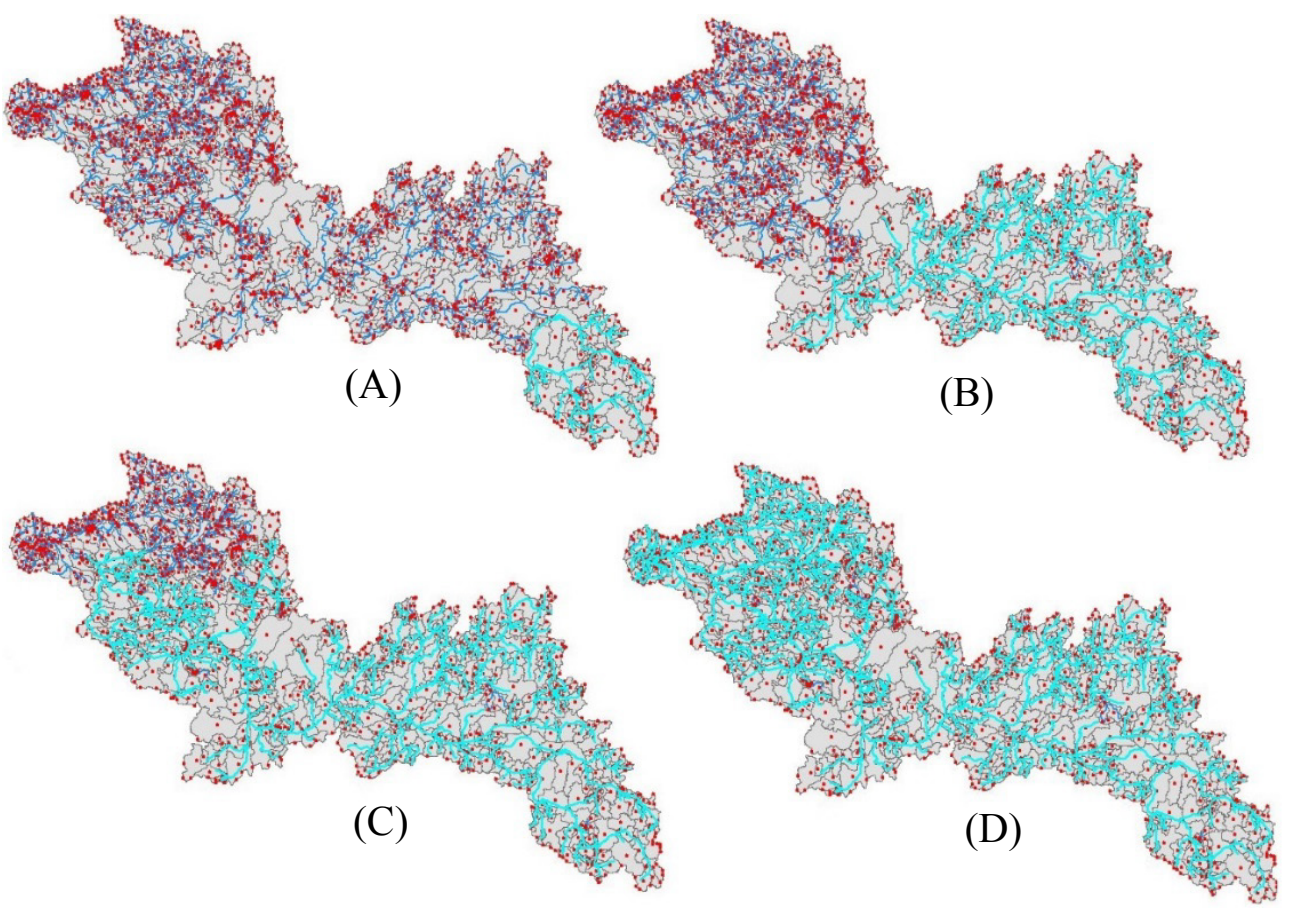

Figure 3.6. Progression of flow accumulation process (A to D) using the traceable geometric network in the Kalamazoo River Watershed.

Figure 3.7 illustrates the effect of applying cumulative adjustment (i.e., cumulative aggregated stream flow disturbance) to the NHDPlus V2 flows in an example case of four connected catchments. In this particular case, cumulative flow adjustment increased the unimpaired flows, demonstrating the dominant effect of return flow due to water withdrawal from groundwater sources. The propagated cumulative adjustment in each catchment was added to the next downstream catchment using the NextDown identifier in the feature classes. 


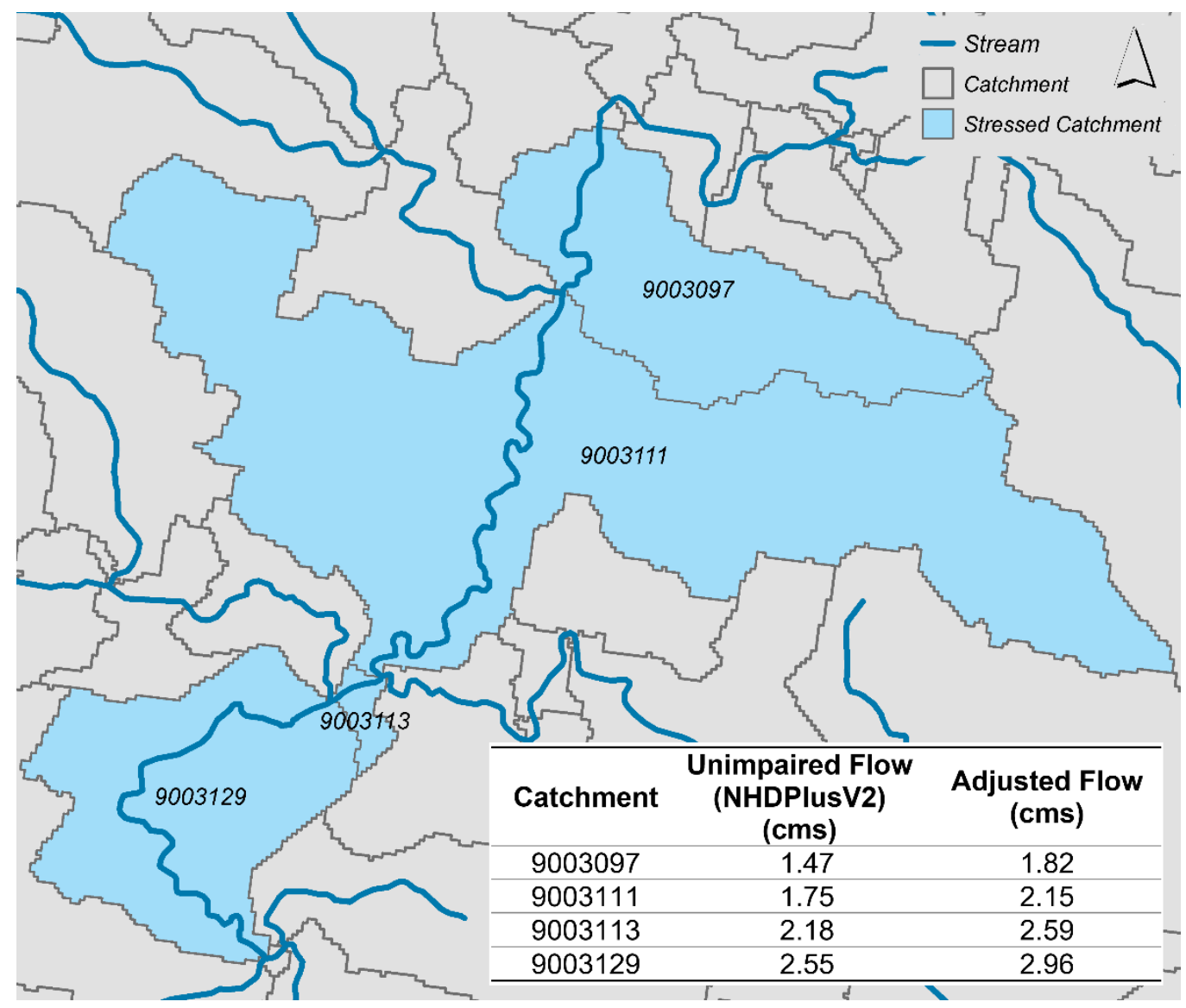

Figure 3.7. Cumulative flow adjustment of the unimpaired flows. 


\subsection{Water stress calculation}

Water stress index was calculated as the ratio between consumptive water use and stream flow to understand whether water demand exceeded water supply (Eq. 8). Catchment scale flows available from NHDPlus V2 (McKay et al., 2012) and estimated consumptive withdrawals available at monthly or annual time scales allowed investigation of temporal and spatial scale impacts in water stress mapping.

WSI $_{i, t}=\left(\right.$ CASFD $\left._{i, t} / Q_{i, t}\right) \times 100$

Here WSI is water stress index (\%); CASFD is the cumulative aggregated stream flow disturbance (volume/time); Qa is the adjusted stream flow (index flow; volume/time); $\mathrm{i}$ is location (catchment); and $\mathrm{t}$ is time (year or month).

The calculation procedure is illustrated through an example of fourteen catchments in Wisconsin. The catchments are labeled alphabetically from A through $\mathrm{N}$, and each catchment is assigned a unique 8-digit ID. Only 6 catchments contained withdrawal locations (a total of 25 points with total withdrawal of 175 MGY) (Figure 3.8). All withdrawals were from deep aquifer, except one withdrawal location in catchment $\mathrm{H}$ which used shallow groundwater as its water source. The water was mainly used for the industrial uses (75 MGY), irrigation (65 MGY), and livestock production (21 MGY). 


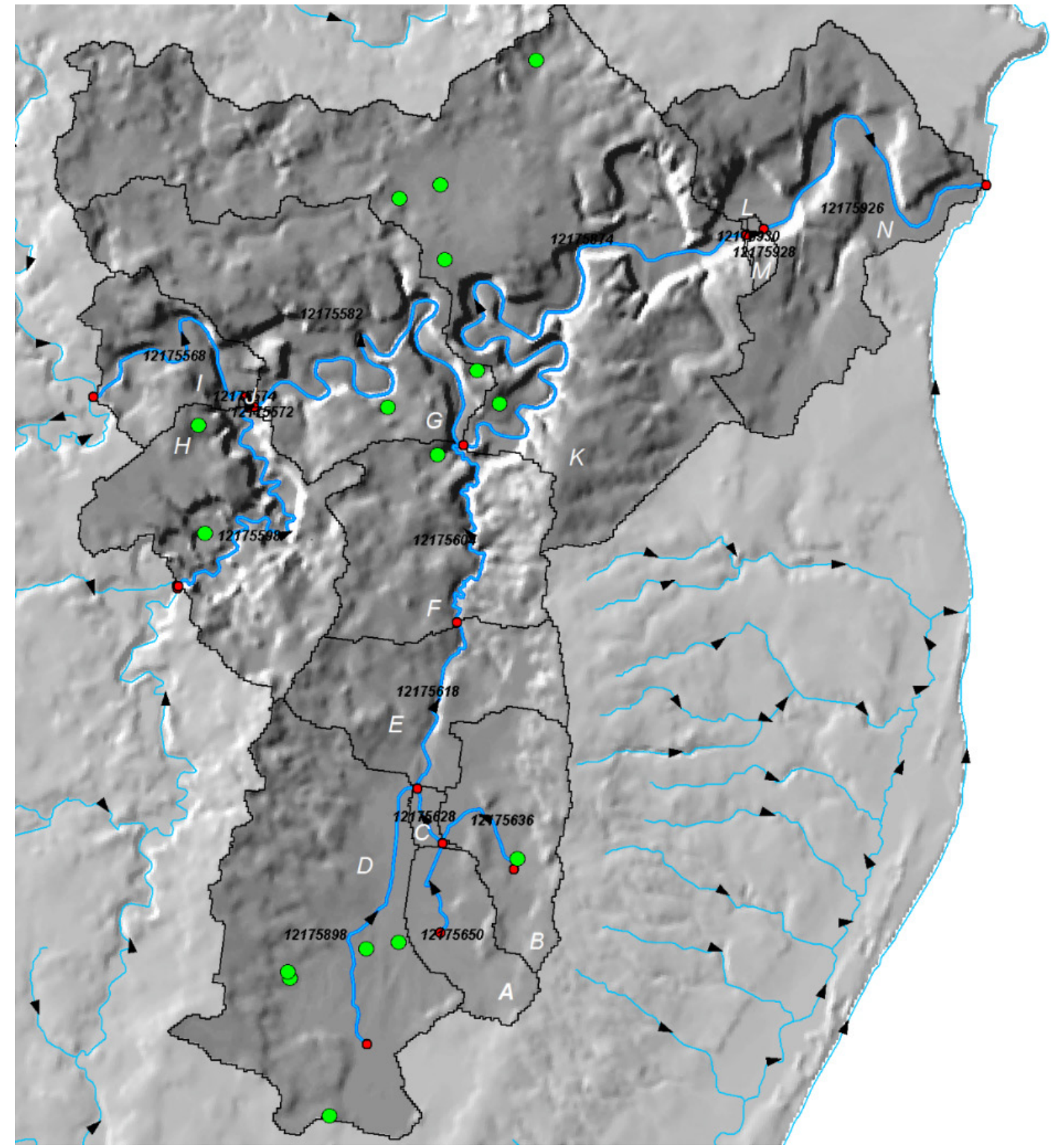

Figure 3.8. Example study site in Wisconsin to illustrate the water stress calculation procedure. Fourteen catchments are labeled alphabetically A-N, green circles represent water withdrawal locations, red circles represent junction connectors, and blue lines with black arrows represent stream network with the flow direction. 
Shallow groundwater (18 MGY) and deep groundwater (1.99 MGY) were pumped in catchment $\mathrm{H}$ for irrigation and commercial uses, respectively. Total withdrawals and consumptive use coefficients (i.e., 0.96 for irrigation and 0.15 for commercial use) were used to calculate consumptive use volume. Surface water depletion fraction $(0.531)$ was applied to shallow groundwater withdrawal to obtain the depletion volume (9.557 MGY) due to pumping water from an aquifer that was hydraulically connected to the stream. Since the consumptive use coefficient for the predominant water use in catchment $\mathrm{H}$ was large, total return flow from this catchment was small (2.41 MGY) and, overall, water withdrawals depleted the surface water as indicated by a negative aggregated stream flow disturbance (-7.14 MGY). In all other catchments located downstream of catchment $\mathrm{H}$, the return flows of deep groundwater withdrawals were added to the streamflow, resulting in positive streamflow disturbances. The NHDPlus V2 streamflow for each catchment (e.g., 22,369.92 MGY in catchment $\mathrm{H}$ ) was adjusted to account for withdrawal impacts on the unimpaired flow for use in the denominator of the water stress formula. Water stress in catchment $\mathrm{H}$ was found to be less than $1 \%$. It is worth noting that since no withdrawal occurred in catchments I and $\mathrm{J}$, these catchments conveyed the cumulative streamflow disturbance from the upstream catchments without changing it. This cumulative streamflow disturbance was applied to the next downstream catchments (e.g., E and K). As catchments $\mathrm{H}$ and $\mathrm{I}$ drain to catchment $\mathrm{J}$, the streamflow adjustment in catchment $\mathrm{J}$ was calculated as the sum of the upstream streamflow adjustments for catchments $\mathrm{H}$ and I. This procedure continued along the network of catchments to allow water stress calculation in downstream catchments. Figure 3.9 illustrates the calculations. 


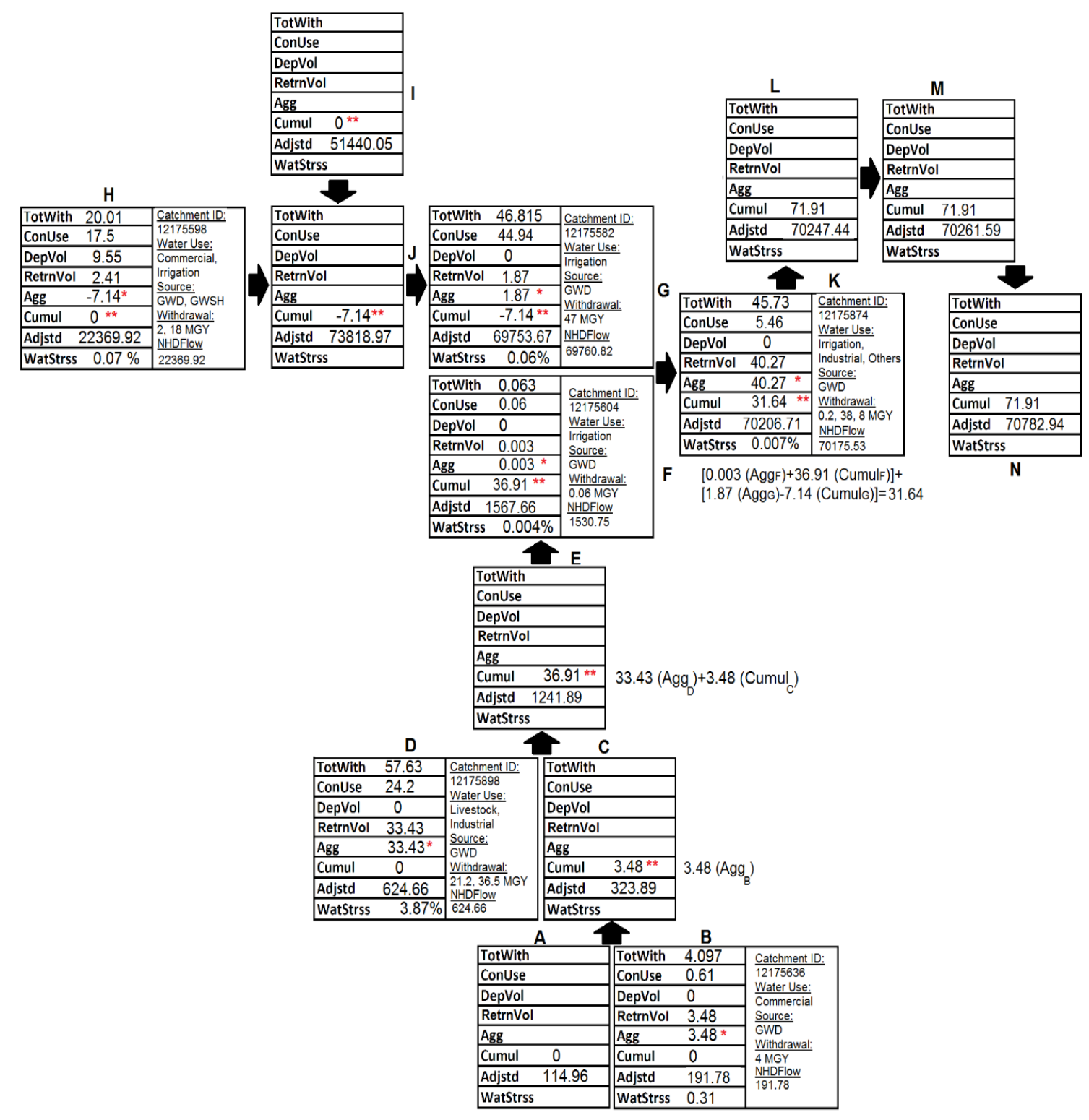

Figure 3.9. Water stress calculation procedure in a spatially connected network of catchments in Wisconsin (diagram of Figure 3.8). All the aggregated $(*)$ and accumulated streamflow disturbances $(* *)$ from the upstream catchments were summed and listed as a cumulative streamflow disturbance for use at the next catchment located immediately downstream. 


\subsection{Ecological criteria}

The presented water stress characterization framework was based on ecological guidelines reported in Hamilton and Seelbach (2010), defining different zones that denote varying levels of ecosystem disturbance due to water withdrawal in Michigan (Figure 3.10). The guidelines are based on streamflow depletion, as well as thermal regime and size of Michigan streams (Figure 3.11), which affect how significantly fish population can vary in response to streamflow disturbance. For example, depleting streamflow by about $25 \%$ can reduce fish population by about $40 \%$ in sensitive streams. Management zones A through $\mathrm{D}$ denote different conditions in which measures to protect the aquatic habitat should be prescribed. A stream whose flow disturbance and fish population belongs to Zone D meets the legal definition of adverse resource impact (ARI). It is critical for water management decisions to follow the natural and seasonal patterns of streamflow to decrease the chance of disturbing sensitive aquatic ecosystems and ARI.

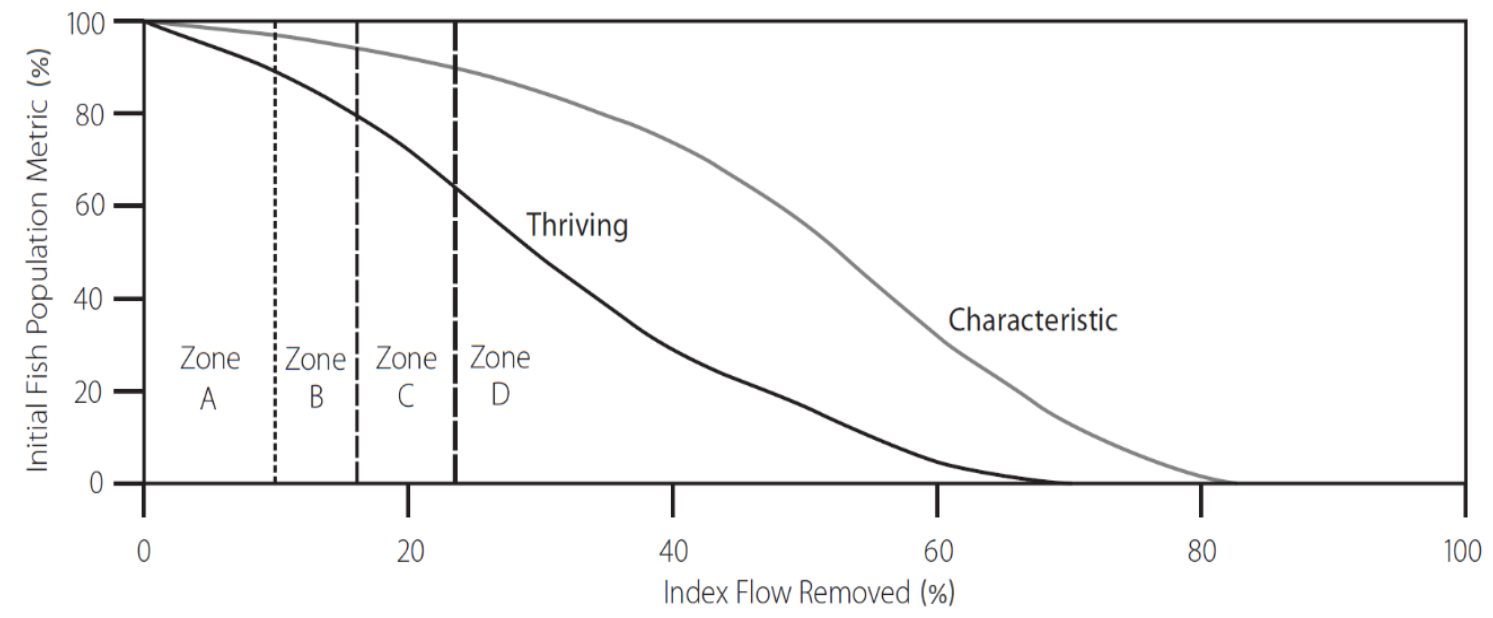

Figure 3.10. Ecological water stress criteria (Adapted from Hamilton and Seelbach (2010)). 


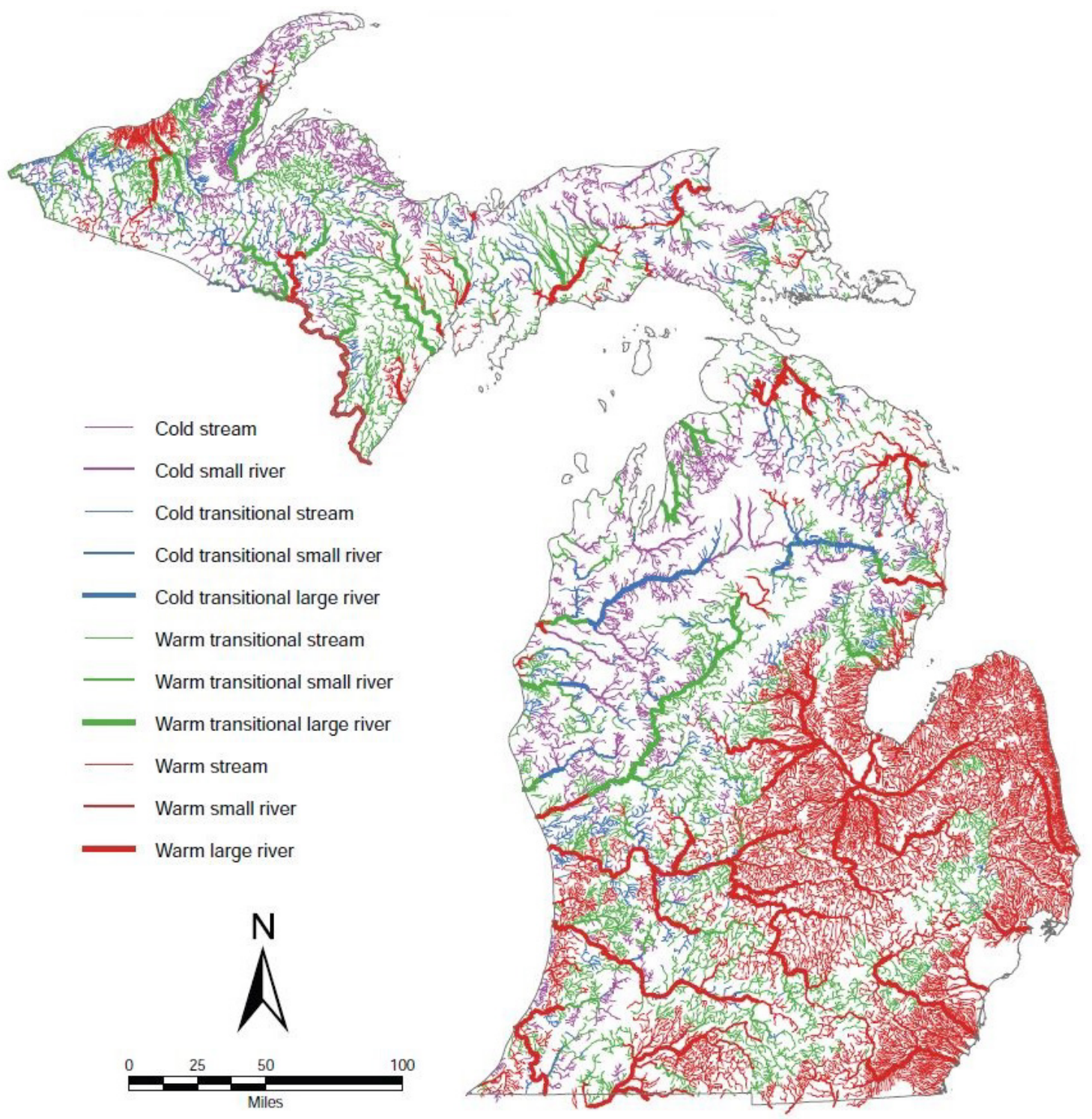

Figure 3.11. Classification of streams and rivers based on size and thermal regime ( Adapted from Zorn et al., 2012).

\subsection{Spatial error assessment}

Different errors might occur during the water stress calculation process. Human error in documenting the withdrawal locations and the reported amounts of withdrawn water, 
inaccuracies of data collecting devices (e.g., poor device calibration before collecting data), errors in calculating consumptive use coefficients, and spatial error are some examples.

The spatial error assessment was based on spatial accuracy of the location of the catchment boundaries and the withdrawal points within the catchments, which have a substantial impact on correctly identifying the stressed catchments. Whether a withdrawal point was actually located within a given catchment determined if that withdrawal would cause water stress in that catchment. Thus, withdrawal points that were far from catchment boundaries (i.e., completely located inside the catchments) were least affected by potential spatial inaccuracy and were more confidently used to designate the stressed catchments.

NHDPlus V2 catchments were derived from a 30-meter resolution DEM, converting the raster based catchments to vector based polygon features. Thus, there is on average a \pm 15 -meter "wiggle room" in each cell which caused error in determining the actual location of catchment boundaries in the vector based data (Figure 3.12).

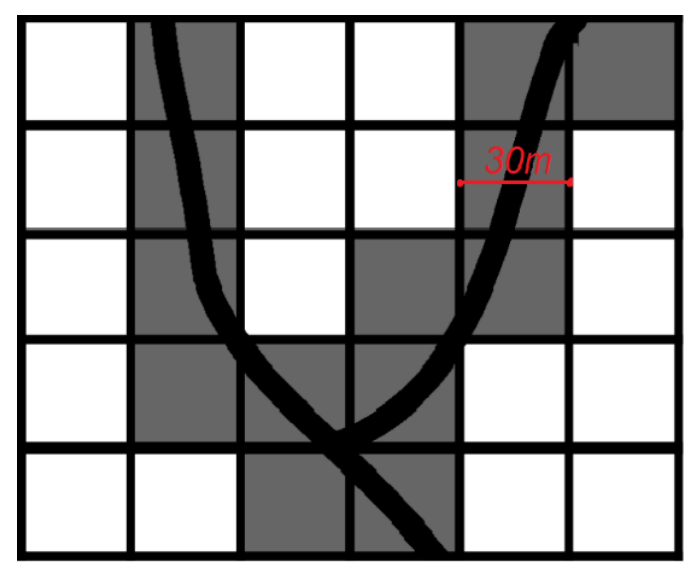

Figure 3.12. Illustration of implicit location of the catchment boundaries (feature dataset) in the 30-meter DEM cells. 
A 30-meter buffer around the catchment boundaries (15-meter on each side) covers the raster cell wiggle room. To evaluate the potential for water stress miscalculation due to the catchment boundary effect, any withdrawal points within the 30-meter buffer zone were eliminated from the analysis. About 5\% of the withdrawal points (about 380) were located inside the 30 -meter buffer zone. This represents only about $1.6 \%$ of the total water withdrawals from the surface water and shallow groundwater.

Similarly, assessment of the effect of the spatial accuracy of water withdrawal locations was done based on the proximity of the withdrawal points to the catchment boundaries. Buffer zones of different sizes (i.e., $30 \mathrm{~m}, 50 \mathrm{~m} 100 \mathrm{~m}, 150 \mathrm{~m}, 310 \mathrm{~m}$, and 620 m) were created around the withdrawal points to represent varying levels of spatial accuracy in order to identify withdrawal points that are completely located inside the NHDPlus V2 catchments taking into account potential spatial error of location. The withdrawal points with buffers cutting across boundaries of catchments other than where the withdrawal point was located were flagged as potential sources of error. Figure 3.13 illustrates different buffers around an example set of withdrawal points within the NHDPlus V2 catchments. 


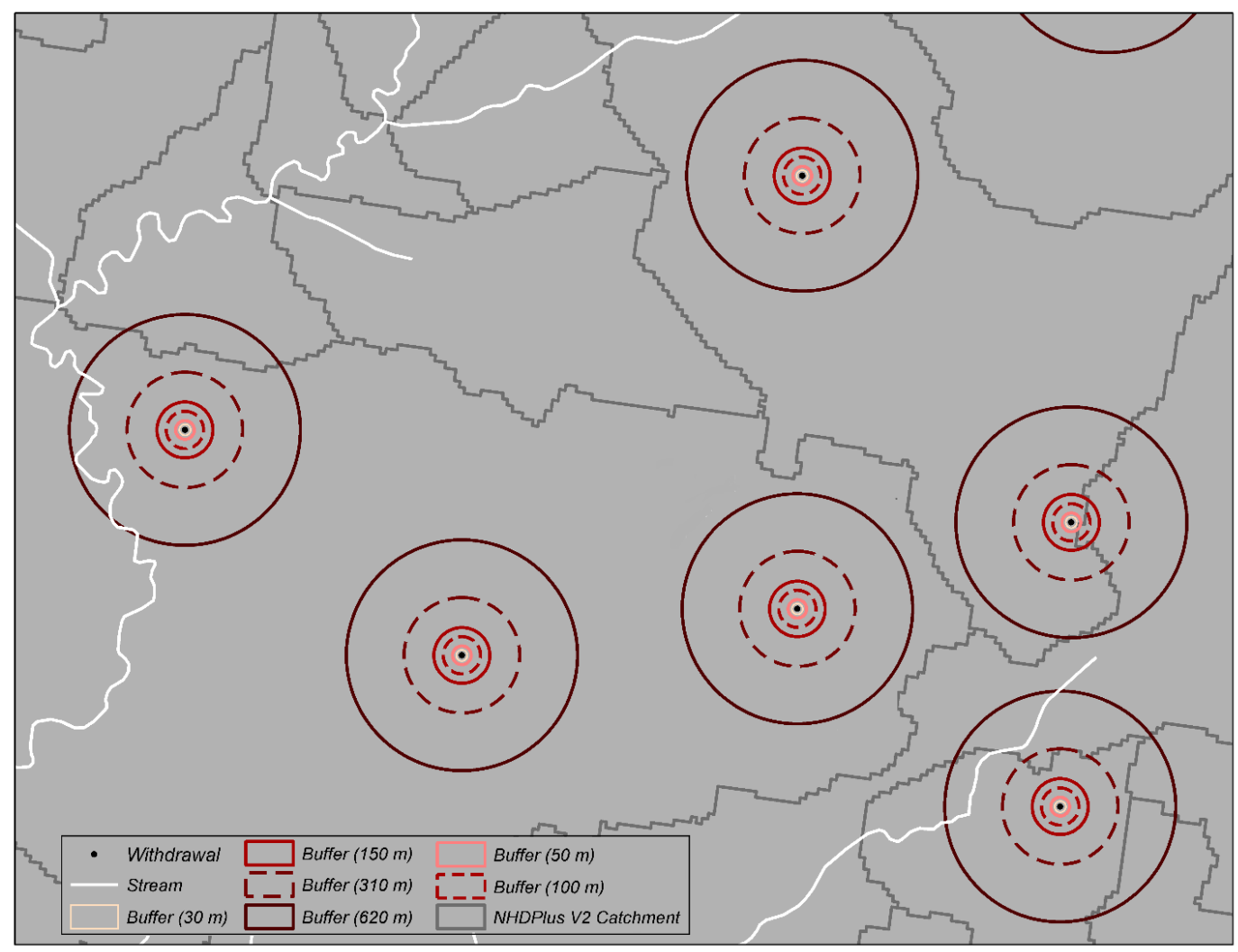

Figure 3.13. Buffer zones around the withdrawal points within the NHDPlus V2 catchments.

The buffer zone based analysis of water withdrawal points demonstrates that $95 \%$ of the total water withdrawal and $70 \%$ of the withdrawal points were located completely within NHDPlus V2 catchment boundaries considering a spatial error of up to $150 \mathrm{~m}$ (Figure 3.14). A smaller number of withdrawal points were fully located within the catchments when larger spatial errors represented by larger buffer zones were considered. In the case of the 620 -meter buffer, only $35 \%$ of the total water withdrawals and $15 \%$ of the withdrawal points were completely located within the catchments. 


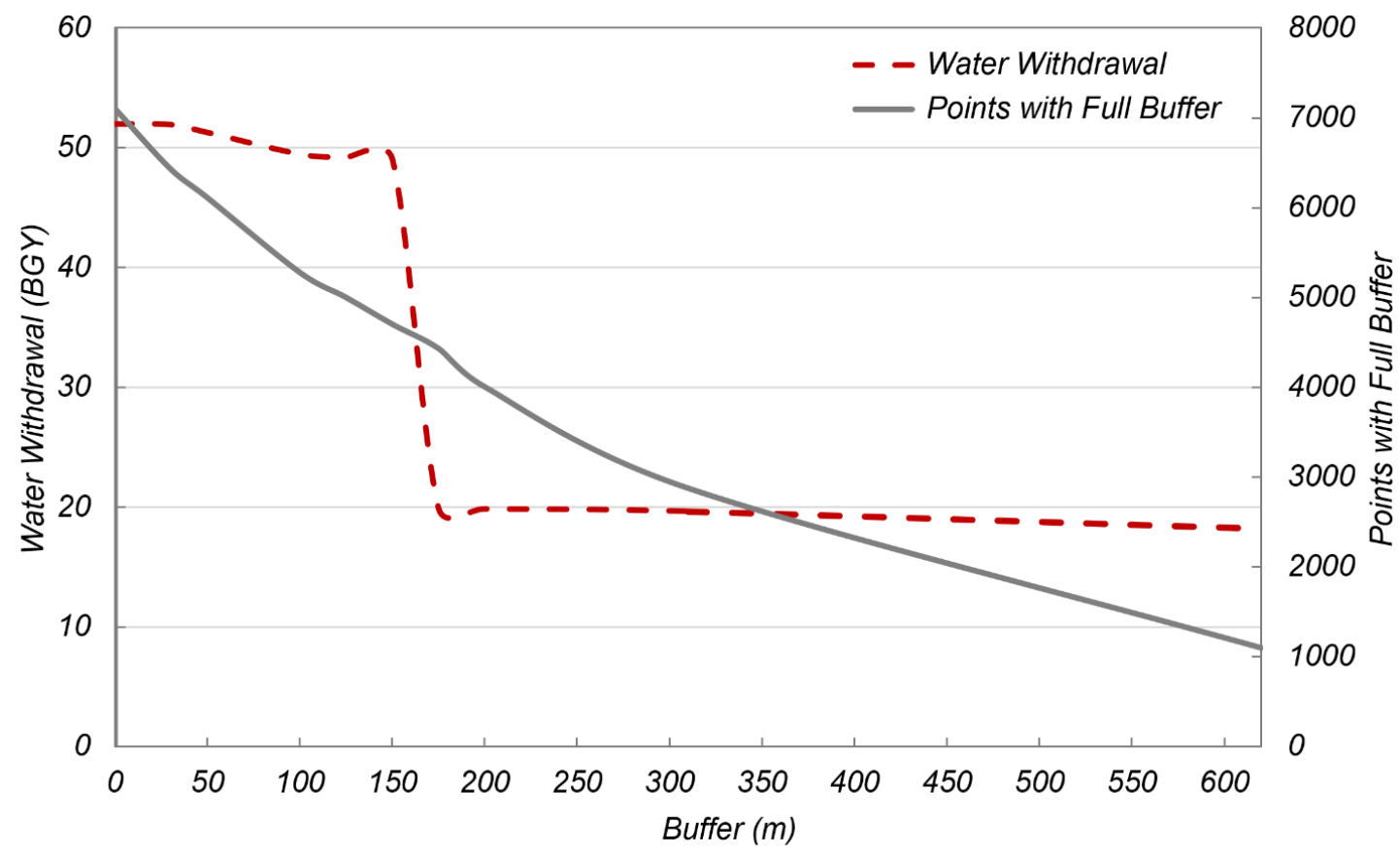

Figure 3.14. Change in the number of withdrawal points and the water withdrawal at varying levels of spatial accuracy of withdrawal locations (i.e., different buffer zone sizes). 


\subsection{References}

Hamilton, D. A. \& Seelbach, P. W. 2010. Determining environmental limits to streamflow depletion across Michigan. The book of the states, 42, 534-537.

Hunt, B. 1999. Unsteady stream depletion from ground water pumping. Ground water, 37, 98-102.

Kraft, G. J., Clancy, K., Mechenich, D. J. \& Haucke, J. 2012. Irrigation effects in the northern lake states: Wisconsin central sands revisited. Ground water, 50, 308-318.

Loucks D. P. \& van Beek, E. 2005. Water resources systems planning and management: an introduction to methods, models and applications. UNESCO, Paris.

Maidment, D. R. 2002. Arc Hydro: GIS for water resources, ESRI, Inc.

Mckay, L., Bondelid, T., Dewald, T., Johnston, J., Moore, R. \& Rea, A. 2012. NHDPlus Version 2: user guide. Unites States Environmental Protection Agency. Available: www. horizon-systems. com/NHDPlus/index. php.(October 2014).

MDEQ 2011, Wellogic User Manual for Local Health Department and State of Michigan Staff, Michigan Department of Environmental Quality, Available: http://www.michigan.gov/documents/deq/dnre-ermd-dwehs-wellogicsomlhdusermanual_334605_7.pdf(March 2017).

Neff, B. P., Piggott, A. \& Sheets, R. 2006. Estimation of shallow ground-water recharge in the Great Lakes Basin, US Department of the Interior, US Geological Survey.

Poff, N. L., Allan, J. D., Bain, M. B., Karr, J. R., Prestegaard, K. L., Richter, B. D., Sparks, R. E. \& Stromberg, J. C. 1997. The natural flow regime. BioScience, 47, 769-784. 
Reeves, H. W. 2010. Water availability and use pilot: A multiscale assessment in the US Great Lakes Basin, US Geological Survey.

Shaffer, K. 2009. Variations in Withdrawal, Return Flow, and Consumptive Use of Water in Ohio and Indiana, with Selected Data from Wisconsin, 1999-2004, US Geological Survey.

Watson, K. A., Mayer, A. S. \& Reeves, H. W. 2014. Groundwater availability as constrained by hydrogeology and environmental flows. Groundwater, 52, 225-238.

Zorn, T. G., Seelbach, P. W. \& Rutherford, E. S. 2012. A Regional-Scale Habitat Suitability Model to Assess the Effects of Flow Reduction on Fish Assemblages in Michigan Streams1. JAWRA Journal of the American Water Resources Association, 48, 871-895. 


\section{Chapter 4: Water stress characterization in the Great Lakes region}

\subsection{Anthropogenic water stress}

The methodology presented in Chapter 3 was applied to quantify and map water stress resulting from water withdrawals in the GLB. The results of the catchment scale analysis on annual and monthly (August) time scales were analyzed to draw insights about the effects of temporal and spatial scale on water stress characterization. Furthermore, ecological water stress thresholds for the state of Michigan (Hamilton and Seelbach, 2010; Zorn et al., 2012) were used as a reference to evaluate the impact of water withdrawals on different stream types classified based on the modified Strahler stream order method (McKay et al., 2012) and thermal regime.

Furthermore, Figure 4.1 illustrates the location of about 3,480 catchments that experienced varying levels of water stress (i.e., non-zero water stress index) due to annual water withdrawals. It includes both positive and negative water stress locations, i.e. catchments where stream flow is predominantly affected by return flow or depletion, respectively. About $94 \%$ of the total stressed catchments had between $-10 \%$ to $10 \%$ water stress. Annual scale water stress indices indicated that $71 \%$ of the withdrawal points cause positive stress whereas $29 \%$ caused negative water stress (Figure 4.2). These calculations were also made for the month of August to illustrate the effect of temporal scale. A significantly larger number of catchments experienced negative water stress in August when total water withdrawals were larger than average and stream flows were smaller, 
making the streams more vulnerable to consumptive water use and flow depletion. Figure 4.2 summarizes the results. 


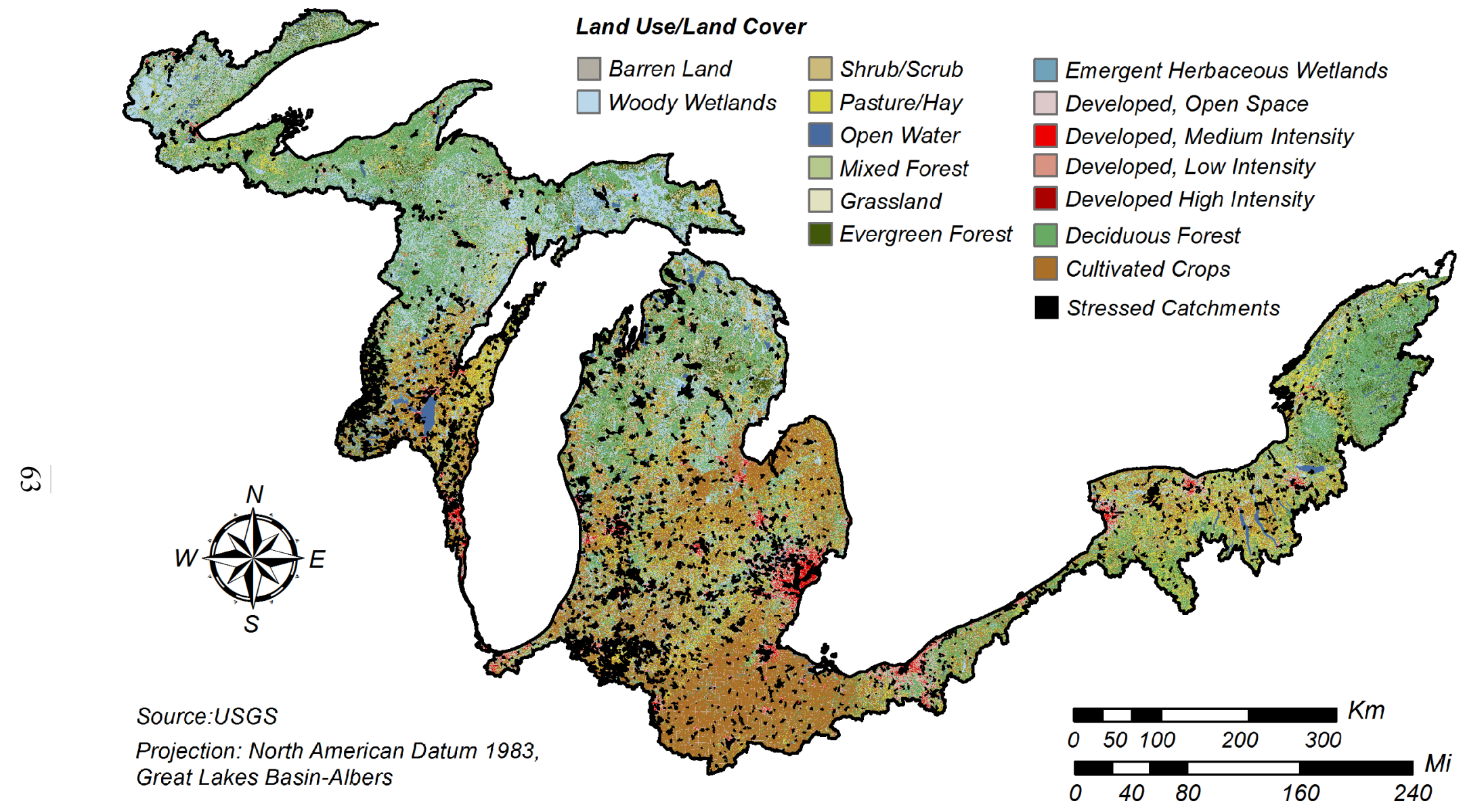

Figure 4.1. Water stress locations (i.e., non-zero water stress index) due to annual water withdrawal overlaid on the 2011 land use/land cover in the GLB (source of NLCD: USGS) 

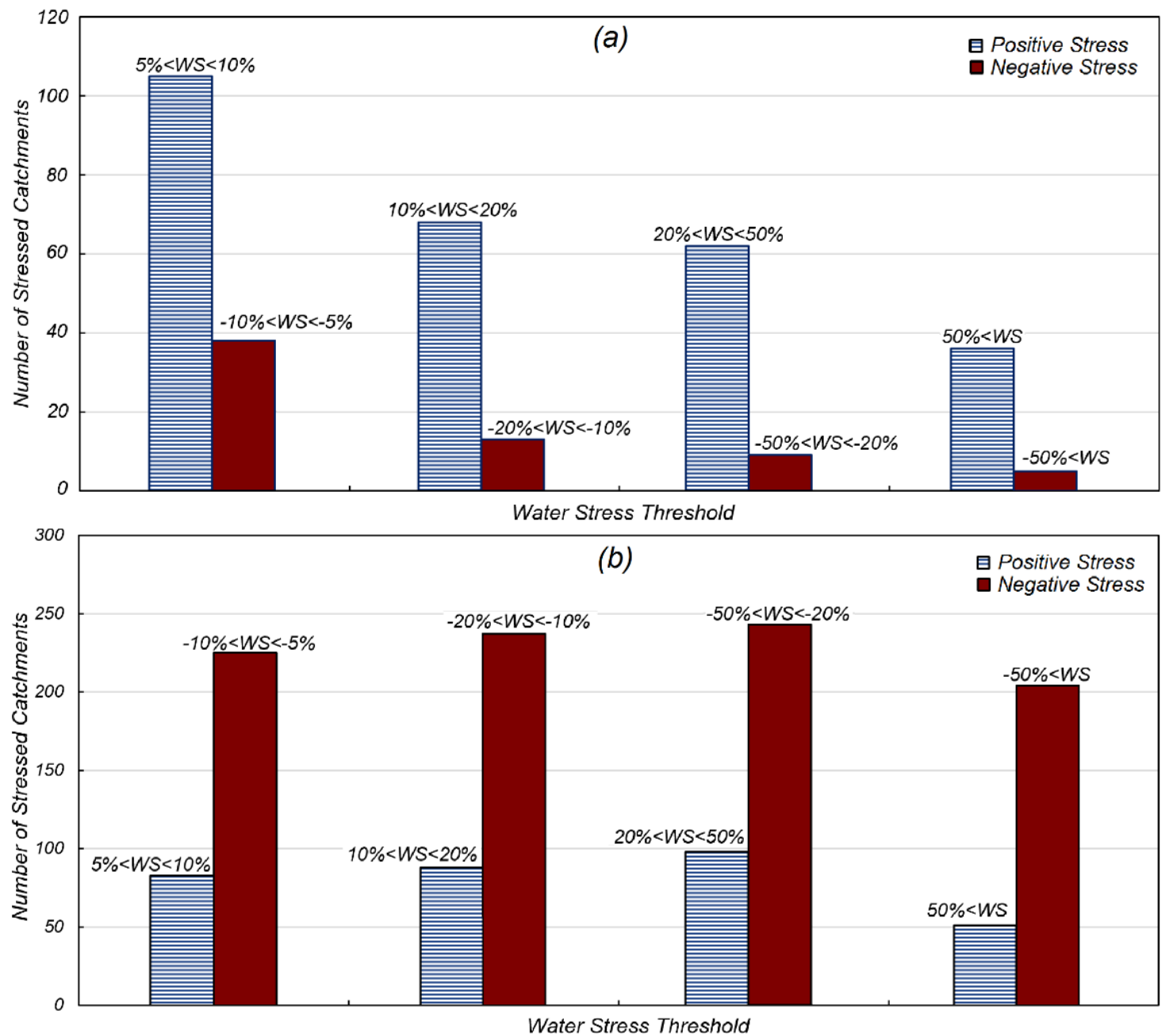

Figure 4.2. Summary of water stress index calculations using annual withdrawals (a) and August withdrawals (b). Note that catchments with water stress index between -5 to 0 and 0 to +5 found in about 3000 catchments (both August and annual) are not shown.

The water stress characterization framework accounted for potential impacts of upstream water withdrawal on downstream water stress, which are captured though propagation of the catchment scale stream flow depletion or return flow (i.e., cumulative flow adjustment) along the stream network. The cumulative flow adjustment in annual 
scale analysis demonstrated the significant effect of return flows which increased the NHDPlus V2 unimpaired flows in many catchments in the GLB. In other words, the collective effect of return flows more than compensated for the depletion effect of withdrawals. This is illustrated in a plot of adjusted flows versus unimpaired NHDPlus V2 flows in which the annual adjusted flows were mostly located on or above the $45^{\circ}$ line (Figure 4.3). In catchments where flow depletion occurred, the magnitude of depletion was typically small.

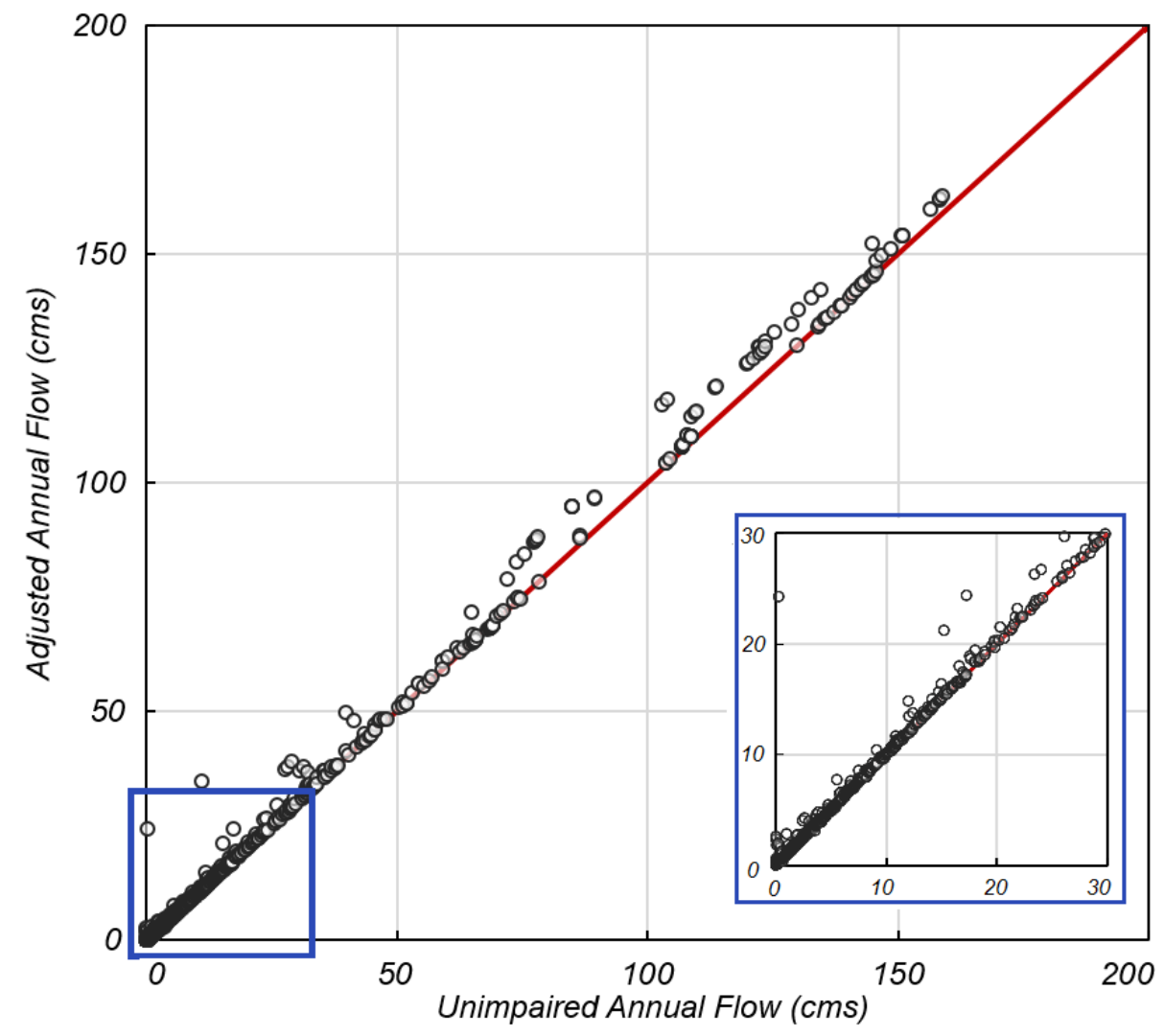

Figure 4.3. Adjusted annual flows versus unimpaired NHDPlus V2 flows. The majority of the adjusted flows are located on or above the 45 -degree line (red line) because of return flows. 
The framework helped quantify localized water stress as a function of consumptive use and surface water availability (i.e., renewable water supply). Analysis of annual withdrawals reveals that about $90 \%$ of the withdrawal points caused different levels of water stress. The remaining $10 \%$ did not appear to cause stress in their immediate vicinity, meaning that return flows and consumptive water used were nearly equal. Localized water stress was more pronounced in the month of August, when about $94 \%$ of the withdrawal points caused stress. Figure 4.4 illustrates withdrawal points that cause water stress (red) and those that did not (green).

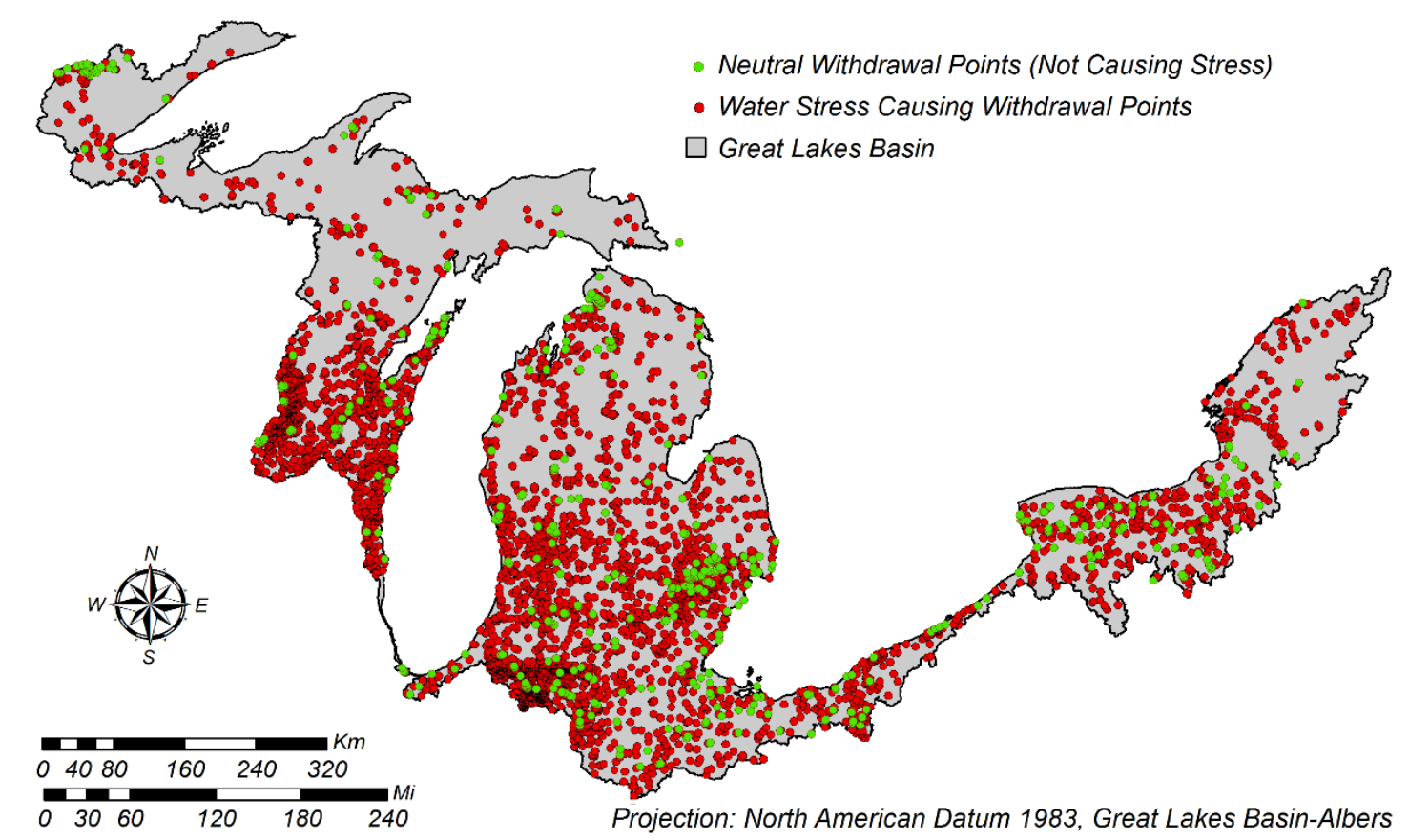

Figure 4.4. Local effect of annual water withdrawal. Water stress causing withdrawal points are shown in red ( $90 \%$ of the total points) and neutral (not causing stress) withdrawal points are shown in green. 
The locations of positive and negative water stresses caused by annual water withdrawals are shown in Figures 4.5 and 4.6. About $89 \%$ of the ctachments were estimated to have positive water stress between $0 \%$ and $5 \%$, while only $4 \%$ of the catchments were estimated to experience water stress levels exceeding $20 \%$. Likewise, about $93 \%$ of the stressed catchments that experienced negative water stress had stress index values between $0 \%$ to $5 \%$ with only about $2 \%$ of having a negative water stress value of more than $20 \%$. Figures 4.5 and 4.6 also summarize land use/land cover classes for catchments where there was significant water stress (i.e., $10 \%$ or more). The majority of positive and negative water stress locations were found in cultivated and developed areas where water was withdrawan for irrigation, domestic and public suply, commercial, industrial, livestock production, mining, and power generation.

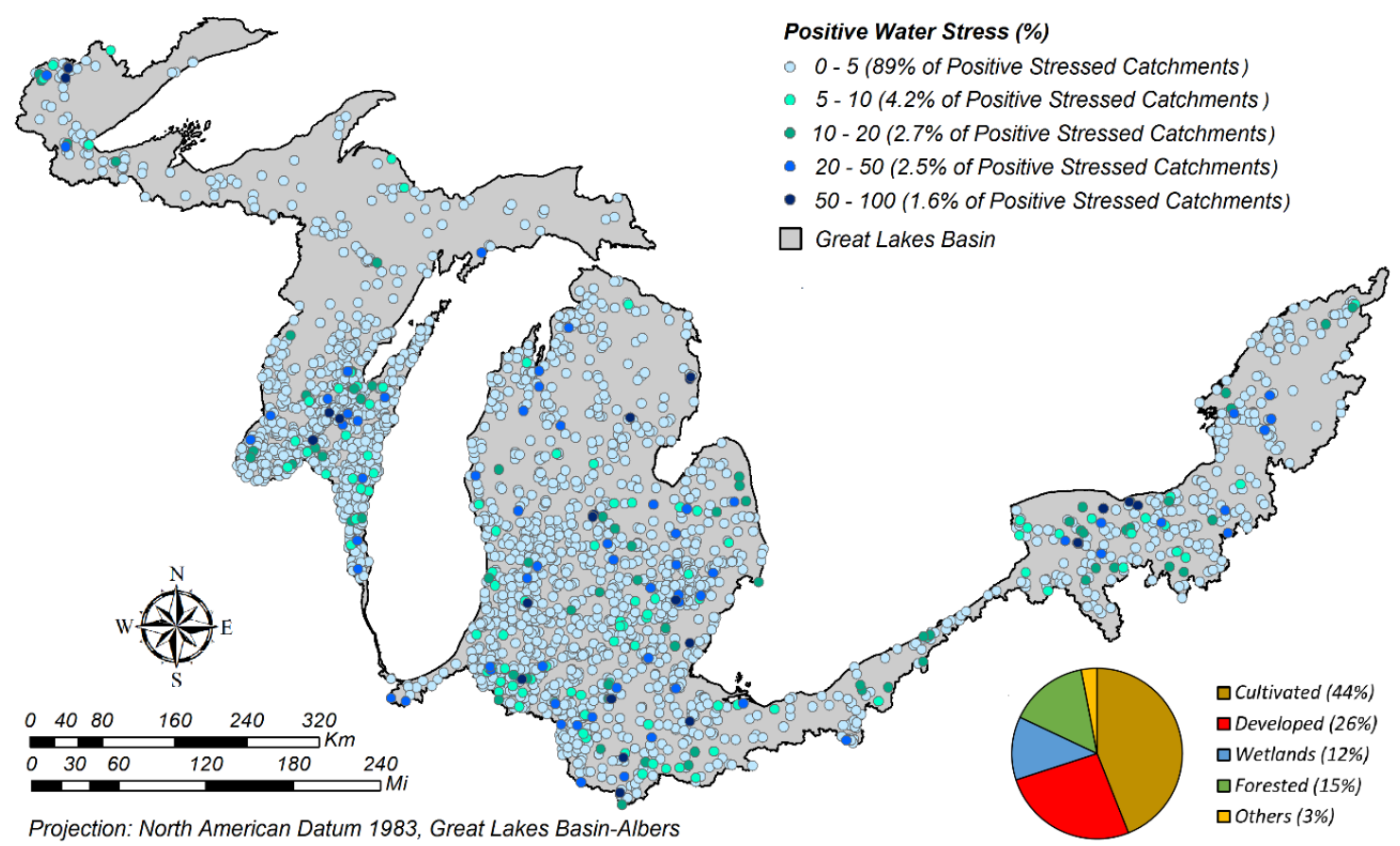

Figure 4.5. Positive water stress locations due to annual withdrawal and return flows, and land use/land cover summary (for water stress greater than $+10 \%$ ). 


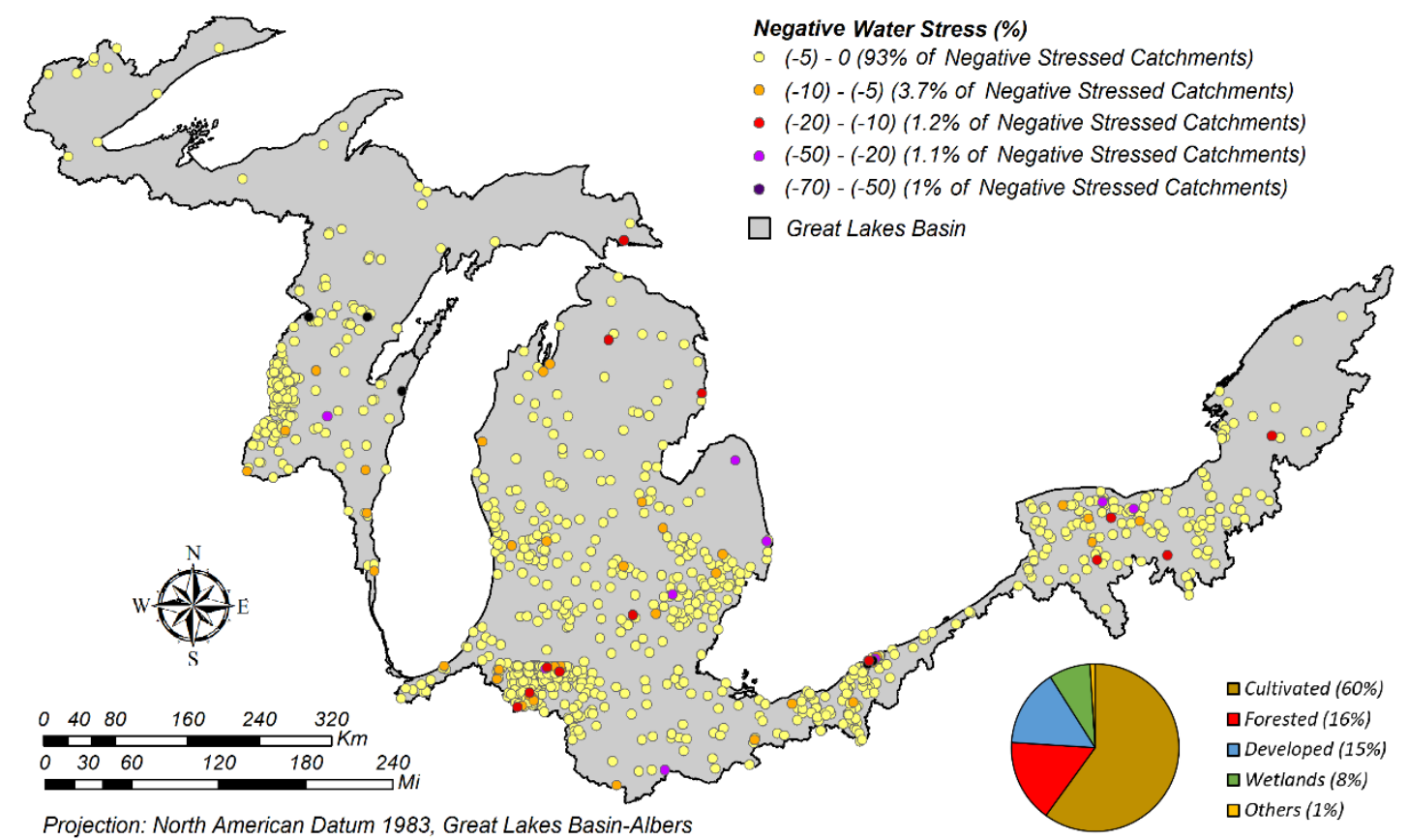

Figure 4.6. Negative water stress locations due to annual withdrawal and return flows, and land use/land cover summary (for water stress less than -10\%).

Water stress index values for the month of August (Figure 4.7 and 4.8) indicated that about $82 \%$ of the catchments had water stress index values between $0 \%-5 \%$. Water stress index values greater than $20 \%$ occurred for $5 \%$ of the catchments. Analysis of land uses indicated that catchments with positive water stress index values greater than $10 \%$ were mostly located in cultivated areas. About $66 \%$ of the catchments that experienced negative water stress had index values $0 \%-5 \%$, and another $16 \%$ had water stress index greater than $20 \%$, denoting potentially severe stress. As with the annual water stress results, most of the stressed catchments were in cultivated and urban areas. 


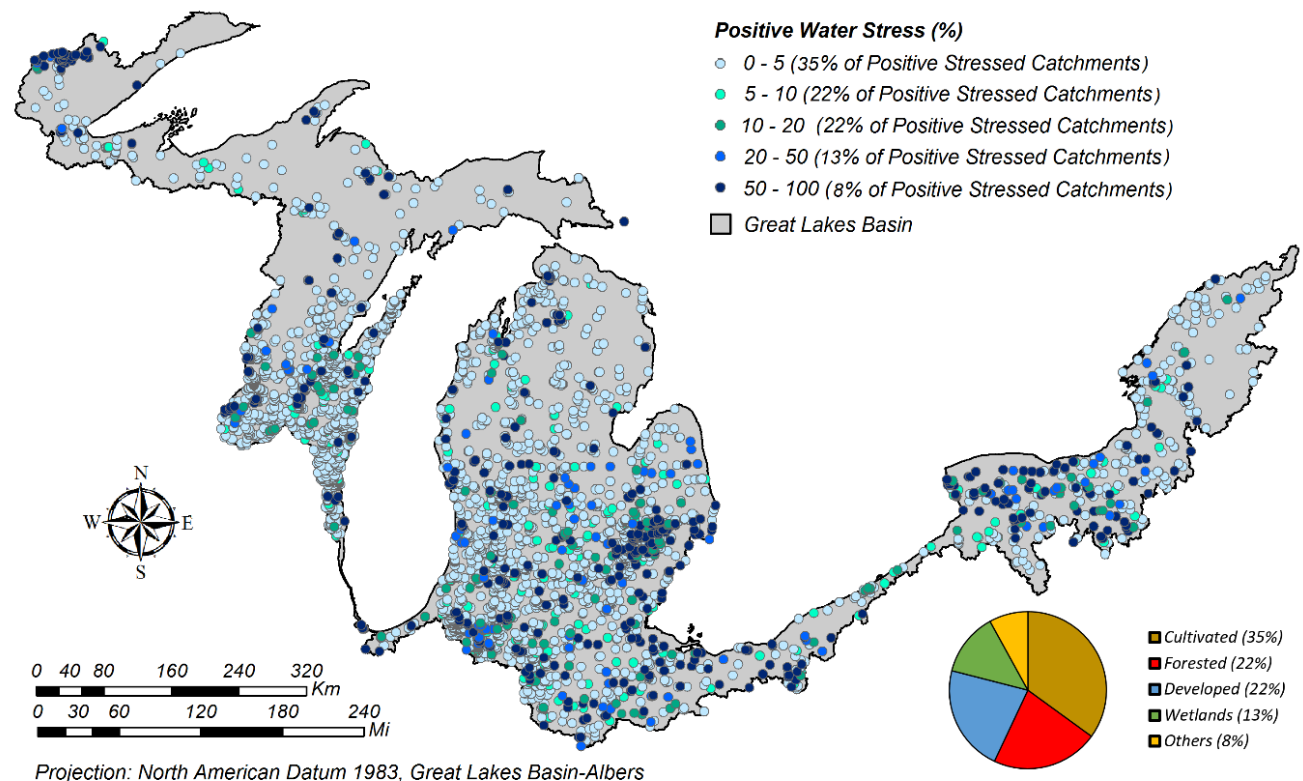

Figure 4.7. Positive water stress locations in August, and land use/land cover summary (for water stress greater than $+10 \%$ ).

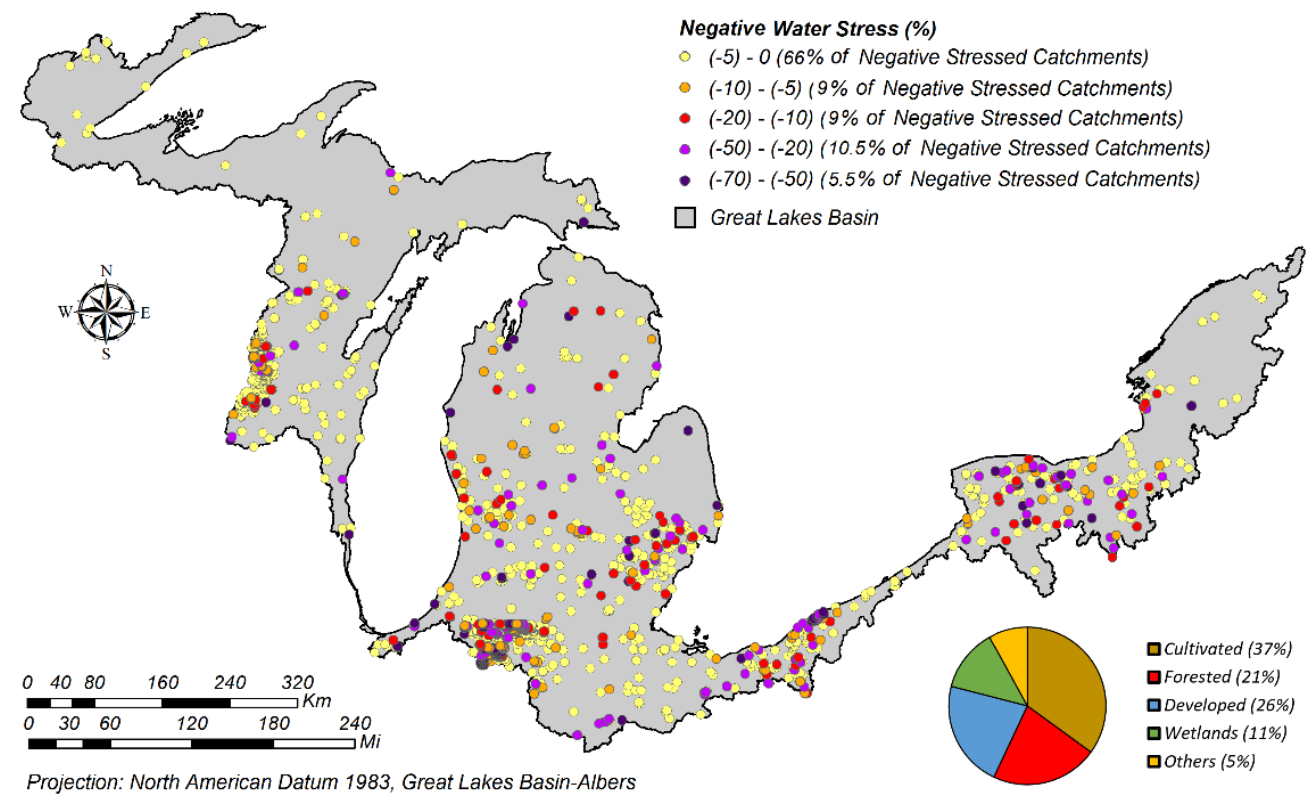

Figure 4.8. Negative water stress locations in August, and land use/land cover summary (for water stress less than -10\%). 


\subsection{Water source and use categories}

The effect of water withdrawal from different sources (e.g., tributary surface water, shallow groundwater, and deep groundwater) was also evaluated by looking closely into catchments where a significant stress was detected (i.e., positive water stress $>10 \%$, and negative water stress $<-10 \%$ ). Direct water withdrawals from the Great Lakes were excluded from water stress index calculations because they do not typically affect inland streams. Figure 4.9 illustrated the withdrawal sources resulting positive or negative water stresses of at least $10 \%$ on an annual basis in the GLB. Of the 300 significantly stressed catchments, groundwater withdrawal points comprise $85 \%$ of withdrawal locations in catchments that experience positive stress, supplying $40 \%$ of total annual water withdrawals (Figure 4.9a). Inland streams were the water source for the remaining $15 \%$ of the withdrawal points, supplying $60 \%$ of the total annual withdrawals. In catchments with negative water stress, about $40 \%$ of total water withdrawal was supplied from shallow groundwater sources while surface water provides $60 \%$ (Figure $4.9 \mathrm{~b}$ ).

Figure 4.10 displayed the location of different water sources where withdrawals cause water stress in August. The groundwater sources provided about $72 \%$ of total August water withdrawals in catchments where positive water stress was detected, of which $30 \%$ was deep groundwater extraction (Figure 4.10a). Surface water comprised $28 \%$ of total withdrawals in these catchments. In catchments that experienced negative water stress in August, groundwater withdrawal from shallow wells $(<100 \mathrm{ft})$ had a significant impact by providing $60 \%$ of the total withdrawal while the remaining $40 \%$ of the withdrawals was from surface water (Figure 4.10b). 

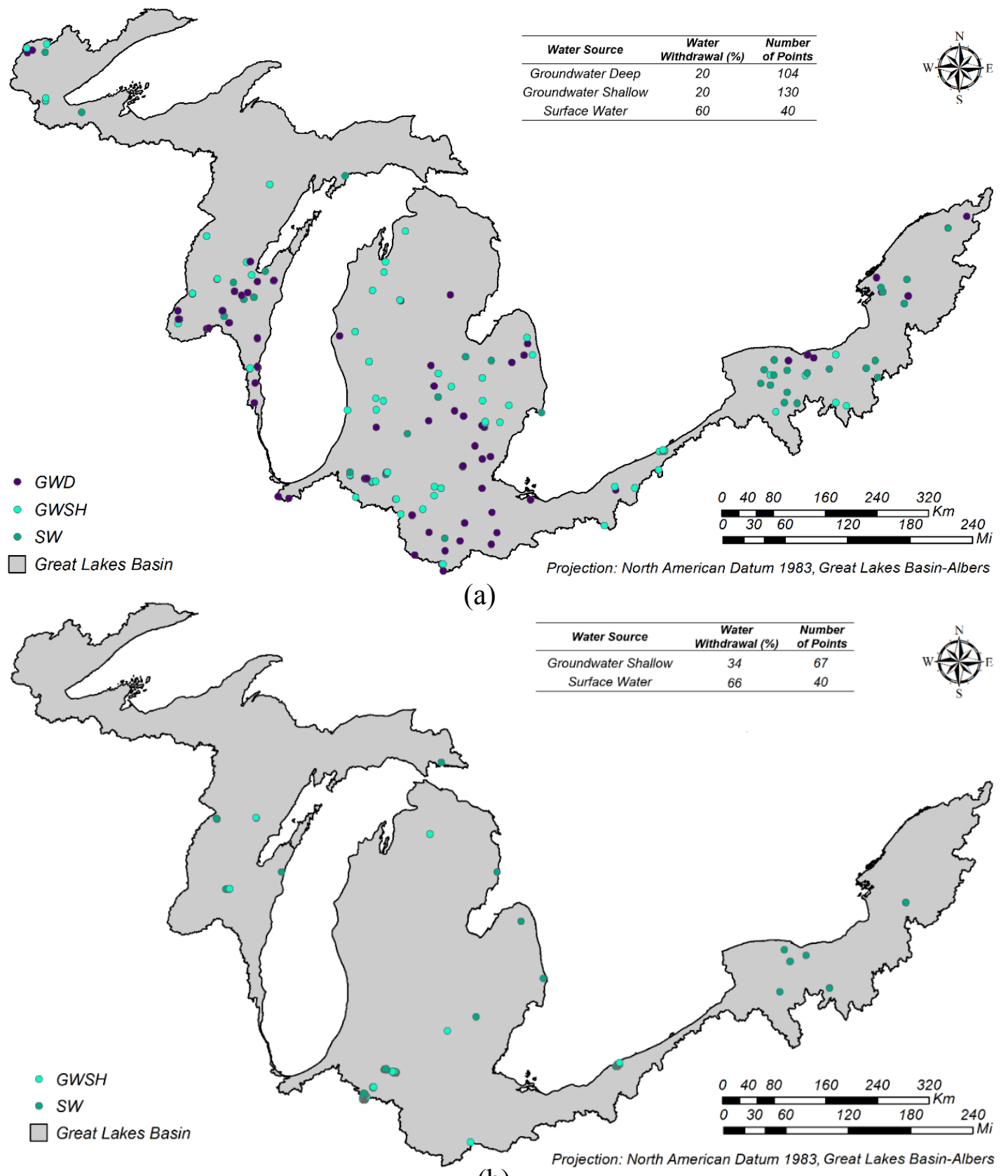

(b)

Figure 4.9. Withdrawal sources in the significantly stressed catchments: (a) positive stressed catchments with the water stress index greater than $10 \%$, (b) negative stresses catchments with the water stress index less than $-10 \%$ due to annual withdrawals. 

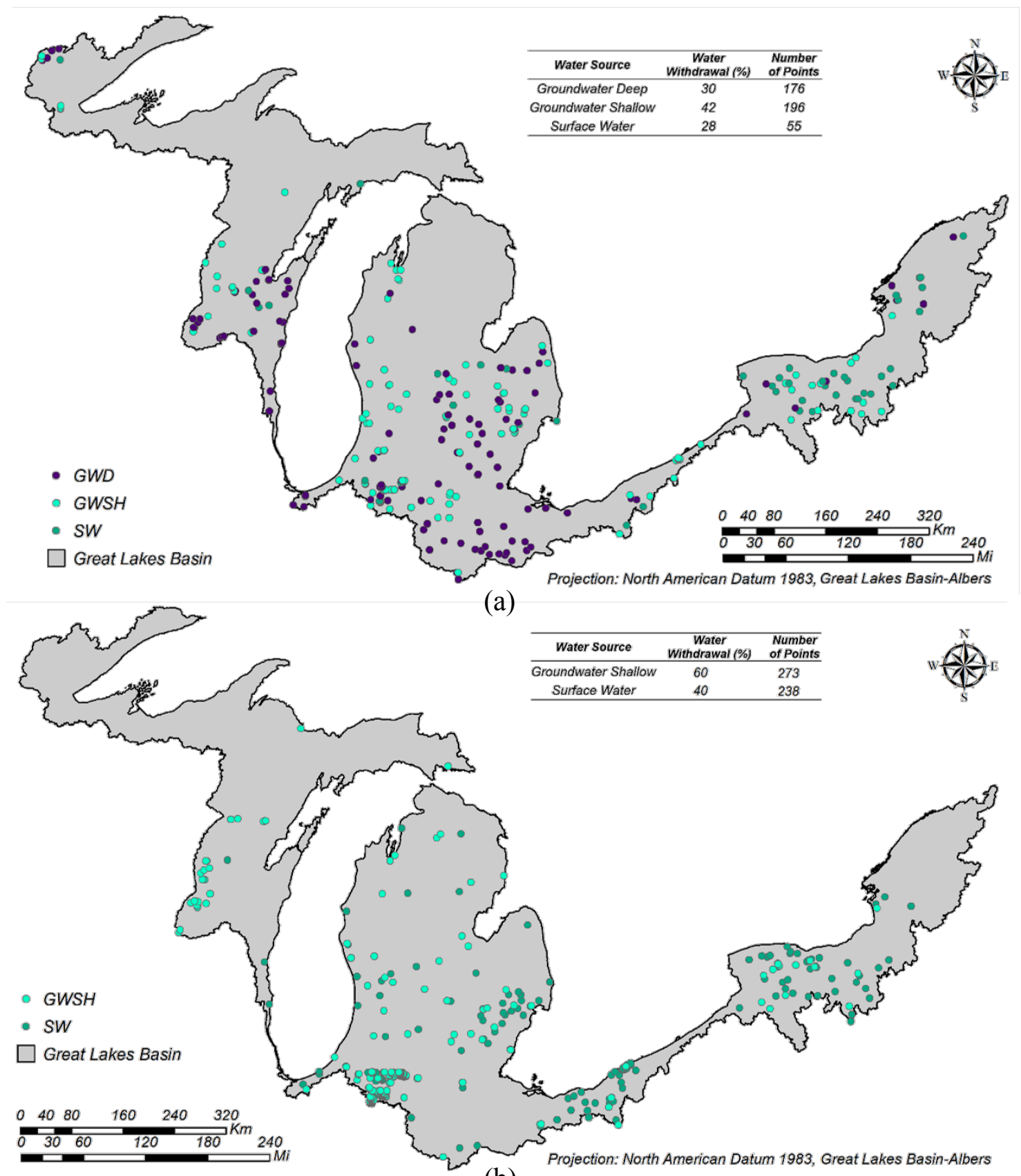

(b)

Figure 4.10. Withdrawal sources in the significantly stressed catchments: (a) positive stressed catchments with the water stress index greater than $10 \%$, (b) negative stresses catchments with the water stress index less than $-10 \%$ due to August withdrawals. 
The effect of water use category on waters stress (positive or negative) was also evaluated in areas with significant water stress levels. Water use categories that had a relatively small consumptive use coefficient (e.g., domestic and public water use) tend to generate positive water stress. By contrast, negative water stress was mostly due to presence of the use categories with larger consumptive use (e.g., agriculture). Figures 4.11 and 4.12 summarized the annual analysis results. For positive stresses greater than $10 \%$ (Figure 4.11), about $64 \%$ of the withdrawals belonged to domestic and public water use category and about 19\% were for industrial purposes. For negative stresses (i.e., water stress index $<-10 \%$ ), $64 \%$ and $35 \%$ of the withdrawn water belonged to irrigation and livestock production, respectively (Figure 4.12).

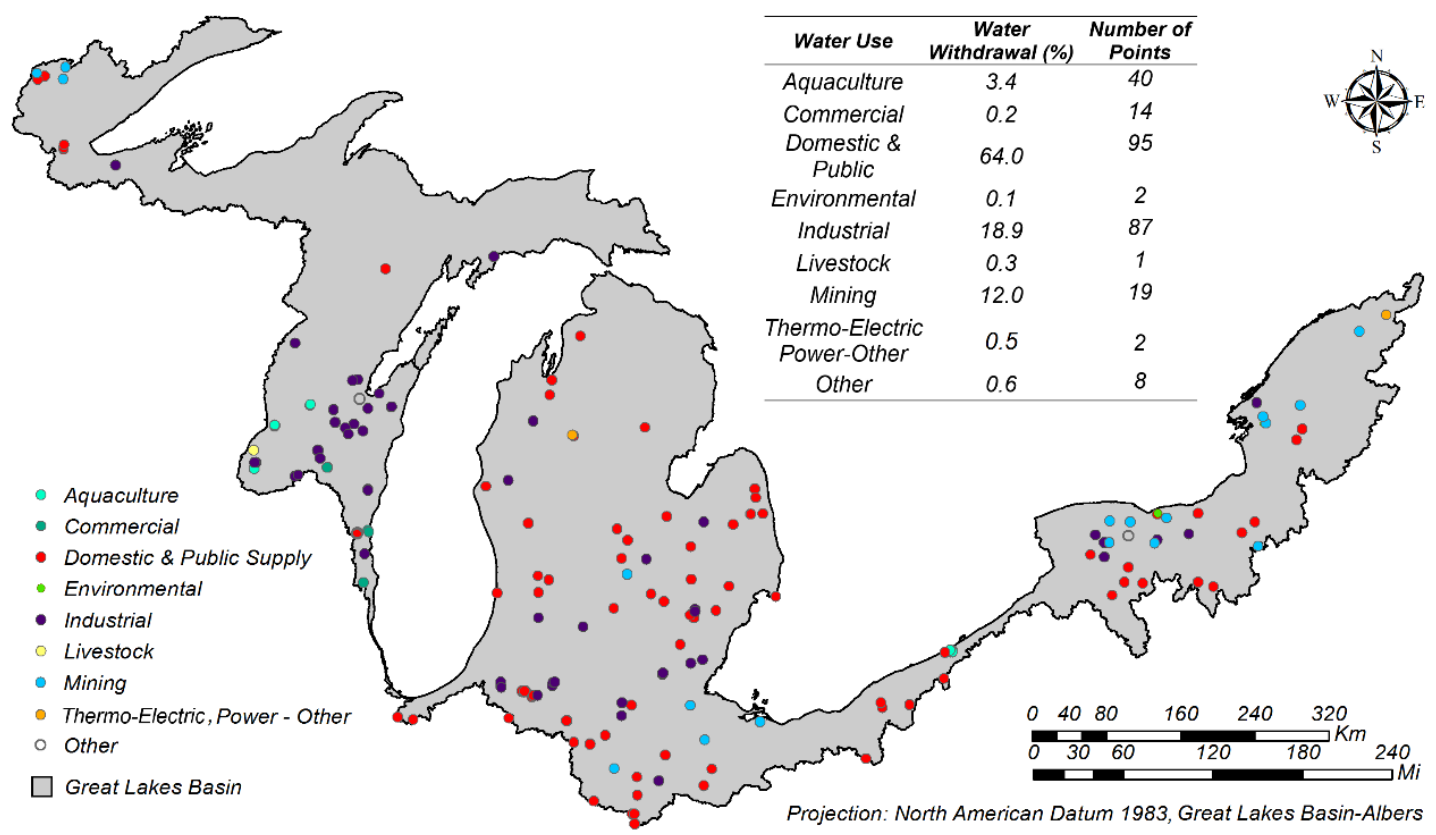

Figure 4.11. Effect of water use category in generating significant positive annual water stress (water stress index greater than 10\%). 


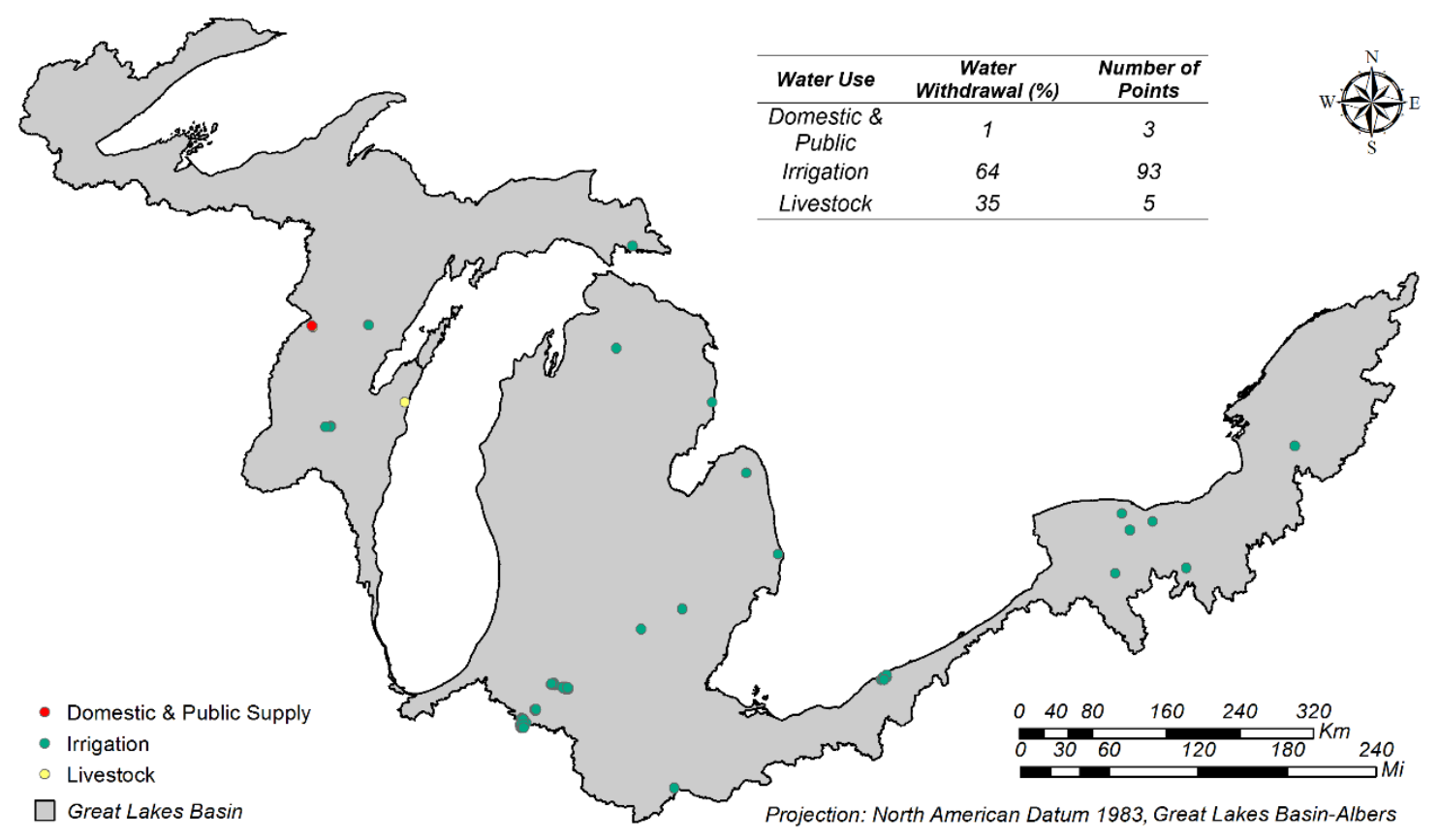

Figure 4.12. Effect of water use category in generating significant negative annul water stress (water stress index smaller than $-10 \%$ ).

Figure 4.13 illustrates the water use categories in areas where positive or negative stress indices exceeded 10\% in August. In catchments with positive stress, more than 50\% of the August withdrawals were for the domestic and public water uses. The remaining withdrawals were split between industrial (30\%), mining (10\%) and agricultural (9\%) purposes (Figure 4.13a). For the negative stresses (Figure 4.13b) less than $-10 \%$, almost all $(98 \%)$ of the withdrawals were for irrigation purposes, with an insignificant number in the industrial and mining sectors (1\% each). 


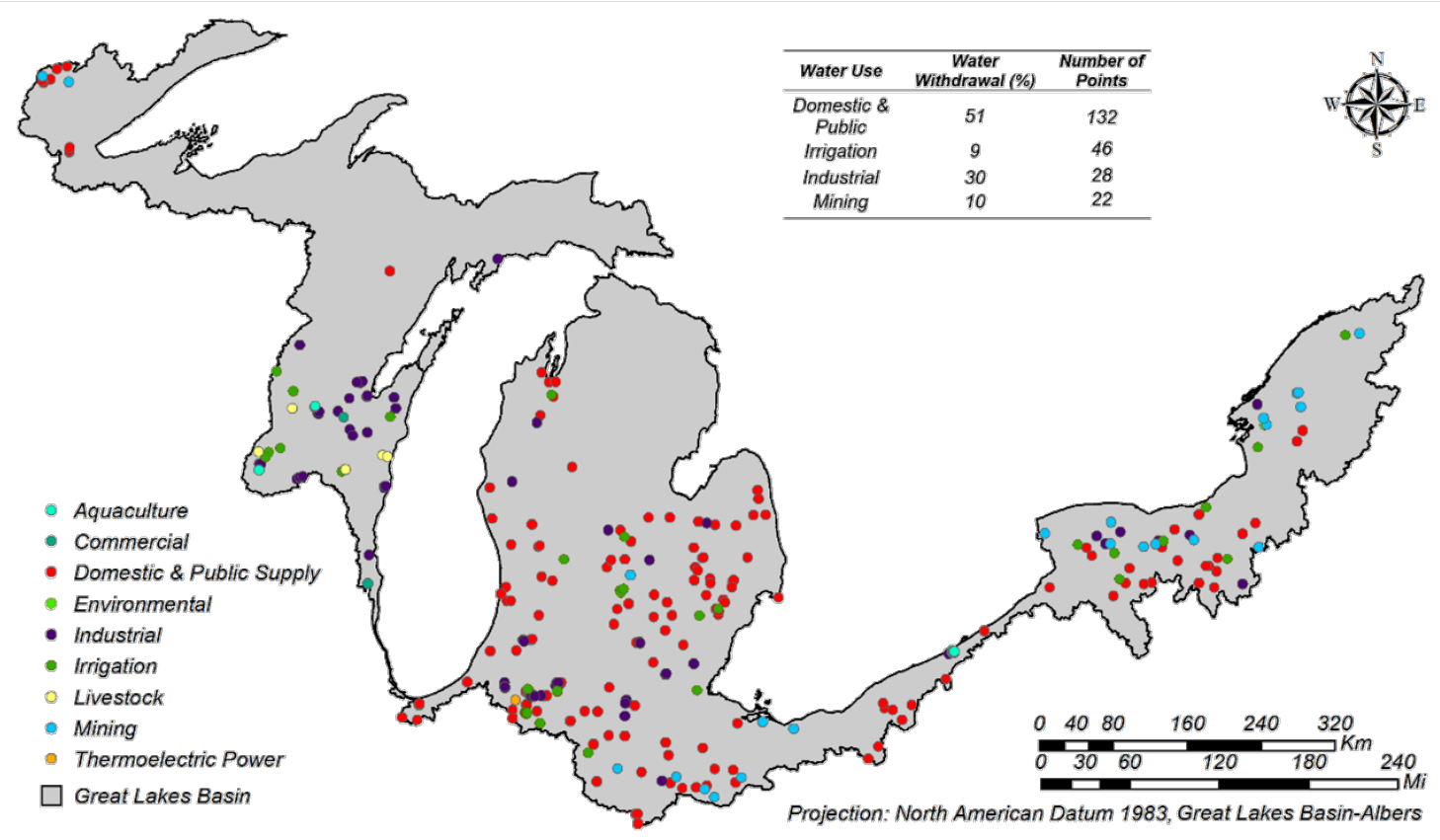

(a)

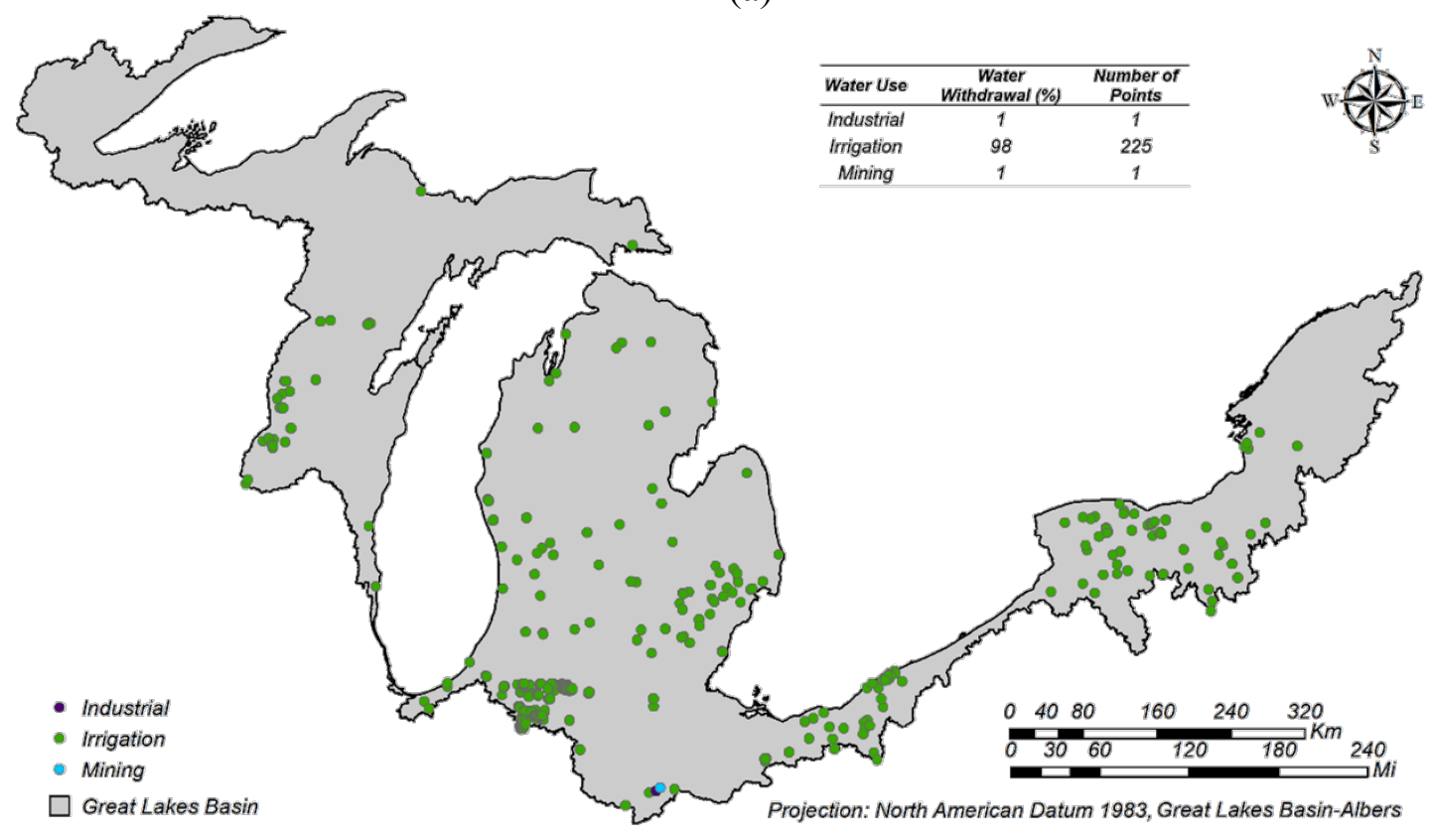

(b)

Figure 4.13. Effect of water use category in generating significant negative water stress in August: (a) positive stress (water stress index greater than 10\%), and (b) negative stress (water stress index smaller than $-10 \%$ ). 


\subsection{Importance of spatial and temporal scales}

A good understanding of spatial scale alongside temporal scale is key for informing water management, so that excessive stress on environmental resources is avoided by addressing potential spatial and temporal vulnerabilities. The current catchment scale water stress analysis demonstrates the relatively high vulnerability of smaller catchments as compared with larger catchments. This finding is important for developing effective monitoring plans and taking timely action to mitigate water stress in vulnerable areas. Figures 4.14 and 4.15 display the distribution of water stress relative to catchment size for annual and August analyses. In general, larger water stress indices are estimated for smaller catchments (e.g., $<10 \mathrm{Km}^{2}$ ), as evidenced by the congregation of points close to the $\mathrm{Y}$-axis in Figure 4.14. Water stress index values decline as catchments become larger, creating a funnel shape along the X-axis. This effect is observed in both annual and August water stress analyses.

The temporal scale analysis also reveals that a significant number of larger catchments may be classified as water stressed in certain months (e.g., August), depending on water withdrawal, consumption, and availability in different catchments. The plot of August water stress indices as a function of catchment size illustrates that a significant number of larger catchments (e.g., 10-20 $\mathrm{Km}^{2}$ ) that were not identified as stressed in the annual scale analysis can be flagged as stressed areas. This is seen in the larger and wider shaped funnel along the $\mathrm{X}$-axis in the August plot, which also shows increased vulnerability to water shortage (i.e., larger number of negative water stress index values). 
Therefore, based on the current water stress analysis, large spatial and temporal scales can mask high water stress, creating a spurious image of sustainable anthropogenic water use.

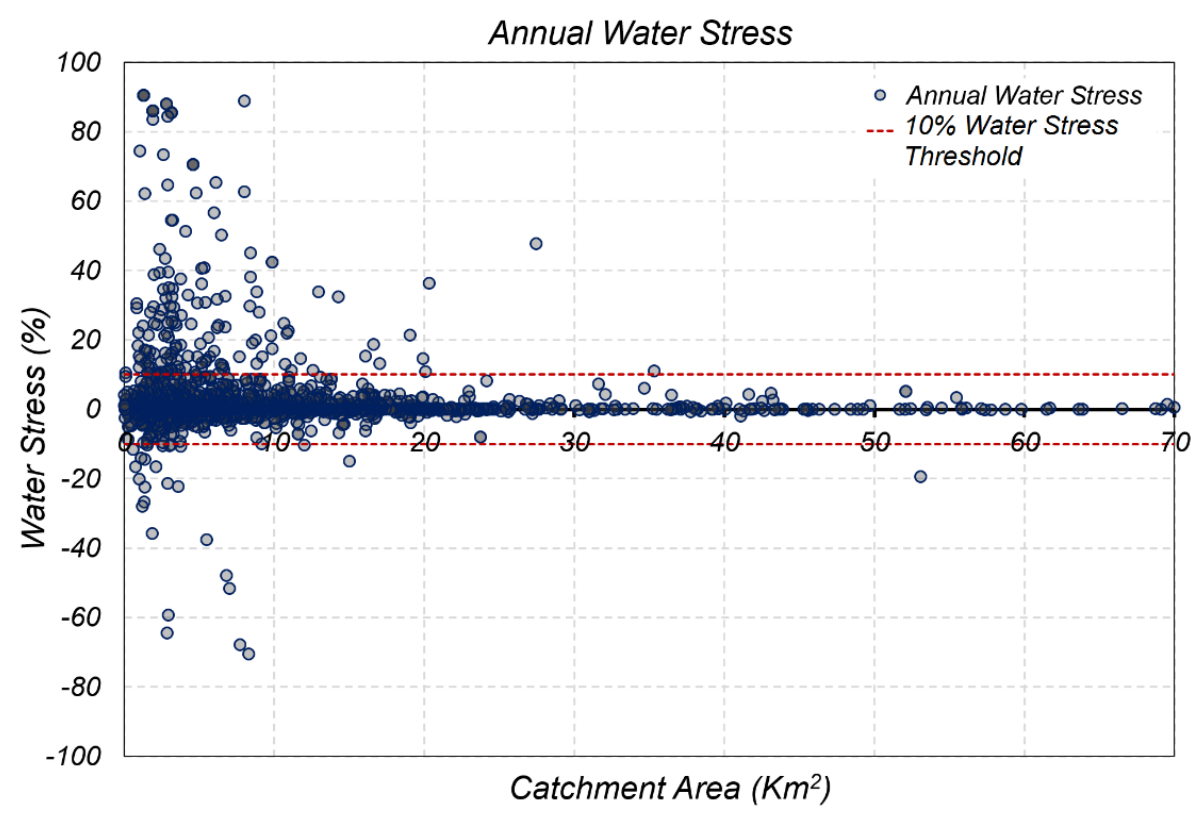

Figures 4.14. Distribution of annual water stress relative to catchment size.

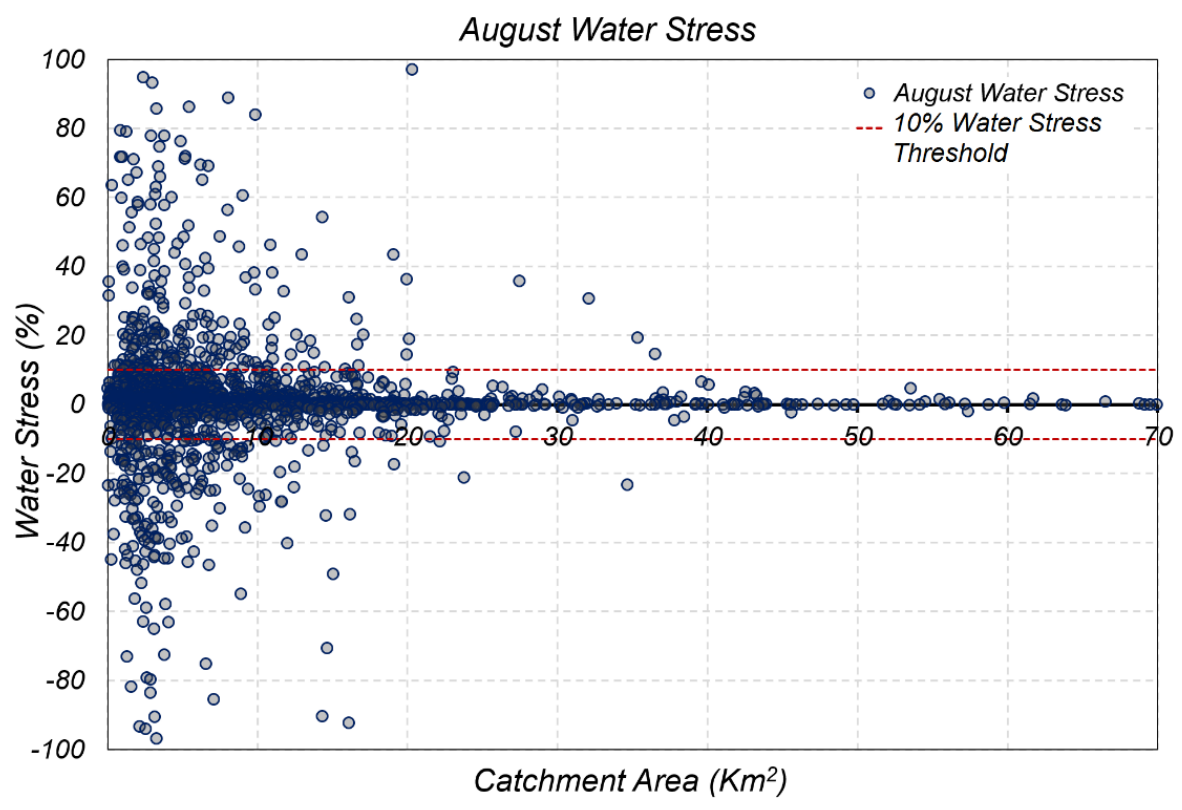

Figures 4.15. Distribution of August water stress relative to catchment size. 
Another interesting finding relates to the effect of water sources on water stress characterization. Analysis of the effect of return flows helps illustrate this point, and provides a way to ensure that the formulation and implementation of the current water stress calculation framework can appropriately account for water stress impacts of withdrawals from different sources. This is investigated by removing groundwater withdrawals from the analysis, thus eliminating return flows associated with deep and shallow groundwater withdrawals, and the depletion effect of shallow groundwater extraction. Expectedly, negative water stress increases significantly, while no positive water stress is detected on the plot of annual water stress (Figure 4.16). The increase in the number of the vulnerable catchments and the severity of water stress is more conspicuous in August (Figure 4.17).

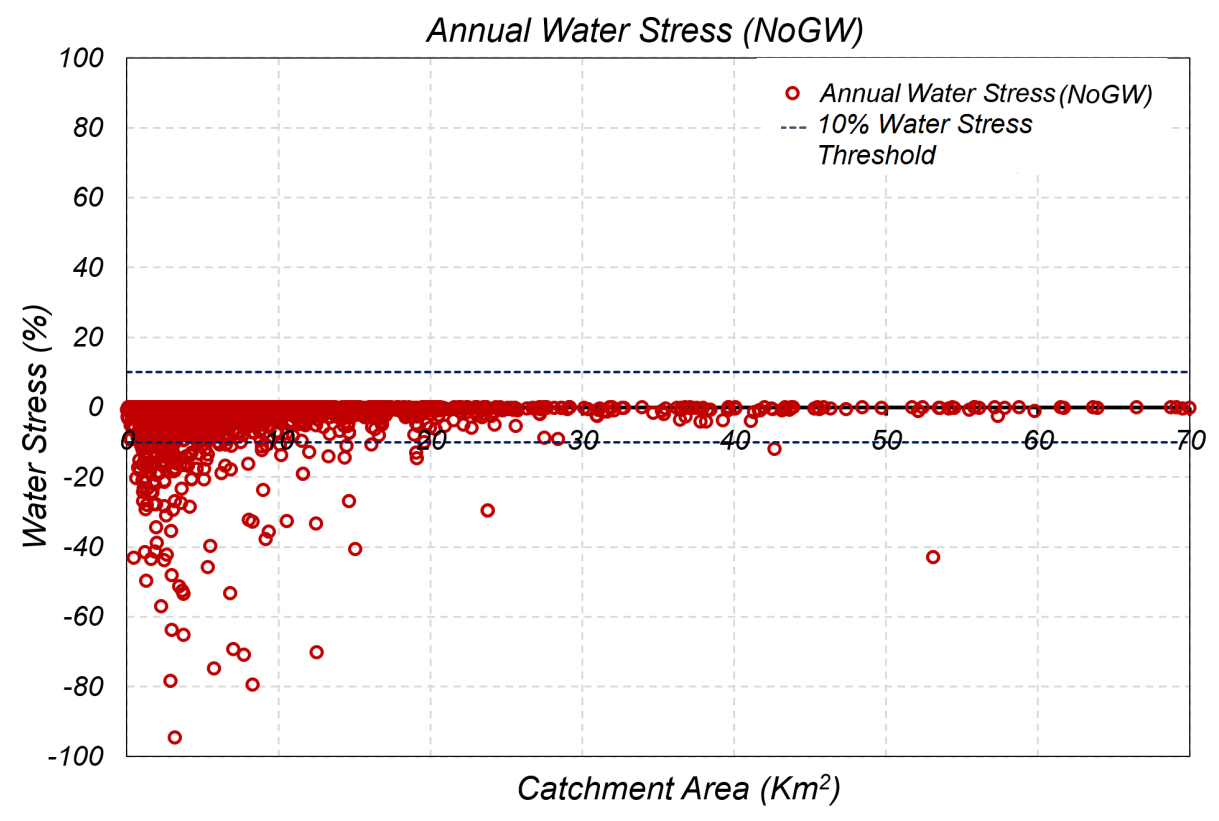

Figures 4.16. Annual water stress relative to catchment size after excluding groundwater. 


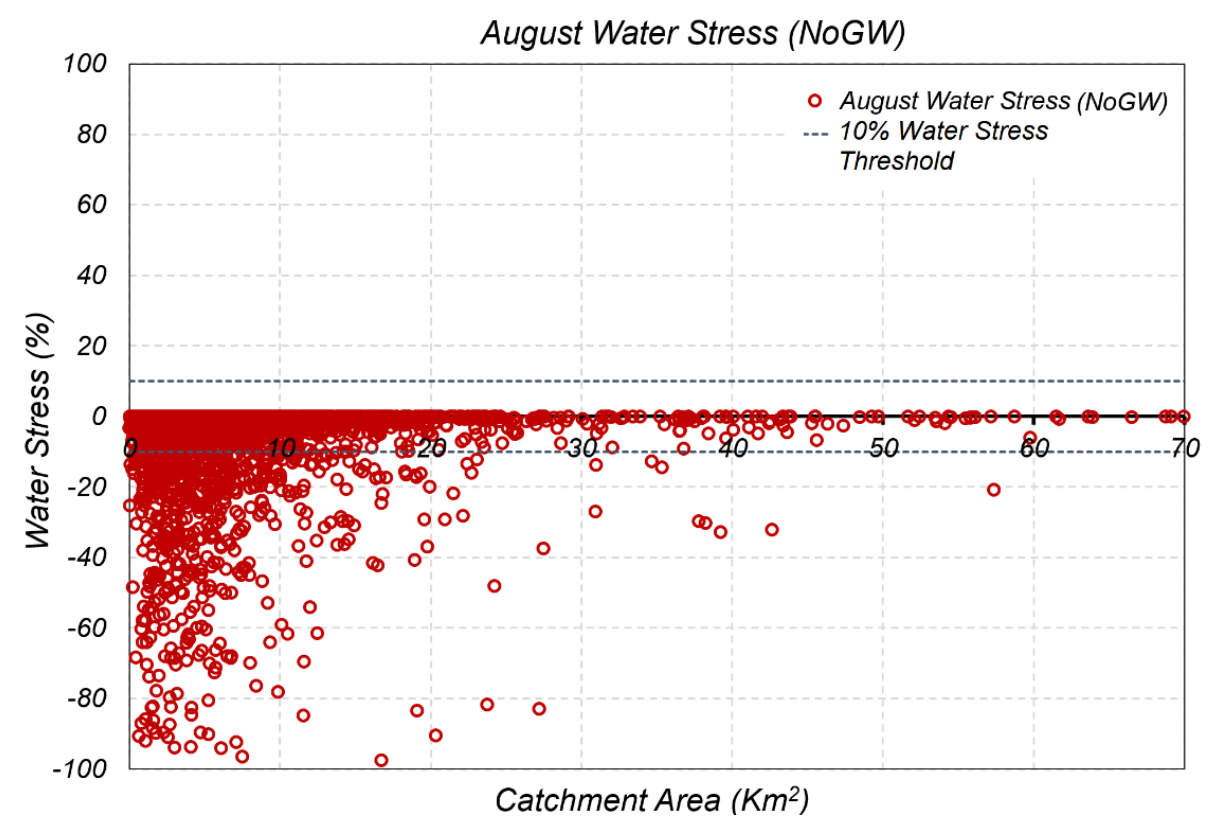

Figures 4.17. August water stress relative to catchment size after excluding groundwater.

\subsection{Stream order and vulnerability to water stress}

The effect of location of catchments within the larger watershed on their vulnerability to water stress is evaluated through analysis of stressed catchments based on the modified Strahler stream order. Figures 4.18 and 4.19 illustrate the stream orders in catchments where positive and negative annual water stress is detected, respectively. The results indicate that catchments with stream order 1 (i.e., headwater streams) are more responsive to flow alterations due to human water withdrawal. About $70 \%$ and $88 \%$ of the positive and negative stresses, respectively, occur in the catchments with stream order 1 . Stream order 2 is the second most vulnerable stream type, where $17 \%$ of the positive stresses and $22 \%$ of the negative stresses occur. As streams become larger, they are less affected by water stress. Only $13 \%$ of the positive and negative stresses, respectively, were found in 
catchments with stream orders 3 or larger, while no negative water stress was detected in catchments with stream orders larger than 2 .

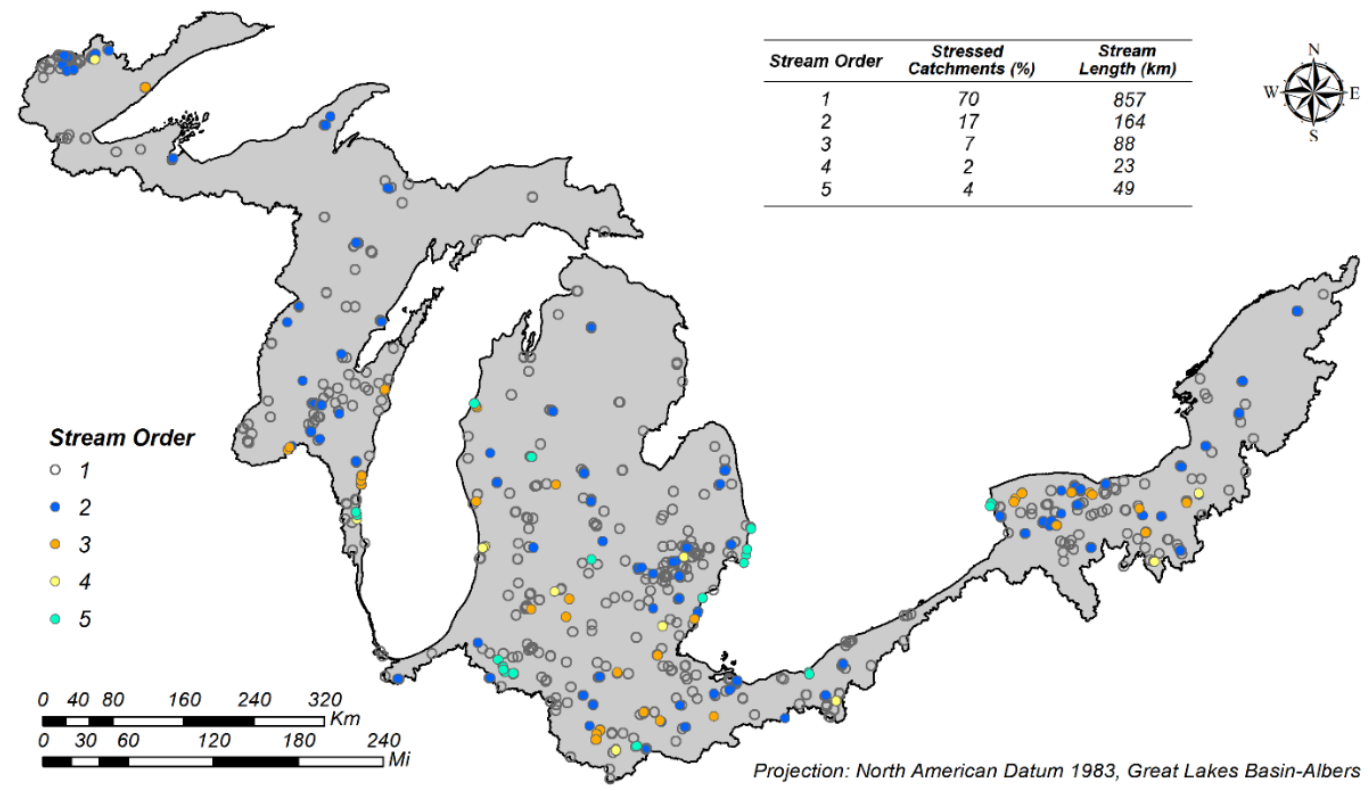

Figures 4.18. Stream orders in catchments with positive annual water stress.

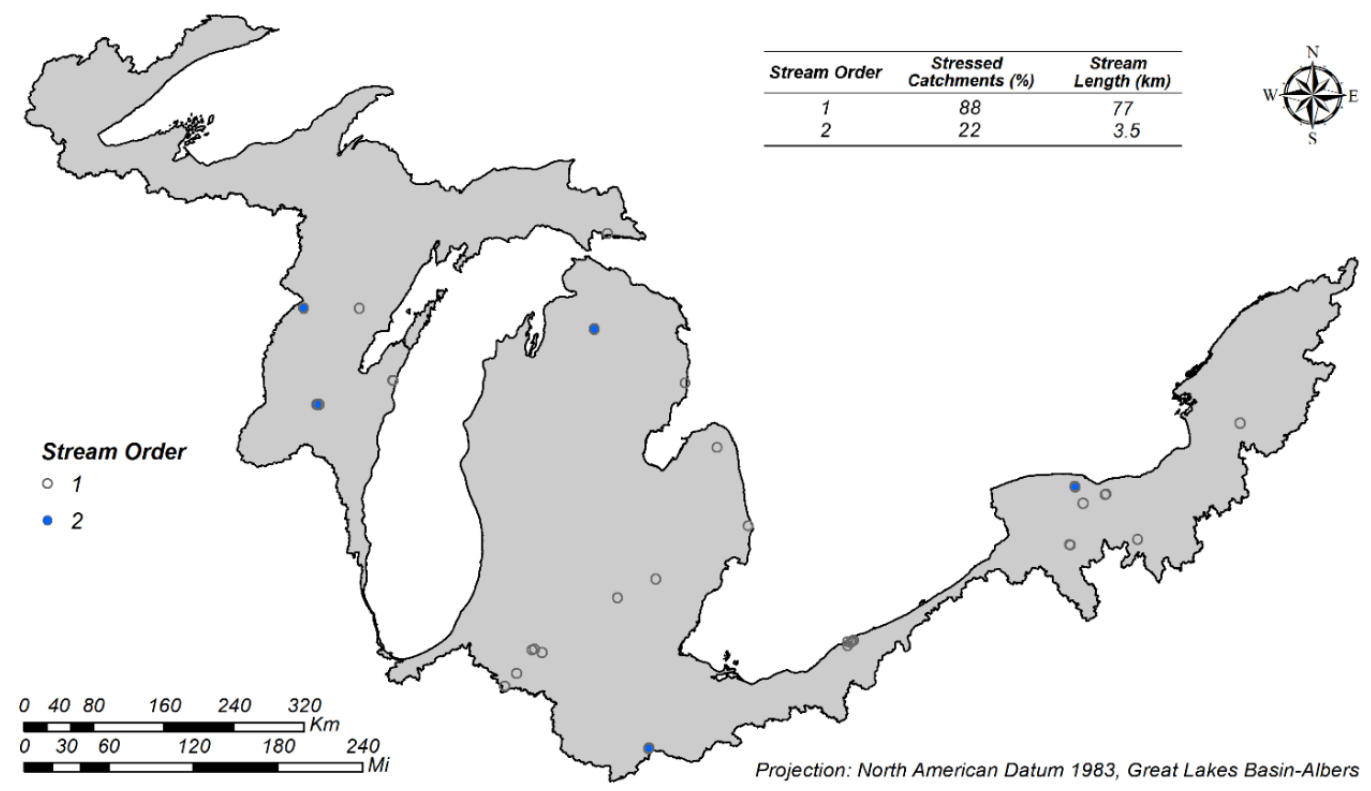

Figures 4.19. Stream orders in catchments with negative annual water stress. 
Figure 4.20 provides maps of catchments with positive and negative stress in August and their corresponding stream orders. The results indicate increased vulnerability of headwater catchments to relatively high withdrawal and low flow conditions in August. About $87 \%$ and $83 \%$ of catchments with positive and negative water stress indices, respectively, were found to have stream order types 1 and 2. Negative water stress locations with stream order 1 are scattered across the GL states, while clusters of catchments with negative water stress are found in southwest and southeast Michigan, Ohio, and New York. Similar to the results of annual scale analysis, larger order streams appear to be less vulnerable to the effects of return flow and streamflow depletion. 


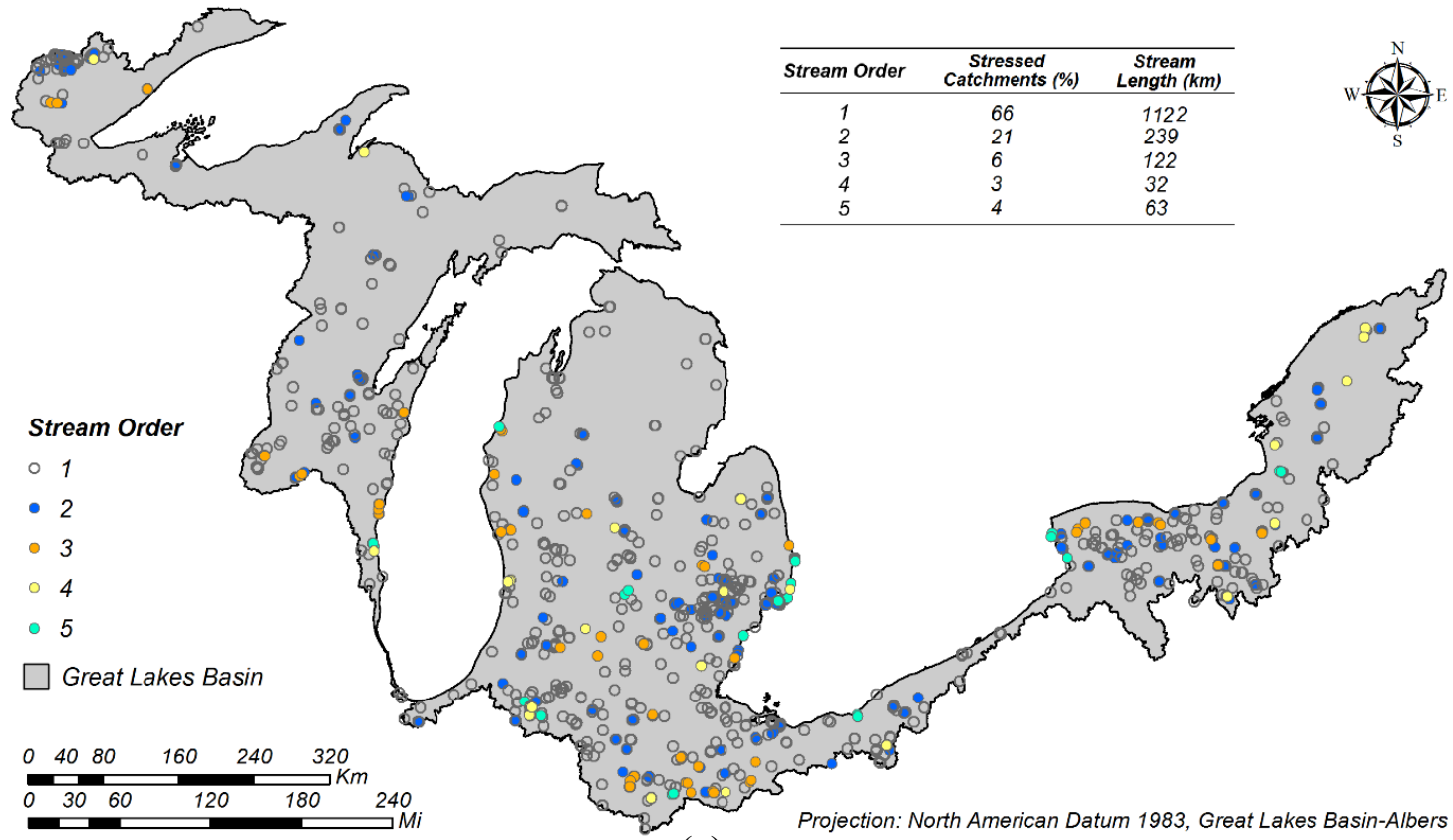

(a)

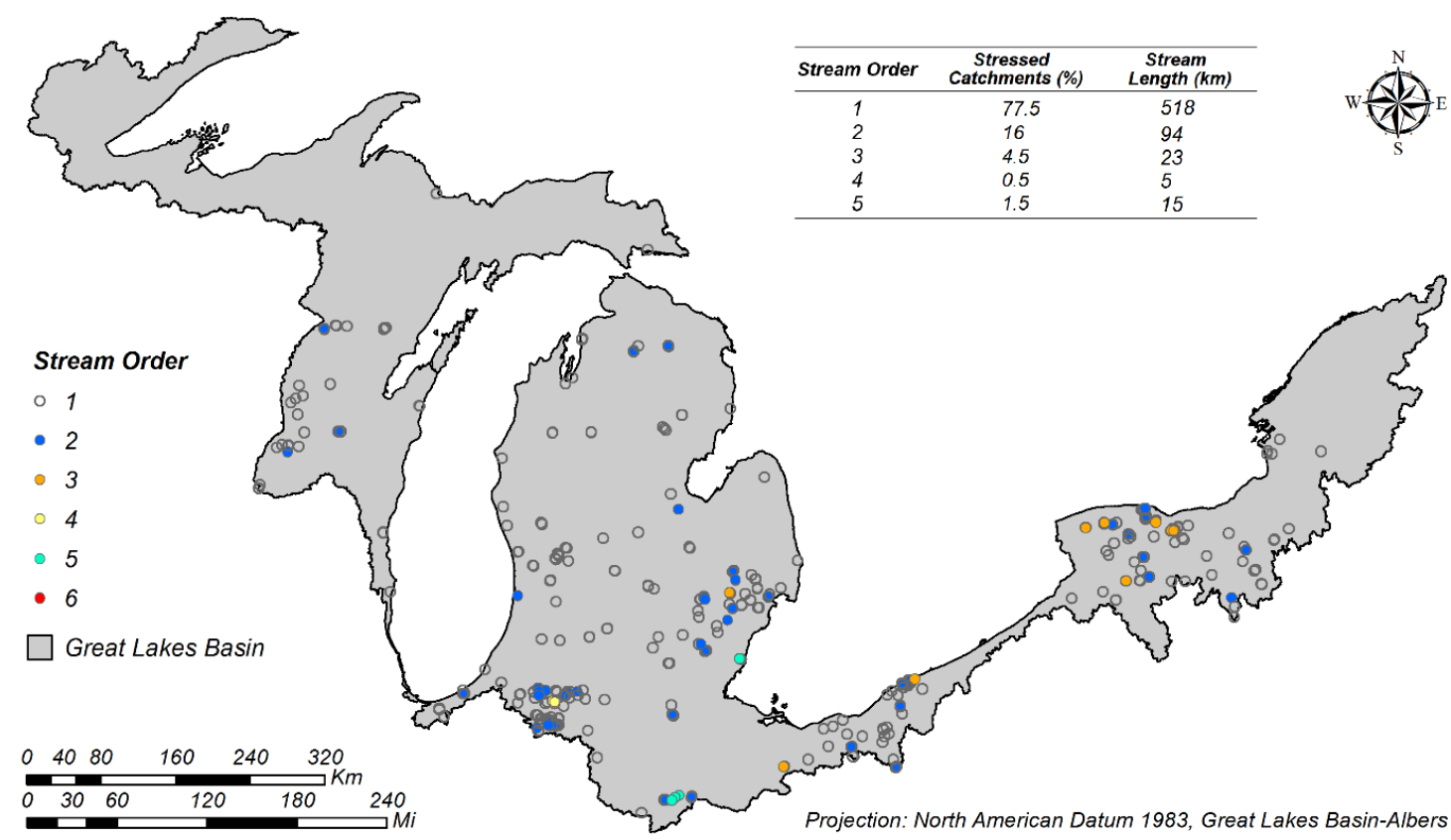

(b)

Figures 4.20. Stream orders in catchments with positive (a) and negative (b) August water stress. 


\subsection{Ecological water stress in Michigan}

Ecological guidelines for assessing varying levels of ecosystem disturbance due to water withdrawal in Michigan (Hamilton and Seelbach, 2010) were used to evaluate ecological water stress in this state. These guidelines were developed based on the concept of adverse impact of reducing index flow on fish habitats. Management zones A through D developed based on the streamflow depletion and thermal regime were used to categorize the catchments with negative water stress. Stream classification based on the thermal regime included different stream types such as large or small cold streams, and transitional streams of different sizes. Figure 4.21, illustrated the lengths of streams in different management zones due to the depletion effect of average annual water withdrawals relative to flow conditions. Each stressed catchment included one of the stream types. Catchments with streams classified as management zone D were severely stressed, threatening aquatic habitats and biodiversity.

The majority of the stressed catchments in Michigan do not fall into the adverse resource impact (ARI) zone under average annual conditions. Most of the stressed catchments were within one of the management zones A and B, while some met the legal definition of ARI. In August, too, the level of stream flow depletion did not create harmful impacts in the majority of the catchments (management zones A and B). However, a considerable length of streams were found as potential areas of concern in August based on the ecological water stress thresholds. Management zones A through D were shown in Figure 4.21 for different stream types, excluding warm transitional streams because of lack of guidelines to establish ecological water stress thresholds for this stream type. About 60 
$\mathrm{Km}$ of streams were classified as ARI locations (management zone D). Also, about $70 \mathrm{Km}$ of streams were in management zones $\mathrm{B}$ and $\mathrm{C}$ that can transition to ARI zones if stream flow depletion increased due to larger future withdrawals. Furthermore, the results demonstrate that cold transitional streams were a common stream type in severely stressed catchments in Michigan.

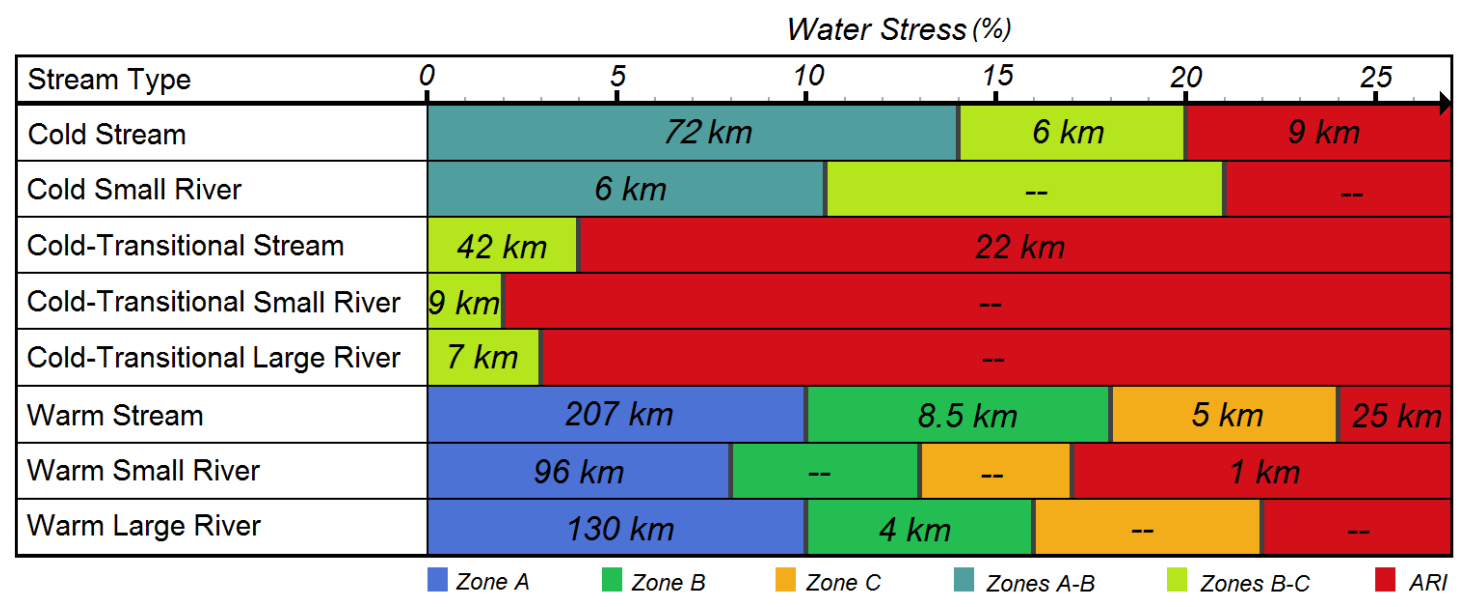

Figure 4.21. Length of Michigan streams in catchments with negative annual water stress in management zones A through D in August. Catchments with warm transitional streams (large and small) were excluded due to unavailability of guidelines for ecological water stress.

In the next step, the catchments with different stream types (e.g., cold stream, cold transitional stream, warm stream, and warm small river) located in the ARI zone were overlaid on land use/land cover data. Figure 4.22 showed common land use/land cover types in catchments with severe water stress in August, which were classified as potential ARI areas. A large number of catchments were found in the cultivated and developed areas with nearly all the withdrawn water for irrigation purposes. Figure 4.23 illustrates that the 
majority of catchments found in the ARI management zone were headwater catchments with stream order 1 or 2 .

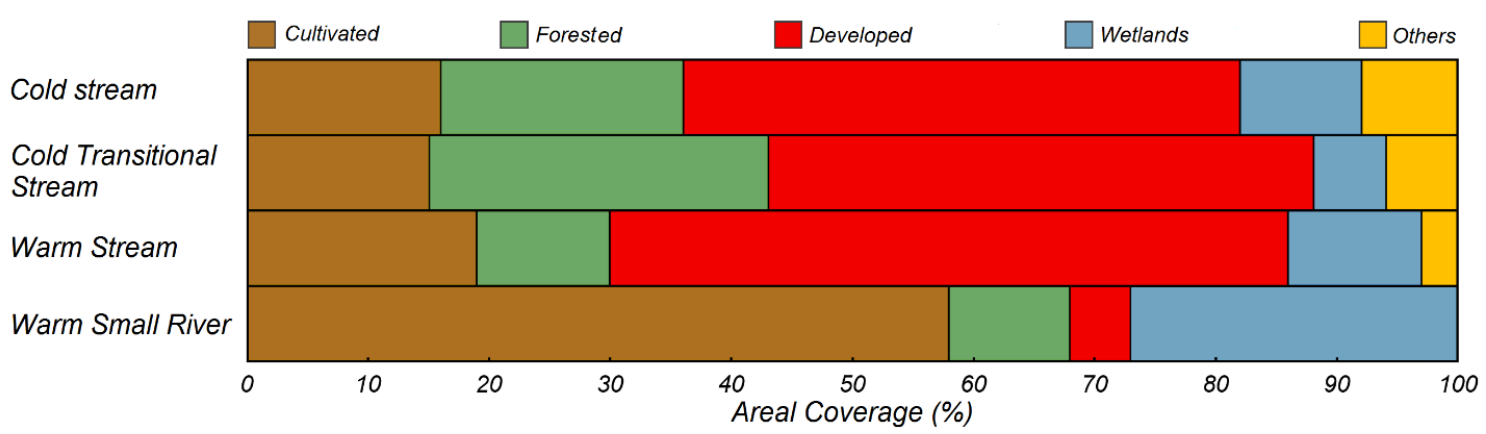

Figure 4.22. Land use/land cover types in catchments classified as potential ARI areas due to severe water stress in August.

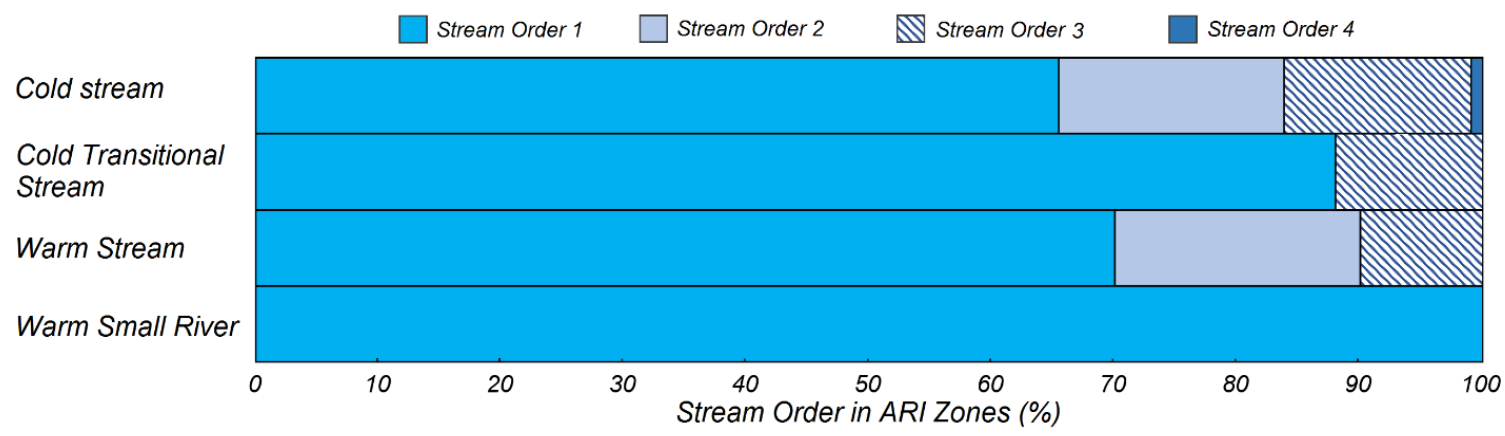

Figure 4.23. Stream orders in catchments classified as potential ARI areas due to severe water stress in August.

\subsection{Discussion}

The GIS-based water stress characterization framework allowed for addressing the spatial dimensions of water stress, accounting for cumulative impacts of upstream alterations on stream flow on downstream conditions. The mapping of stressed catchments facilitated the identification of areas of concern in terms of excessive water stress and associated adverse ecological impacts. This information was critical for developing ARI 
monitoring campaigns and devising strategies and plans to maintain ecological integrity of aquatic habitats. Figures 4.24 through 4.27 provided example maps of stressed catchments in southwestern Michigan, summarizing the effects of temporal scale through comparison of annual and August water stress index analyses. Furthermore, the overlay of stressed catchments on the satellite image of the area depicts the actual land use/land cover (Figure 4.25). Figure 4.27 displayed stressed the catchments for a hypothetical condition in which return flows were excluded from water stress index calculations, illustrating their significant role as an important streamflow altering mechanism. 


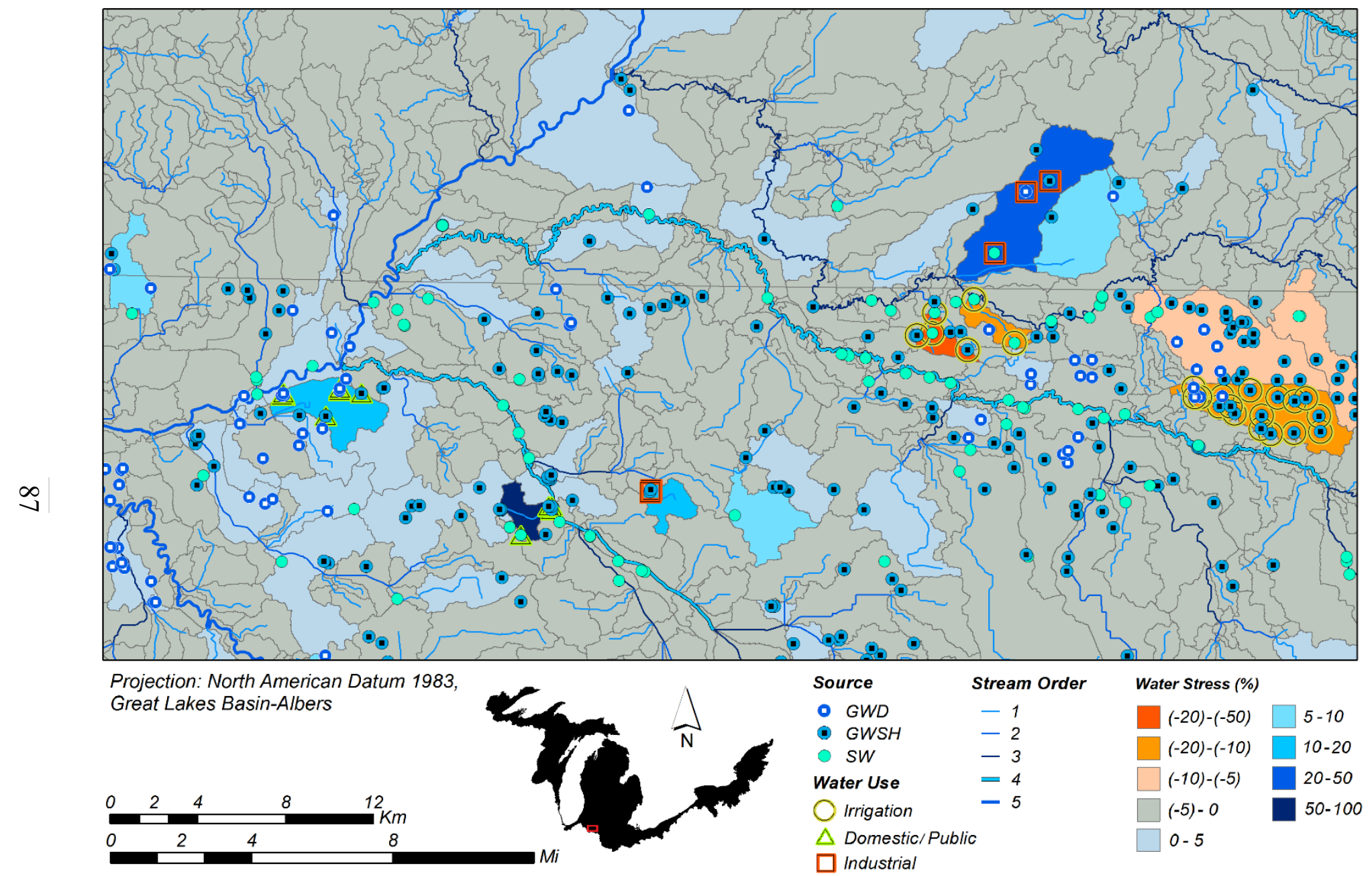

Figure 4.24. Stressed catchments due to annual water withdrawals in southwestern Michigan. Water use classification is shown just for the stressed catchments more than +20 and less than -20 . 


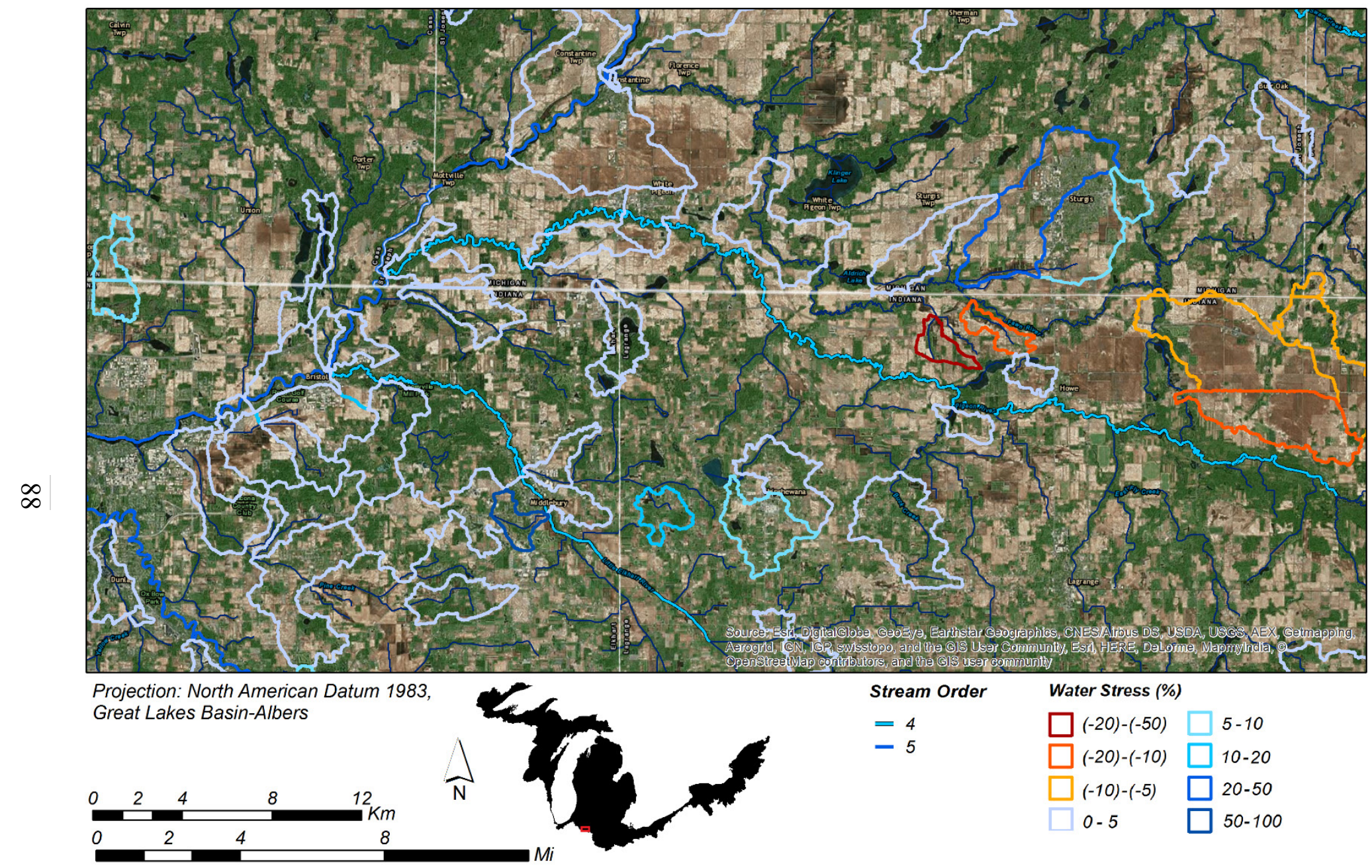

Figure 4.25. Stressed catchments due to annual water withdrawals in southwestern Michigan overlaid by a satellite image. 


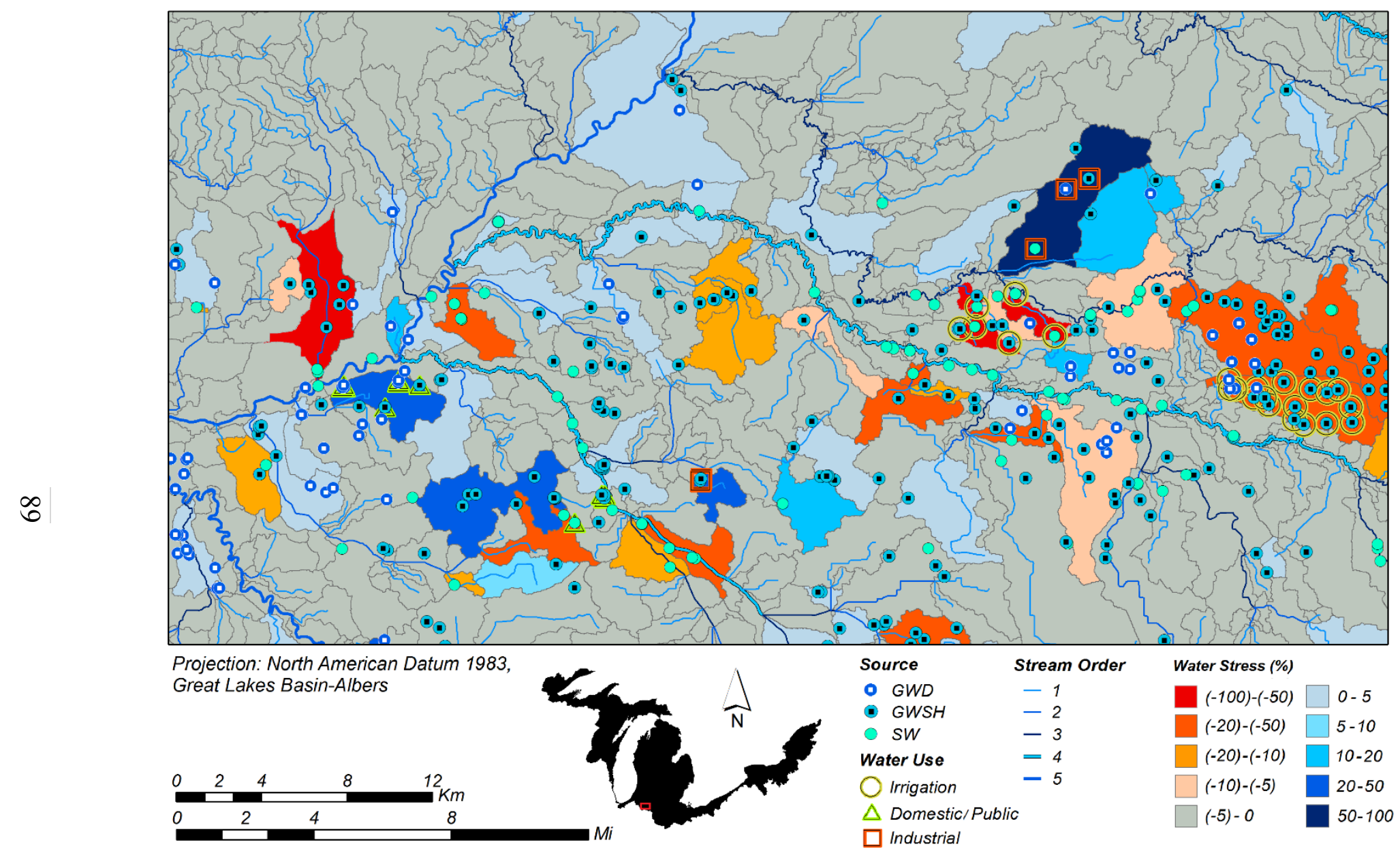

Figure 4.26. Stressed catchments due to August water withdrawals in southwestern Michigan. Water use classification is shown just for the stressed catchments more than +20 and less than -20 . 


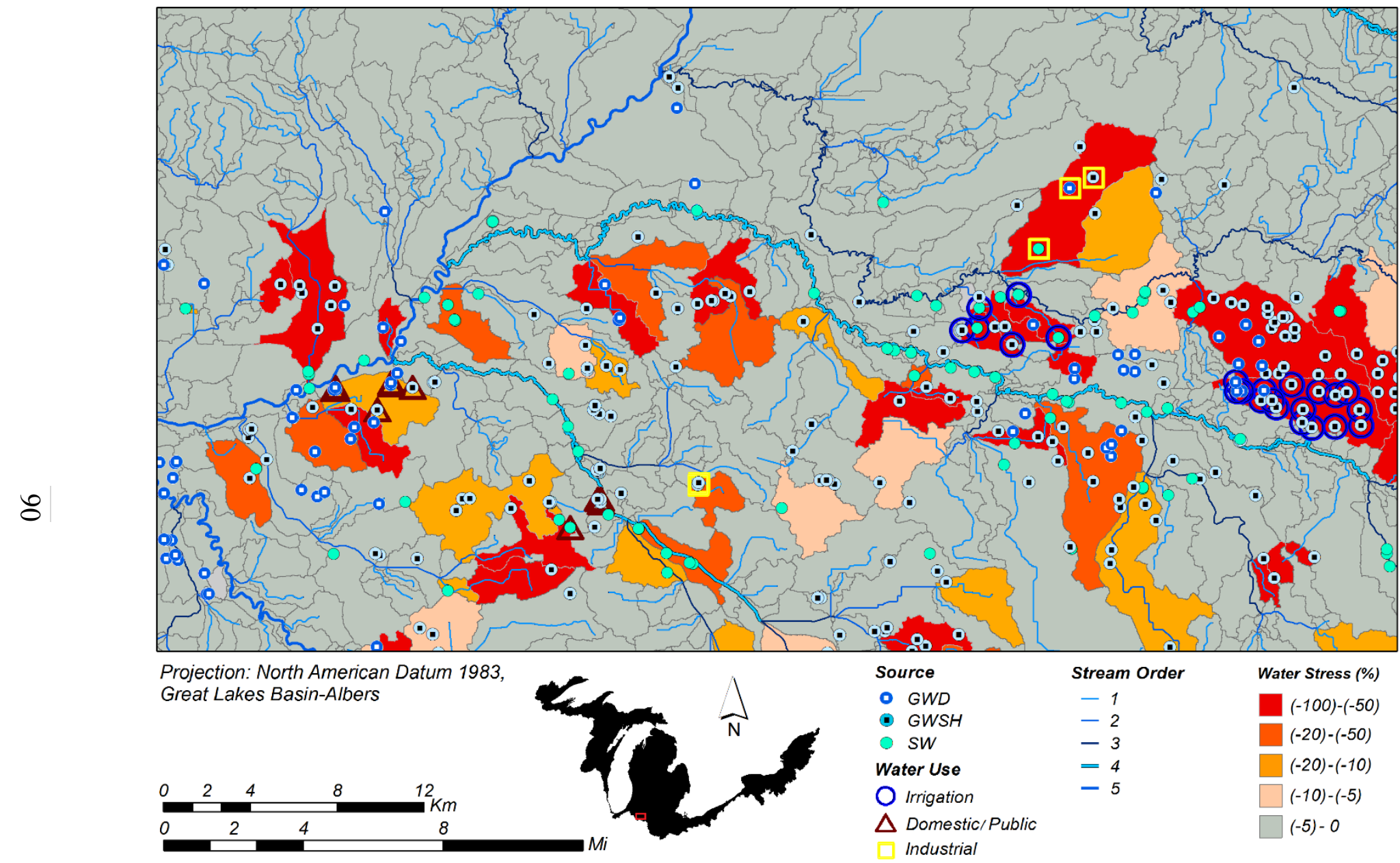

Figure 4.27. Stressed catchments in southwestern Michigan after excluding return flows. Water use classification is shown just for the stressed catchments more than +20 and less than -20 . 
The multitude of catchments identified in management zones B though C suggests potential vulnerability to increased water withdrawal as the ecological conditions in these catchments can transition to management zone $\mathrm{D}$, which denotes adverse resource impacts. Figures 4.28 summarizes the potential impacts of increasing water withdrawals across the GL states on the extent of significant water stress (i.e., water stress index values greater than 5\%). The figure compares the current conditions as a baseline scenario with scenarios in which all water withdrawals are increased by $10 \%, 20 \%$, and $30 \%$, indicating an increasing trend in the number of stressed catchments. The number of catchments with high to severe water stresses (i.e., water stress index greater than 20\%) in August increases significantly under scenarios of high water withdrawal increase (e.g., 20\% and 30\%).

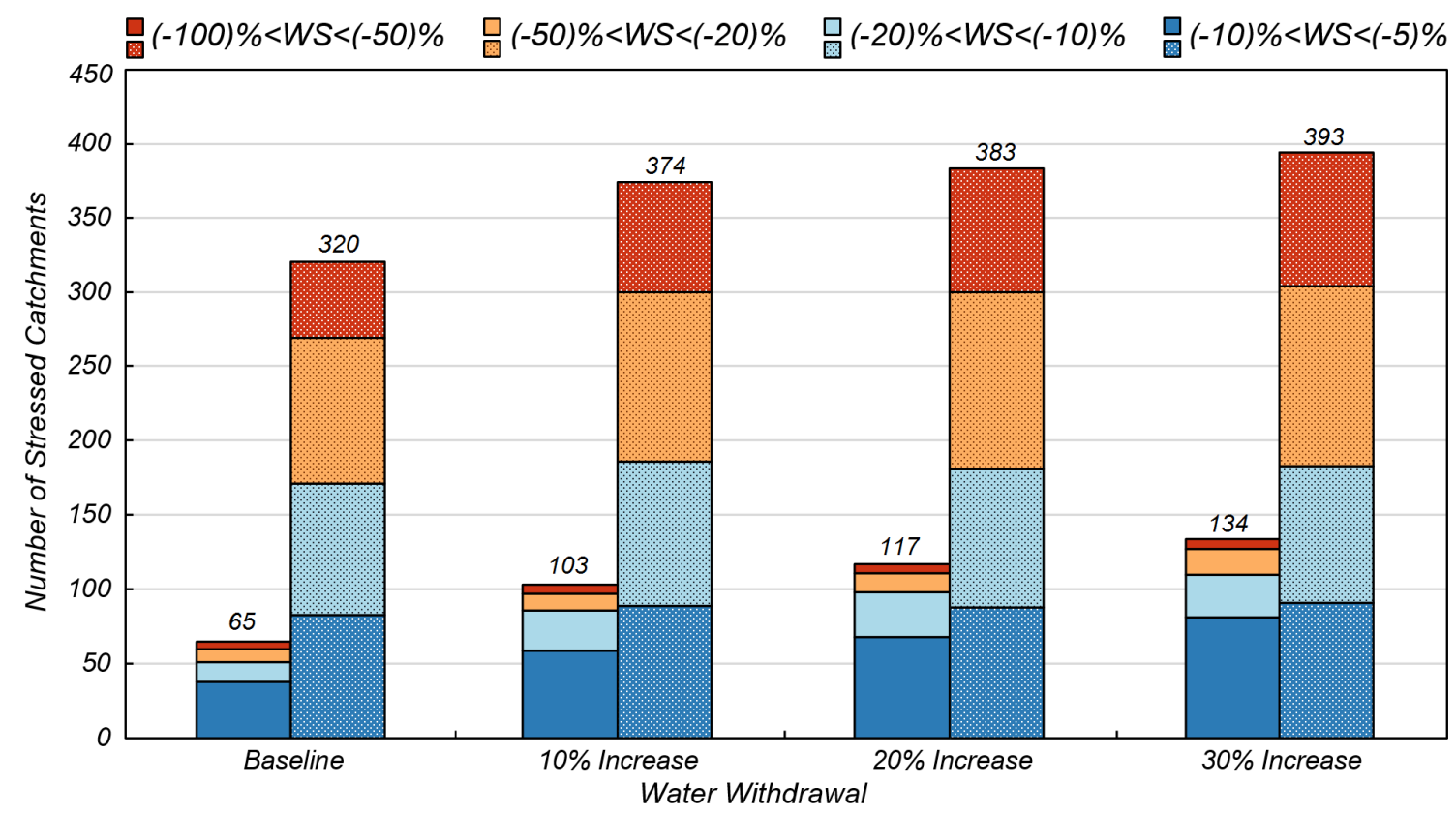

Figure 4.28. Number of stressed catchments under scenarios of increasing water withdrawals on annual (left) and August (right) water stress. 
The presented results provided a lower bound estimate of water stress in the GLB because only major water withdrawal locations with withdrawal capacities of greater than 100,000 gallons/day were included in the analysis. While water withdrawal locations with smaller capacities would affect positive and negative water stress, obtaining the required the data to extend the water stress calculations to these locations poses a challenge. Furthermore, it is assumed that the return flows were returned to the same catchment in which withdrawal occurs, although, in reality, there might be cases in which water utilities sold water to other water utilities to meet demand in catchments other than where the original water was withdrawn.

There was a need for a unified water withdrawal and transfer reporting protocol across the GL states. The process of cross-walking the water withdrawal data from each state to a common classification scheme was time-consuming and might involve subjective interpretation of water use classes. For example, in Minnesota, the categories of ditch, dug pit/holding pond, quarry/mine/gravel pit and wetland were counted as shallow groundwater extractions as they were all associated with groundwater. As another example, the analysis should differentiate between water uses for different types of power generation such as thermoelectric and hydropower with different consumption use coefficients. These distinctions were made on a case by case basis in the data preparation phase. Extending the reporting requirement to all water withdrawals in the GL states and using a common water use classification could facilitate a more realistic water stress characterization, reducing the potential subjectivity and associated uncertainties in the process. 
Monthly consumptive use values were another critical piece of information for determining water consumption and return flow in the water stress calculations. Monthly consumptive use values for Ohio were used for all the GL states due to unavailability of state-specific information (Shaffer, 2009). Furthermore, since monthly consumptive use information was not available for the rest of the GL states, the annual consumptive use coefficients were used for representing monthly water consumption in the domestic and public use sector (Shaffer, 2009). A better understanding of the consumptive nature of water withdrawals for different use categories and seasons in the GL states would improve water stress index calculations.

The presented water stress characterization framework was sensitive to the location of withdrawal points. Accurate latitude-longitude coordinates of the withdrawal points would be critical for estimating the fraction of streamflow depletion in areas where shallow aquifers that were hydraulically connected to nearby streams were the main water source (Watson et al., 2014). In the current water stress analysis, some water withdrawal data were excluded because of concerns about accurate location and reported withdrawal source. For example, water withdrawal points with coordinates in the middle of inland lakes were not considered. Also excluded were Great Lakes withdrawal and groundwater withdrawal from wells that were very close to the Great Lakes (i.e., less than $1 \mathrm{Km}$ ), assuming that these water withdrawal locations were hydraulically connected to the Great Lakes and were thus were not of highest concern in terms of their impact on inland surface water disturbance.

There was also opportunity to improve understanding of the links between surface water availability and the ecological integrity of aquatic habitats. Of the GL states, 
Michigan was the only state for which ecological guidelines for varying levels of water stress had been established, although objective guidelines for determining adverse impacts of water stress (i.e., ARI threshold) in warm transitional streams were unavailable for this state. The ecological guidelines should be developed for streams in other GL states to facilitate the analysis of the potential adverse impacts of anthropogenic water use on aquatic habitats. Furthermore, the ecological impacts of return flows in terms of magnitude, thermal regime, and water quality should be better understood.

\subsection{References}

Hamilton, D. A. \& Seelbach, P. W. 2010. Determining environmental limits to streamflow depletion across Michigan. The book of the states, 42, 534-537.

McKay, L., Bondelid, T., Dewald, T., Johnston, J., Moore, R., and Rea, A. 2012. NHDPlus Version 2: User Guide, 2012.

Shaffer, K. 2009. Variations in Withdrawal, Return Flow, and Consumptive Use of Water in Ohio and Indiana, with Selected Data from Wisconsin, 1999-2004, US Geological Survey.

Watson, K. A., Mayer, A. S. \& Reeves, H. W. 2014. Groundwater availability as constrained by hydrogeology and environmental flows. Groundwater, 52, 225-238.

Zorn, T. G., Seelbach, P. W. \& Rutherford, E. S. 2012. A Regional-Scale Habitat Suitability Model to Assess the Effects of Flow Reduction on Fish Assemblages in Michigan Streams1. JAWRA Journal of the American Water Resources Association, 48, 871-895. 


\section{Chapter 5: Summary and future work}

\subsection{Summary of main findings}

Maintaining the natural flow regime, which is critical for aquatic ecosystems, requires an understanding of the impact of water withdrawal from different sources on aquatic habitats. An integrative water stress calculation framework was presented in this dissertation to quantify potential impacts of water withdrawal from surface water, shallow groundwater, and deep groundwater to meet the water demands of different economic sectors. Using GIS technology, water stress in the stream network was calculated based on withdrawal sources and water use categories at different spatial and temporal scales in order to map potentially harmful streamflow disturbances in the GL region.

The presented water stress calculation framework uses water withdrawal and hydrographic data organized in a GDB to facilitate systematic spatial analysis throughout the GLB. It integrates previous water stress calculation methodology development efforts at Michigan Technological University (e.g., impact of groundwater withdrawal from aquifers in hydraulic connection with nearby streams), and uses Arc Hydro to trace catchment scale streamflow disturbance (i.e., the sum of flow depletion and return flow) along the stream network in a spatially continuous and topologically correct fashion. Available ecological guidelines were used to identify areas that are prone to adverse resource impact due to significant reduction of stream flow and associated decline in the number of fish populations. 
Although the majority of catchments do not experience significant water stress (i.e., water stress index between 0 and $\pm 5 \%$ ), results indicate that small headwater catchments are vulnerable to significant water stress. A coarse temporal scale such as annual tends to mask these vulnerabilities. A significantly larger number of catchments in the study area were found to be prone to significant water stress on a monthly time scale. In particular, catchment scale water stress was more pronounced and widespread when a low-flow month (e.g., August) is considered during which water consumption by different use sectors is higher. Analysis of August water stress in Michigan, where ecological guidelines are available to evaluate the effect of water stress on aquatic habitats, indicates potentially harmful ecological water stress. A significant length of cold streams and cold transitional streams were found to be threatened by adverse resource impacts (ARI) that reduce fish populations. This finding illustrates the importance of maintaining environmental flows through adjusting water withdrawals in low-flow months in order to mitigate harmful impacts on sensitive aquatic habitats.

\subsection{Recommendations to improve water stress characterization in the GL region}

The challenges of implementing the presented water stress characterization framework were related to availability, quality and consistency of water withdrawal and consumption data, and a quantitative and qualitative understanding of the links between water stress and ecological integrity of aquatic habitats across the GL states. Creating a consistent database of water withdrawals is time consuming not only due to size of the data sets in a catchment scale water stress mapping application of this size, but also because of the lack of unified water withdrawal reporting protocols in different states. Differences in 
tracking of water withdrawals in terms of definition of use categories, water withdrawal locations, and consumptive and non-consumptive water uses leave room for subjective designation of the withdrawn water to different use sectors. Therefore, a key recommendation is to devise and implement uniform and consistent reporting protocols in order to systematically improve the understanding of water withdrawal and consumption across the GL region.

Equally important is an improved understanding of ecological thresholds for water withdrawal in different areas. Scaling up the analysis of ecological waters tress is hindered by the lack of pertinent guidelines. The ecologically-based flow alteration thresholds in Michigan provide a good starting point for other GL states. The ecological frameworks should address potential effects of large flow fluctuations due to positive and negative water stress in different types of aquatic habitat classified based on size and thermal regime.

\subsection{Future work}

The GLB is an important region of the world in terms of availability of freshwater resources shared by the U.S. and Canada. The current water stress characterization focused only on U.S. side of the GLB. Extending the analysis to include the Canadian side is a logical next step in order to provide a holistic understanding of local water stress as a function of water consumption and availability in the GLB. Likewise, the framework can be applied to other parts of the U.S. to map anthropogenic water stress and associated impacts on aquatic ecosystems to inform regional water resources planning and environmental management. Creating appropriate online platforms for local water stress mapping could raise public awareness about local water availability and ecological impacts 
of water use. Furthermore, collecting field evidence in vulnerable catchments can help gauge the performance of the presented theoretical water stress analysis framework.

Finally, a preliminary analysis of the links between land use types and water stress suggests that the majority of the stressed catchments are in areas where large withdrawals are made to meet irrigation and domestic and public supply needs. In the future, spatial statistical models of local water stress can be developed based on a setsof explanatory variables such as land use types, stream order, and water consumption, among others. 


\title{
Appendix: Copyright Clearance
}

\author{
This documentation is for Figure 4.1.
}

https://www2.usgs.gov/laws/info_policies.html

4/14/2017

Information Policies and Instructions

Policy on Release of Information - As an integral part of its mission, the USGS has a continuing responsibility to keep the public informed of its various programs, activities, and research. It is the policy of the USGS to conduct its activities and to make the results of its scientific investigations available in a manner that will best serve the whole public, rather than the interest or benefit of any special group, corporation, or individual. The Internet affords the USGS a mechanism to achieve that broad distribution, impartially and simultaneously, in accordance with its mission and information dissemination policy.

Schedule and Priorities for Release of Information - The diversity of scientific expertise enables the USGS to carry out large-scale, multidisciplinary investigations that build the base of knowledge about the Earth. In turn, decisionmakers at all levels of government-and citizens in all walks of life-have the information tools they need to address pressing societal issues. As such, there is no set schedule on which the USGS releases its information; rather, the readiness of the science for release determines the schedule. Priority of release is consistent with the Department of the Interior Schedule of Content.

News releases are issued and information is posted on the USGS Home Page whenever a significant earthquake or other natural disaster occurs, a major personnel appointment is announced, budget information is available, or a science program has results to announce.

The USGS is a scientific publisher and regularly and routinely presents the results of its scientific research and investigations in printed and/or online format in publication series. Bibliographic citations and information on accessing and obtaining USGS information products are available in the USGS Publications Warehouse.

Contact - If you have questions concerning release of USGS information, contact the USGS Web.

\section{Copyrights and Credits}

USGS-authored or produced data and information are considered to be in the U.S. public domain. While the content of most USGS Web pages is in the U.S. public domain, not all information, illustrations, or photographs on our site are. Some non USGS photographs, images, and/or graphics that appear on USGS Web sites are used by the USGS with permission from the copyright holder. These materials are generally marked as being copyrighted. To use these copyrighted materials, you must obtain permission from the copyright holder under the copyright law.

When using information from USGS information products, publications, or Web sites, we ask that proper credit be given. Credit can be provided by including a citation such as the following:

Credit: U.S. Geological Survey

Department of the Interior/USGS

U.S. Geological Survey/photo by Jane Doe (if the photographer/artist is known)

Additional information on Acknowledging or Crediting USGS as Information Source is available.

Policy - For relevant USGS policy on copyrights and trademarks, refer to the Survey Manual chapter entitled, "Use of Copyrighted Material in USGS Information Products."

Contact - If you have questions concerning the use of USGS information, contact the USGS Web.

\section{USGS Visual Identity System}

To reinforce visually who we are and what we do, the USGS uses a visual identity system that provides planning and design solutions for USGS information products. A key component of the visual identity system is the USGS identifier. This identifier is trademarked and must be used in accordance with the rules outlined at Visual Identity System. Information on who may use the USGS identifier and how to obtain a copy of it is available at Use of the Trademarked USGS Identifier by Non-USGS Orqanizations.

Policy - For relevant USGS policy on the Visual Identity System, refer to the Survey Manual chapter entitled, "USGS Visual Identity System." 


\section{This documentation is for Figure 4.25 (online satellite image has been used).}

https://www.digitalglobe.com/legal/product-terms-and-conditions

DigitalGlobe $(1)$

6.2 INVOICES. DigitalGlobe will invoice Customer for Products upon delivery unless otherwise set forth in Section 6.4 below or in Exhibit A.

6.3 CREDIT ACCOUNT. If Customer wishes to establish a credit account, Customer must complete a credit application and otherwise comply with DigitalGlobe's requirements for establishing a credit account. DigitalGlobe may revoke Customer's credit account at any time.

6.4 PAYMENT. If DigitalGlobe authorizes a credit account, Customer must pay all invoices within thirty (30) days following the date of invoice. If Customer does not have a credit account or DigitalGlobe determines that Customer's credit history and/or credit rating are not sufficient for the Order Confirmation, Customer may be required to pre-pay Fees, in which case Customer will be invoiced following acceptance of the Order Confirmation. All Fees are payable in US Dollars. All past due amounts will accrue interest at the lower rate of: (a) 1.5\% per month; or (b) the highest rate permissible under applicable law. In the event of non-payment, DigitalGlobe reserves the right to suspend all current orders and any Subscription Services and refuse future orders until all past due amounts have been paid.

6.5 TAXES. All Fees do not include any sales, use, value-added, foreign withholding or other taxes, duties, fees, excises or tariffs imposed on the licensing, sale or use of the Products (collectively, "Taxes"). Customer is responsible for, and if applicable will reimburse DigitalGlobe within thirty (30) days of request, all Taxes and any related penalties, except for taxes imposed on DigitalGlobe's net income. If Customer is required to withhold Taxes from payments, the amount due and payable to DigitalGlobe must still equal the Fees that would otherwise be payable had the Taxes not been withheld, and Customer must provide DigitalGlobe with a receipt or other acceptable documentation from the applicable taxing authority evidencing the payment of the Taxes.

7. COmpliance with End User License Terms

7.1 CERTIFICATION. Upon DigitalGlobe's written request, and not more than once per calendar year, Customer will certify its compliance with licenses granted under this Agreement. If Customer is unable to provide this certification, Customer will work in good faith with DigitalGlobe to convey the proper license type and remit the appropriate Fees as remedy for any noncompliance. In addition, DigitalGlobe reserves the right to terminate all licenses and this Agreement for non-compliance in accordance with Section 11.2 below.

7.2 AUDIT. DigitalGlobe or its authorized representative will have the right to perform an audit to determine Customer's compliance with this Agreement and the licenses granted hereunder. Customer will grant DigitalGlobe auditors access to the business location(s), books and records, employees and/or contractors pertaining to Customer's use of the Products. The audit will: (a) require a minimum of thirty (30) days prior written notice; (b) be conducted no more than once per calendar year: (c) be limited to a three (3) year audit period unless non-compliance findings are noted, in which case the audit period can be expanded; (d) be conducted during reasonable business hours; and (e) be subject to reasonable confidentiality requirements.

7.3 AUDIT FINDINGS. If an audit results in a finding of non-compliance, DigitalGlobe may, at its discretion: (a) invoice any additional license fees due based on the standard DigitalGlobe Fees in place at the time of the original license grant: (b) assess interest charges from the time of the original Fee payment due date in accordance with Section 6.4 above; (c) recover the cost of the audit if additional Fees exceed five percent (5\%) of the Fees paid during the audit period; and (d) terminate this Agreement and the DigitalGlobe licenses in accordance with Section 11.2 below. Customer must pay all invoices within thirty (30) days following the date of invoice.

\section{INTELLECTUAL PROPERTY.}

8.1 TITLE AND OWNERSHIP. All right, title and interest in and to the Products, including all corrections, enhancements, or other modifications made by DigitalGlobe or any third party at DigitalGlobe's instruction, and all Intellectual Property Rights therein are the sole and exclusive property of DigitalGlobe or its suppliers, as applicable. Any permitted Derivatives of the Imagery Products created by Customer pursuant to these License Terms may only be used by Customer in accordance with the use rights and restrictions applicable to Customer's use of the underlying Product. All rights not expressly granted to Customer in this Agreement are reserved by DigitalGlobe.

8.2 PROPRIETARY RIGHTS NOTICES. Customer will not delete, alter, cover or distort any copyright, trademark or other proprietary rights notice placed by DigitalGlobe on or in the Products and will ensure that all notices are reproduced on all copies. All Derivatives must include the following copyright notice: [Product] @ [YEAR] DigitalGlobe, Inc. 


\title{
In Chapter 3, sub-section 3.3 Arc Hydro tool from ESRI was used to run part of the
}

\section{analysis.}

\author{
https://www.arcgis.com/home/termsofuse.html
}

$4 / 14 / 2017$

https://www.arcgis.com/home/termsofuse.htm

\section{LICENSE AND SERVICES AGREEMENT}

IMPORTANT-READ CAREFULLY

\begin{abstract}
Unless superseded by a signed license agreement between you and Esri, Esri is willing to provide Esri Offerings to you only if you accept all terms and conditions contained in this Agreement. Please read the terms and conditions carefully. You may not use the Esri Offerings until you have agreed to the terms and conditions of the Agreement. If you do not agree to the terms and conditions as stated, click "I do not accept the agreement" below; you may then request a refund of applicable fees paid.
\end{abstract}

This Agreement is between you ("Customer") and Environmental Systems Research Institute, Inc. ("Esri"), a California corporation with a place of business at 380 New York Street, Redlands, California 92373-8100 USA.

\subsection{GENERAL GRANT OF RIGHTS AND RESTRICTIONS}

1.1 Attachment A contains definitions of capitalized terms used throughout this Agreement. Each section of this Agreement may include additional definitions that are used exclusively within that section.

1.2 Grant of Rights. In consideration of Customer's payment of all applicable fees and in accordance with this Agreement, Esri grants to Customer a personal, nonexclusive, nontransferable right to

a. Use the Esri Offerings as set forth in the Documentation and applicable Ordering Documents;

b. Copy and make derivative works of the Documentation for Customer's own internal use in conjunction with Customer's authorized use of Products. Customer will include the following copyright attribution notice acknowledging the proprietary rights of Esri and its licensors in any derivative work:

"Portions of this document include intellectual property of Esri and its licensors and are used under license. Copyright @ [Customer will insert the actual copyright date(s) from the source materials.] Esri and its licensors. All rights reserved."

The grants of rights in this section (i) continue for the duration of the subscription or applicable Term or perpetually if no Term is applicable or identified in the Ordering Documents and (ii) are subject to additional rights and restrictions in this Agreement including Attachment B.

1.3 Consultant or Contractor Access. Customer may authorize its consultants or contractors to use Esri Offerings exclusively for Customer's benefit. Customer will be solely responsible for its consultants' and contractors' compliance with this Agreement and will ensure that each consultant or contractor discontinues use of the Esri Offerings upon completion of work for Customer. Access to or use of Esri Offerings by consultants or contractors that is not exclusively for Customer's benefit is prohibited.

1.4 Evaluation and Beta Licenses. Products acquired under an evaluation license or subscription or under a Beta program are intended for evaluation and testing purposes only and not for commercial use. Any such use is at Customer's own risk, and the Products do not qualify for Maintenance. If Customer does not convert to a purchased license or subscription prior to the expiration of the evaluation term, Customer may lose any content and customizations made during the evaluation term. If Customer does not wish to purchase a license or subscription, Customer should export such content before the end of Customer's evaluation period.

1.5 Educational Programs. Customer agrees to use Esri Offerings provided under an educational program solely for educational purposes during the educational use Term. Customer shall not use Products for any Administrative Use unless Customer has acquired an Administrative Use license. "Administrative Use" means administrative activities that are not directly related to instruction or education, such as asset mapping, facilities management, demographic analysis, routing, campus safety, and accessibility analysis. Customer shall not use Products for revenue-generating or for-profit purposes.

1.6 Grant Programs. Customer may use Esri Offerings provided under a grant program for noncommercial purposes only. Except for cost recovery of using and operating the Esri Offerings, Customer shall not use Esri Offerings for revenue-generating or for-profit purposes.

1.7 Other Esri Limited-Use Programs. If Customer acquires Esri Offerings under any limited-use program not listed above, Customer's use of the Esri Offerings may be subject to the terms set forth in the applicable launching page or enrollment form or as described on Esri's website in addition to the non-conflicting terms of this Agreement.

1.8 Reservation of Rights. All Esri Offerings are the copyrighted works of Esri or its licensors; all rights not specifically granted in this Agreement are reserved.

2.0 SOFTWARE TERMS OF USE

2.1 License Types. Esri licenses Software under the following license types:

a. Concurrent Use License: Customer may install and use the Software on computer(s) on a network, but the number of simultaneous https://mww.arcgis.com/home/termsofuse.htm 